\title{
MARISA MARTINS
}

\section{MOLHABILIDADE DE APATITA E SUA INFLUÊNCIA NA FLOTAÇÃO}

Tese apresentada à Escola Politécnica da Universidade de São Paulo para obtenção do Título de Doutora em Engenharia. 


\section{MARISA MARTINS}

\section{MOLHABILIDADE DE APATITA E SUA INFLUÊNCIA NA FLOTAÇÃO}

Tese apresentada à Escola Politécnica da Universidade de São Paulo para obtenção do Título de Doutora em Engenharia.

Área de concentração:

Engenharia Mineral

Orientador:

Prof. Dr. Laurindo de Salles Leal Filho 


\section{FICHA CATALOGRÁFICA}

Martins, Marisa

Molhabilidade de apatita e sua influência na flotação / M.

Martins. -- São Paulo, 2009.

$119 \mathrm{p}$.

Tese (Doutorado) - Escola Politécnica da Universidade de São Paulo. Departamento de Engenharia de Minas e de Petróleo.

1. Flotação de minérios 2. Química de superfície 3. Fosfatos I. Universidade de São Paulo. Escola Politécnica. Departamento de Engenharia de Minas e de Petróleo II. t. 
Aos meus pais, Emílio e Maria Victória, com carinho. Sem uma base sólida, não há edificação que resista. 


\section{AGRADECIMENTOS}

A autora gostaria de expressar seus sinceros agradecimentos:

Ao Prof. Dr. Laurindo de Salles Leal Filho, pela oportunidade em realizar este trabalho e pela supervisão acadêmica prestada durante seu desenvolvimento;

À CAPES, FDTE e FUSP, pela concessão da bolsa de estudos, em períodos distintos, durante a realização deste trabalho;

Aos colegas e amigos do LFQI: Ivani, Odair, Célio, Thiago, Kelly Ivone, Adriana e Daniela.

À Dra. Marisa Bezerra de Mello Monte, por disponibilizar o Laboratório de Química de Superfície do CETEM/CNPq para as medidas de ângulo de contato, pela atenção com que me recebeu e pelas informações;

Aos professores Eduardo César Sansoni, Eldon Azevedo Masini e Patrícia Matai pelos esclarecimentos e sugestões; Henrique Khan, por disponibilizar o Laboratório de Caracterização Tecnológica para a preparação da seção polida utilizada nas medidas de ângulo de contato, e ao professor Excelso Ruberti pela análise de WDS realizada no Instituto de Geociências da USP.

Às bibliotecárias Maria Cristina Martinez Bonesio, pelo auxílio na organização das referências bibliográficas; e Silvia de La Torre, pela prontidão na edição da ficha catalográfica;

Aos amigos Eliana, Gabriela, Cristina, Rosa e Sérgio pelo constante apoio e amizade;

Aos meus familiares e entes queridos, principalmente aos meus pais, Emilio e Maria Victória, e aos meus irmãos William, Emilio Carlos, Míriam, Márcia e Marília, pelo apoio e carinho incondicionais; 
Àqueles que sempre me acompanham e olham por mim, dando-me forças para seguir em meu caminho e cumprir com meus deveres, gostaria de dedicar um agradecimento especial.

Enfim, a todos que de alguma forma contribuíram para a realização deste trabalho...

Muito Obrigada! 


\section{RESUMO}

Este trabalho aborda a molhabilidade de apatita por água em temperatura ambiente $\left(20-25^{\circ} \mathrm{C}\right)$ objetivando contribuir para um melhor entendimento de seu comportamento em sistemas de flotação. Água, devido às fortes forças atrativas entre suas moléculas, não espalha completamente sobre sólidos de baixa energia como apatita pré-tratada com surfatantes aniônicos de cadeia longa. Este comportamento é explorado por engenheiros de processamento mineral para separar apatita de minerais de ganga via flotação aniônica direta em circuitos industriais ao redor do mundo. Nesta tese, a molhabilidade de apatita (tratada ou não com oleato de sódio- $\mathrm{NaOl}$ em $\mathrm{pH}=10,5)$ foi caracterizada pelo ângulo de contato de avanço da água $\left(\theta_{\mathrm{a}}\right)$, trabalho de adesão $\left(\mathrm{W}_{\mathrm{a}}\right)$ da água sobre apatita e coeficiente de espalhamento (S) de água sobre o sólido. Medidas diretas de $\theta_{\mathrm{a}}$ sobre os planos frontal (010) e basal (001) de um cristal de apatita bem definido proveniente de IpiráBA (apatita-Ipirá) foram executadas pelo Método da Bolha Cativa (MBC), enquanto determinações indiretas de $\theta_{\mathrm{a}}$ foram realizadas pelo Método da Ascensão Capilar (MAC) através da percolação de líquidos (água e/ou metanol) através de leitos partículas de apatita-Ipirá ou apatita-Cajati (proveniente de Cajati-SP). No MAC, o uso de hexano foi adequado para determinar a magnitude da constante de empacotamento (c) para partículas de apatita de baixa molhabilidade $\left(\theta_{a}>>0^{\circ}\right)$, enquanto que a água se mostrou mais apropriada para ser usada na determinação da constante $c$ para partículas de apatita não tratadas com surfatantes $\left(\theta_{\mathrm{a}} \sim 0^{\circ}\right)$. Ensaios de microflotação foram conduzidos com apatita-Ipirá em $\mathrm{pH}=10,5$ e com $\mathrm{NaOl}(0-75 \mathrm{mg} / \mathrm{L})$ enquanto ensaios de flotação gama foram executados com minério de fosfato proveniente de Cajati-SP previamente tratado com amido $(37,5 \mathrm{mg} / \mathrm{L})$ e alquil sarcosinato de sódio-Berol ${ }^{\otimes} 867(25 \mathrm{mg} / \mathrm{L})$ em $\mathrm{pH}=10,6$. Os resultados das medidas de $\theta_{\mathrm{a}}$ e dos ensaios de microflotação indicaram uma relação de causaefeito entre a concentração de $\mathrm{NaOl}$ (0-75mg/L), molhabilidade de apatita-Ipirá e sua resposta à microflotação: as maiores recuperações foram obtidas com as maiores concentrações do coletor $\mathrm{NaOl}$, maiores valores de $\theta_{a}$, menores valores de $\mathrm{W}_{\mathrm{a}} \mathrm{e}$ valores mais negativos de $\mathrm{S}$. Os valores de $\theta_{\mathrm{a}}$ diretamente medidos sobre as faces de um cristal de apatita-Ipirá pelo $\mathrm{MBC}$ mostrou que $\mathrm{NaOl}$ adsorve 
preferencialmente sobre o plano (010) comparado ao plano (001). Além disso, a tensão superficial crítica de molhabilidade $\left(\gamma_{c}\right)$ da apatita-lpirá, pré-tratada com $75 \mathrm{mg} / \mathrm{L}$ de $\mathrm{NaOI}$, foi de $30,2 \mathrm{erg} / \mathrm{cm}^{2}$ para o plano (001) versus $29,6 \mathrm{erg} / \mathrm{cm}^{2}$ para o plano (010). Após serem condicionadas com reagentes de flotação (amido=37,5mg/L e Berol $^{\circledR} 867=25 \mathrm{mg} / \mathrm{L}$ em $\left.\mathrm{pH}=10,6\right)$ e flotadas em estágio rougher, partículas de apatita-Cajati exibiram $\theta_{a}=64.2^{\circ} \pm 1.1^{\circ}$. O valor de $\gamma_{c}$, determinado via experimentos de flotação gama foi $\gamma_{c} \sim 34,5 \mathrm{erg} / \mathrm{cm}^{2}$; enquanto $\gamma_{c}$ determinado por diagramas $\cos \theta \mathrm{x}$ $\gamma_{L V}$ foi de $\gamma_{c} \sim 33,9 e r g / \mathrm{cm}^{2}$. Os resultados de flotação gama com o minério de fosfato de Cajati mostrou um platô de máxima recuperação de apatita (95-98\%) quando $52,7 \mathrm{erg} / \mathrm{cm}^{2}<\gamma_{\mathrm{LV}}<72,9 \mathrm{erg} / \mathrm{cm}^{2}$. Ao contrário da apatita, a recuperação dos minerais de ganga (silicatos e carbonatos) foi estritamente ascendente com o aumento de $\gamma_{\mathrm{LV}}$. A maior Eficiência de Separação apatita/ganga (E.S. = recuperação de apatita menos a recuperação de ganga) foi obtida em $\gamma_{L V}=50,5 \mathrm{erg} / \mathrm{cm}^{2}$ para apatita/silicatos e em $\gamma_{L V}=51,4 \mathrm{erg} / \mathrm{cm}^{2}$ para apatita/carbonatos. Os resultados dos experimentos de flotação gama indicaram que, no circuito industrial de Cajati-SP, $\gamma_{L V}$ pode ser modulada pela dosagem do coletor, e sua magnitude pode guiar engenheiros na tomada de decisões a respeito da dosagem de coletor que promova a maior seletividade de separação apatita/ganga. Entretanto, a falta de instrumentos apropriados para realizar medidas on-line confiáveis de $\gamma_{\mathrm{Lv}}$ tem impedido a execução destas medidas em circuitos industriais. Deste modo, decisões a respeito da dosagem do coletor feitas pelos engenheiros continuam a ser baseadas em uma abordagem empírica ao invés de científica.

Palavras-chave: Molhabilidade. Apatita. Flotação. Ângulo de contato. 


\section{ABSTRACT}

This work approaches the wetting of apatite by water at room temperature $\left(20-25^{\circ} \mathrm{C}\right)$ aiming at to contribute towards a better understanding of its behavior in flotation systems. Water, because of its powerful attractive forces, does not readily spread over the surface of low energy solids as apatite pre-treated with anionic long chain surfactants. This behavior is exploited by mineral processing engineers to separate apatite from gangue minerals via direct anionic flotation in industrial plants around the world. In this thesis, the wettability of apatite (treated or not with sodium oleate$\mathrm{NaOl}$ at $\mathrm{pH}=10.5)$ was characterized by the advancing water contact angle $\left(\theta_{\mathrm{a}}\right)$, work of adhesion $\left(\mathrm{W}_{\mathrm{a}}\right)$ of water to apatite and the spreading coefficient $(\mathrm{S})$ of water over the solid. Direct measurements of $\theta_{a}$ on either frontal-(010) or basal-(001) planes of a well formed apatite crystal from Ipirá-BA (apatite-Ipirá) were carried out via Captive Bubble (CB) method, whereas indirect determinations of $\theta_{\mathrm{a}}$ were accomplished via Capillary Rise $(\mathrm{CR})$ method by means of percolation of liquids (water and/or methanol) through particle beds of apatite-Ipirá and apatite-Cajati (from Cajati-SP). At $\mathrm{CR}$ method, the use of hexane was adequate to determine the magnitude of packing constant (c) for apatite particles of low wettability $\left(\theta_{a}>>0^{\circ}\right)$, whereas water proved to be more appropriate to be used in the determination constant $\mathrm{c}$ for apatite particles non-treated with surfactants $\left(\theta_{\mathrm{a}} \sim 0^{\circ}\right)$. Microflotation tests were conducted with apatite-Ipirá at $\mathrm{pH}=10.5$ with $\mathrm{NaOI}(0-75 \mathrm{mg} / \mathrm{L})$ whereas gamma flotation tests were carried out with phosphate ore from Cajati-SP previously treated with starch $(37.5 \mathrm{mg} / \mathrm{L})$ and sodium alkyl sarcosinate-Berol ${ }^{\circledR} 867(25 \mathrm{mg} / \mathrm{L})$ at $\mathrm{pH}=10.6$. Results from measurements of $\theta_{a}$ and microflotation experiments indicated a cause-effect relationship between concentration of $\mathrm{NaOI}(0-75 \mathrm{mg} / \mathrm{L})$, wettability of apatite-Ipirá and its microflotation response: the highest recoveries were yielded at higher concentration of collector $\mathrm{NaOl}$, higher values of $\theta_{\mathrm{a}}$, lower values of $\mathrm{W}_{\mathrm{a}}$ and more negative the values of $S$. Values of $\theta_{a}$ directly measured on the faces of a crystal of apatite-Ipirá by $\mathrm{CB}$ method showed that $\mathrm{NaOl}$ adsorbs preferentially onto (010) plane compared to (001) plane. Moreover, the critical surface tension of wettability $\left(\gamma_{c}\right)$ of apatite-Ipirá, pre-treated with $75 \mathrm{mg} / \mathrm{L}$ of $\mathrm{NaOl}$, was $30.2 \mathrm{erg} / \mathrm{cm}^{2}$ for (001)-plane versus $29.6 \mathrm{erg} / \mathrm{cm}^{2}$ for (010)-plane. After being conditioned with flotation reagents 
(starch $=37.5 \mathrm{mg} / \mathrm{L}$ and Bero ${ }^{\otimes} 867=25 \mathrm{mg} / \mathrm{L}$ at pH=10.6) and floated at rougher stage, particles of apatite-Cajati exhibited $\theta_{a}=64.2^{\circ} \pm 1.1^{\circ}$. The value of $\gamma_{c}$, determined via gamma flotation experiments was $\gamma_{c} \sim 34.5 \mathrm{erg} / \mathrm{cm}^{2}$; whereas $\gamma_{c}$ determined by $\cos \theta \times$ $\gamma\left\llcorner v\right.$ plots was $\gamma_{c} \sim 33.9 \mathrm{erg} / \mathrm{cm}^{2}$. Results from gamma flotation experiments with phosphate ore from Cajati showed a plateau of maximum apatite recovery (95-98\%) when $52.7 \mathrm{erg} / \mathrm{cm}^{2}<\gamma_{L V}<72.9 \mathrm{erg} / \mathrm{cm}^{2}$. Unlike apatite, the recovery of gangue minerals (silicates and carbonates) was strictly ascending when $\gamma_{L V}$ was increased. The highest Efficiency of Separation apatite/gangue (E.S. = recovery of apatite minus recovery of gangue) was attained at $\gamma_{\mathrm{LV}}=50.5 \mathrm{erg} / \mathrm{cm}^{2}$ for apatite/silicates and at $\gamma_{\mathrm{LV}}=51.4 \mathrm{erg} / \mathrm{cm}^{2}$ for apatite/carbonates. The results from gamma flotation experiments indicate that, at the industrial plant of Cajati-SP, $\gamma\llcorner v$ can be modulated by collector dosage, and its magnitude can provide guidance to practitioners to make decision on collector dosage to achieve a desired value of $\gamma_{L V}$ which promotes the best selectivity of the separation apatite/gangue. Notwithstanding, the lack of suitable instruments to accomplish on-line reliable measurements of $\gamma_{L V}$ has been hindering the implementation of those measurements at industrial circuits. This way, decisions on collector dosage made by practitioners continue to be based rather on empirical than on scientific approach.

Keywords: Wettability. Apatite. Flotation. Contact angle. 


\section{LISTA DE ILUSTRAÇÕES}

Figura 1 - Analogia entre as propriedades mecânicas da interface e as de uma mola

Figura 2 - Forças de atração entre moléculas na superfície e no interior de um líquido.

Figura 3 - Diagrama simplificado da interface entre duas fases condensadas 1 e 2 .

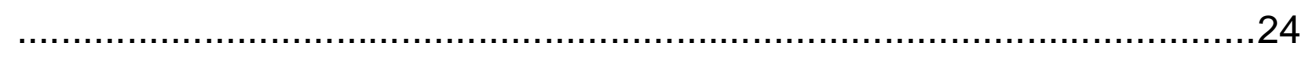

Figura 4 - Representação do ângulo de contato entre uma gota de líquido e a superfície de um sólido em um meio gasoso......................................27

Figura 5 - Efeito do trabalho de coesão do líquido e do trabalho de adesão do líquido ao sólido sobre a molhabilidade do sólido. 29

Figura 6 - Representação do conceito de tensão crítica de molhabilidade de Zisman. 32

Figura 7 - Adesão partícula/bolha no processo de flotação...................................34

Figura 8 - Representação do ângulo de contato entre uma bolha de gás e um sólido disperso em um líquido.

Figura 9 - Distribuição dos átomos formadores da fluorapatita em sua rede cristalina.

Figura 10 - Representação da cela unitária da fluorapatita.

Figura 11 - Localização dos íons $\mathrm{B}\left(\mathrm{F}^{-}, \mathrm{OH}^{-}, \mathrm{Cl}^{-}\right)$na estrutura cristalina da apatita. .40

Figura 12 - Planos normalmente exibidos por cristais de fluorapatita. 41

Figura 13 - Modelo de coordenação oleato/fluorita.

Figura 14 - Isotermas de adsorção de oleato em apatita, fluorita e calcita em $\mathrm{pH}=9,5$ e temperatura $20-25^{\circ} \mathrm{C}$. 45

Figura 15 - Sistemas apresentando $\theta>0$; (a) gotas sésseis (b) bolhas cativas $(\mathrm{S}=$ sólido, $\mathrm{L}=$ líquido e $\mathrm{G}=$ gás). .47

Figura 16 - Diagrama dos domínios hidrodinâmicos. .52

Figura 17 - Planos basal (001) e frontal (010) selecionados do cristal de apatita-lpirá e polidos. .55

Figura 18 - Sistema de microflotação. 61

Figura 19 - Cubeta de vidro para empacotamento da amostra e papéis de filtro....65 
Figura 20 - Determinação do ângulo de contato utilizando o tensiômetro K12.........65

Figura 21 - Representação esquemática de uma curva da massa adquirida pelo leito de partículas ao ser percolado pelo líquido em função do tempo. 66

Figura 22 - Ângulo de contato de avanço da água deionizada sobre partículas de apatita-Ipirá em função da concentração de oleato $\left(20,0 \pm 0,0^{\circ} \mathrm{C}\right) \ldots \ldots \ldots .77$

Figura 23 - Trabalho de adesão da água sobre apatita-lpirá versus concentração de

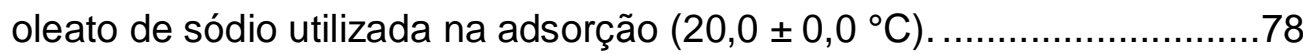

Figura 24 - Coeficiente de espalhamento da água sobre apatita-Ipirá versus concentração de oleato de sódio utilizada na adsorção $\left(20,0 \pm 0,0{ }^{\circ} \mathrm{C}\right) \ldots 79$

Figura 25 - Ângulo de contato de avanço da água sobre planos basal e frontal do cristal de apatita-Ipirá, em função da concentração de oleato de sódio $\left(20^{\circ} \mathrm{C}\right)$

80

Figura 26 - Trabalho de adesão da água nos planos basal e frontal do cristal de apatita-Ipirá, em função da concentração de oleato de sódio $\left(20^{\circ} \mathrm{C}\right)$.......81

Figura 27 - Coeficiente de espalhamento da água sobre planos basal e frontal do cristal de apatita-Ipirá, em função da concentração de oleato de sódio $\left(20^{\circ} \mathrm{C}\right)$.

Figura 28 - Flotabilidade da apatita Ipirá versus ângulo de contato de avanço........88

Figura 29 - Determinação de $\gamma_{c}$ dos planos basal (001) e frontal (010) da apatitaIpirá, tratada com oleato de sódio (75 mg/L ou $\left.2,7.10^{-4} \mathrm{~mol} / \mathrm{L}\right)$. .91

Figura 30 - Ângulo de contato de apatita previamente tratada com amido e Berol ${ }^{\circledR} 867$ versus energia livre superficial da solução água/metanol. 93

Figura 31 - Diagrama dos domínios hidrodinâmicos das forças inerciais, capilares e gravitacionais com os valores experimentais de Weber versus Bond......96

Figura 32 - Recuperação de apatita versus energia livre superficial da solução água/metanol. .98

Figura 33 - Recuperação de apatita e carbonatos versus energia livre superficial da solução água/metanol. 99

Figura 34 - Recuperação de apatita e silicatos versus energia livre superficial da solução água/metanol.

Figura 35 - Eficiência de separação de Schulz (E.S.) apatita/silicatos versus energia livre superficial da solução água/metanol. 100

Figura 36 - Eficiência de separação de Schulz (E.S.) apatita/carbonatos versus energia livre superficial da solução água/metanol 


\section{LISTA DE TABELAS}

Tabela 1 - Interações intermoleculares

Tabela 2 - Energia livre superficial de líquidos e suas contribuições dispersivas e não-dispersivas $\left(20^{\circ} \mathrm{C}\right)$.

23

Tabela 3 - Componentes da energia livre superficial de alguns líquidos.................26

Tabela 4 - Equações combinadas para o cálculo de energia livre superficial de sólidos e suas componentes a partir de medidas de ângulo de contato. .28

Tabela 5 - Características da solução de flotação e coletor usado no circuito de

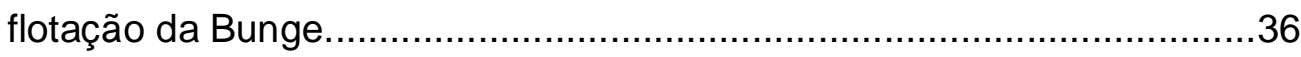

Tabela 6 - Substituições na rede cristalina da fluorapatita. ......................................40

Tabela 7 - Densidade de sítios cálcio superficiais para fluorita, calcita e apatita. ....46

Tabela 8 - Parâmetros hidrodinâmicos usados para caracterizar o escoamento em

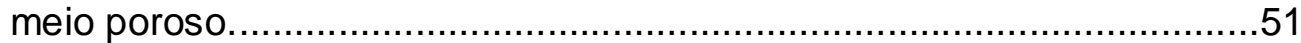

Tabela 9 - Composição química das amostras de apatita......................................54

Tabela 10 - Mineralogia típica do minério de fosfato de Cajati - SP ......................55

Tabela 11 - Composição química, distribuição granulométrica e grau de liberação da

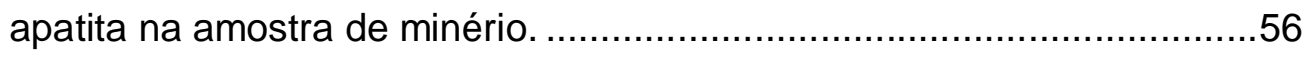

Tabela 12 - Composição química e distribuição granulométrica da amostra que

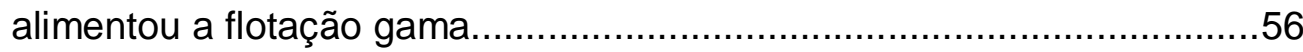

Tabela 13 - Energia livre superficial, densidade e viscosidade dinâmica do hexano, metanol, água deionizada e soluções água/metanol $\left(20,0 \pm 0,1^{\circ} \mathrm{C}\right) \ldots \ldots \ldots .58$

Tabela 14 - Valores de c obtidos com hexano e com água deionizada $\left(20,0 \pm 0,2{ }^{\circ} \mathrm{C}\right)$. 75

Tabela 15 - Ângulo de contato de avanço de água sobre apatita-Ipirá em função da concentração de oleato de sódio e da constante c $\left(20,0 \pm 0,0^{\circ} \mathrm{C}\right) \ldots \ldots \ldots . .75$

Tabela 16 - Ângulo de contato $\left(\theta_{a}\right)$, trabalho de adesão $\left(W_{a}\right)$ e coeficiente de espalhamento (S) de água sobre apatita-Ipirá em função da concentração de oleato de sódio utilizada na adsorção $\left(20,0 \pm 0,0^{\circ} \mathrm{C}\right)$. 78

Tabela 17 - Ângulo de contato entre água e os planos basal e frontal do cristal de apatita-Ipirá, em função da concentração de oleato de sódio utilizada na adsorção $\left(20^{\circ} \mathrm{C}\right)$ 
Tabela 18 - Previsão da precipitação de oleato de cálcio em solução a partir de uma concentração hipotética de cálcio de $\left[\mathrm{Ca}^{2+}\right]=5 \times 10^{-8} \mathrm{M}$.

Tabela 19 - Ângulos de contato de avanço de água sobre amostras de apatita prétratadas com oleato de sódio, determinados pelos métodos da ascensão capilar e da bolha cativa.

Tabela 20 - Flotabilidade de apatita-Ipirá em função da concentração de oleato de sódio ( $\mathrm{pH}=10,5$ e $\left.25^{\circ} \mathrm{C}\right)$. 87

Tabela 21 - Ângulo de contato dos planos basal e frontal do cristal de apatita-Ipirá (pré-tratados com oleato $=75 \mathrm{mg} / \mathrm{L}$ ), em função da energia livre superficial da fase líquida $\left(20^{\circ} \mathrm{C}\right)$ 90

Tabela 22 - Ângulo de contato de avanço de solução água/metanol sobre partículas de apatita-Cajati, em função de $\gamma_{L V}$ da fase líquida $\left(20,0 \pm 0,1^{\circ} \mathrm{C}\right)$. .93

Tabela 23 - Valores dos parâmetros hidrodinâmicos dos sistemas experimentais na determinação de ângulo de contato pelo método da ascensão capilar....95

Tabela 24 - Desempenho da separação de apatita versus minerais de ganga em ensaios de flotação rougher $\left(\gamma\left\llcorner v=35.1 \mathrm{erg} / \mathrm{cm}^{2}\right.\right.$ a $\left.20,0 \pm 0,1^{\circ} \mathrm{C}\right)$. 


\section{SUMÁRIO}

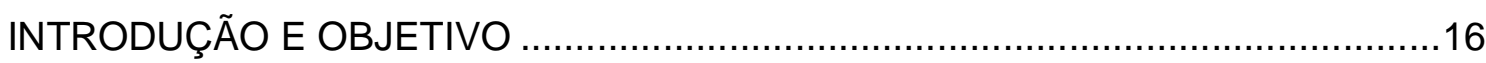

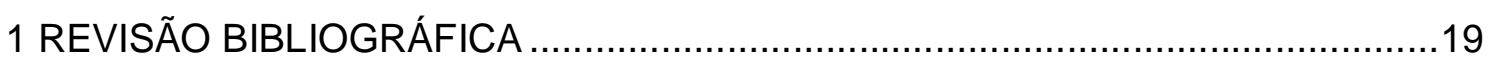

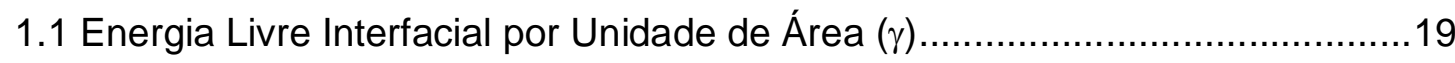

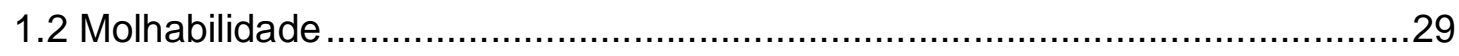

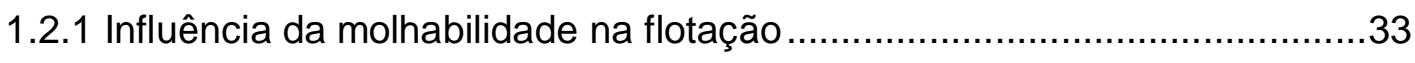

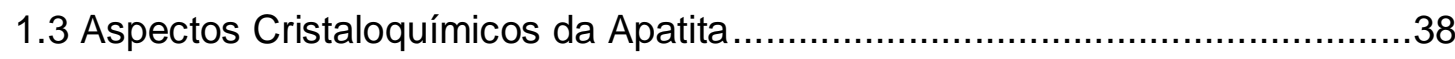

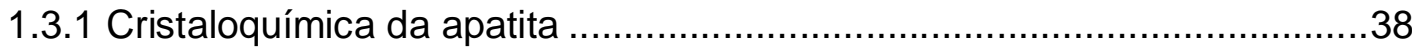

1.3.2 Cristaloquímica da apatita versus molhabilidade ...................................42

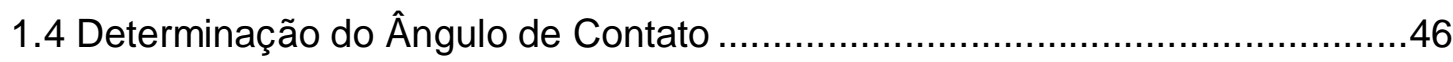

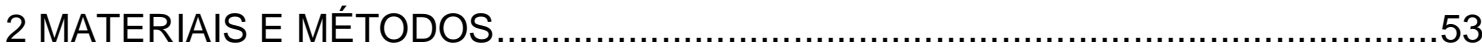

2.1 Obtenção, Preparação e Caracterização das Amostras de Apatita e Minério de

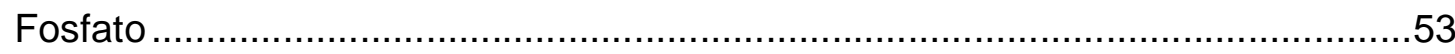

2.1.1 Preparação e purificação das amostras de apatita....................................53

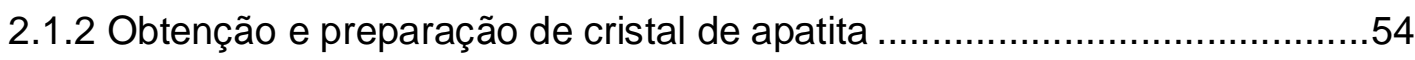

2.1.3 Preparação e caracterização tecnológica do minério de fosfato..................55

2.1.4 Enriquecimento do minério de fosfato visando futuros ensaios de flotação gama

2.2 Reagentes

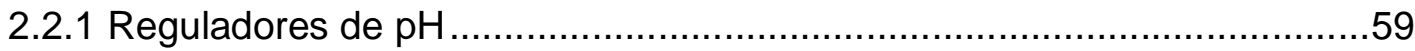

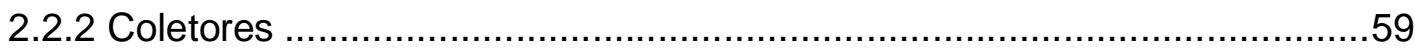

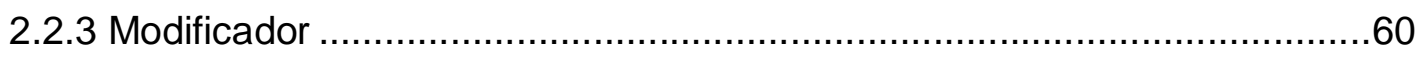

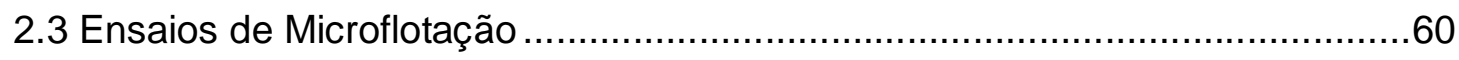

2.4 Enriquecimento do Minério de Fosfato por Flotação........................................62

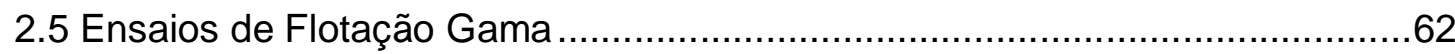

2.6 Determinação de Energia Livre Superficial $(\gamma\llcorner v)$.........................................63

2.7 Determinação de Ângulo de Contato pelo Método da Ascensão Capilar.........64

2.7.1 Determinação de ângulo de contato da apatita-Ipirá pré-tratada com oleato

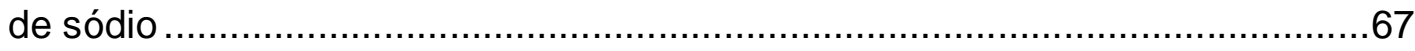

2.7.2 Determinação de ângulo de contato da apatita-Cajati pré-tratada com

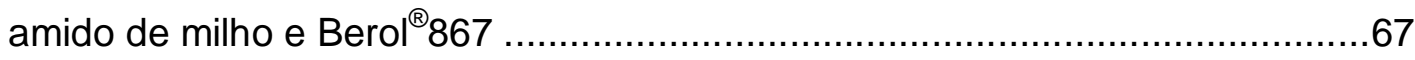


2.7.3 Hidrodinâmica da percolação da fase líquida através do leito de partículas

2.8 Determinação de Ângulo de Contato pelo Método da Bolha Cativa .................71

2.8.1 Determinação de ângulo de contato no sistema apatita/ar/água................71

2.8.2 Determinação de ângulo de contato no sistema apatita/ar/solução

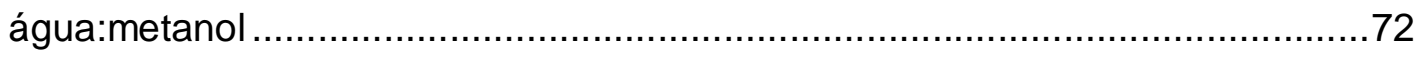

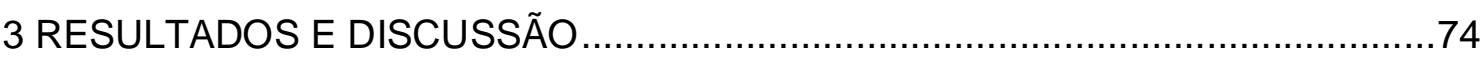

3.1 Ângulo de Contato da Apatita-Ipirá Pré-tratada com Oleato de Sódio ..............74

3.1.1 Método da ascensão capilar (tensiômetro) ..............................................74

3.1.2 Método da bolha cativa (goniômetro de contato) ……................................79

3.1.3 Comparação dos métodos utilizados na determinação do ângulo de

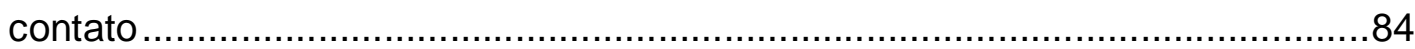

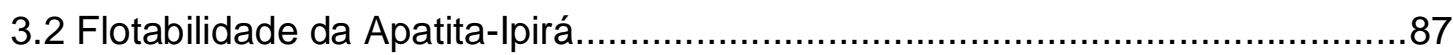

3.3 Tensão Superficial Crítica de Molhabilidade da Apatita-Ipirá Pré-tratada com Oleato de Sódio 88

3.4 Tensão Crítica de Molhabilidade da Apatita-Cajati Pré-tratada com Amido de Milho e Berol ${ }^{\circledR} 867$ 92

3.5 Hidrodinâmica da Percolação da Fase Líquida Através do Leito de Partículas 94

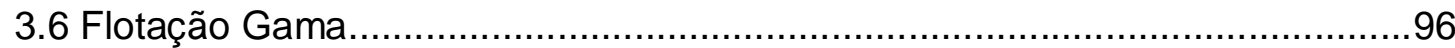

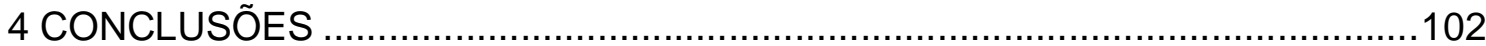

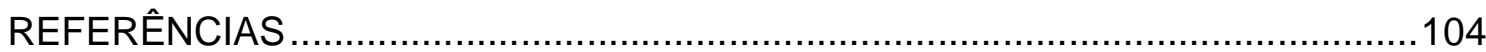

APÊNDICE 1 - RESULTADOS DE ENERGIA LIVRE SUPERFICIAL ...................111

APÊNDICE 2 - RESULTADOS DE CONSTANTE C …..................................115

APÊNDICE 3 - RESULTADOS DE ANGULO DE CONTATO …...........................116 


\section{INTRODUÇÃO E OBJETIVO}

Matérias-primas minerais raramente podem ser utilizadas pelo homem sem prévio processamento e o conjunto das operações unitárias a que se submete um minério para adequá-lo química e fisicamente às especificações do mercado consumidor denomina-se tratamento (ou beneficiamento) de minérios. Embora existam minérios que são convenientemente tratados a seco, a maior parte dos processos industriais hoje em voga no mundo é conduzida a úmido, ou seja, em suspensões aquosas ou polpas.

Dentro do universo das operações unitárias de beneficiamento mineral que são executadas a úmido, o desempenho de duas delas (flotação e filtragem) é afetado pela intensidade da interação entre a água e os sólidos nela suspensos (LEJA, 1982; STROH; STAHL, 1991). Daí a motivação para se estudar a molhabilidade de minerais por água sob condições físicas e químicas que caracterizam o processamento em escala industrial. Tanto na flotação como na filtragem, além da presença de água e sólidos, ocorre também uma fase gasosa (ar) que força a percolação da água através da torta de filtragem ou por bolhas que aderem a partículas minerais promovendo sua flotação. Em ambos os casos, o avanço da fase aquosa sobre a superfície do sólido implica no retrocesso da fase gasosa, e vice-versa (ROSEN, 1989).

Via de regra, apatita é um mineral portador de fósforo e cálcio, exibindo ainda outros importantes componentes que variam em função de sua gênese, tais como os ânions flúor, carbonato e hidroxila, além dos cátions magnésio e alumínio, entre outros (KANAZAWA, 1989). Tratando-se da mais importante fonte de fósforo disponível na crosta terrestre, a escolha de tal mineral como objeto desta tese é bastante justificada seja pela extensão das jazidas de apatita existentes no Brasil e/ou pela necessidade de melhorar o desempenho dos atuais processos industriais de beneficiamento mineral. 
Como veremos nos capítulos vindouros, a molhabilidade de sólidos por água versus ar pertence ao domínio da físico-química de interfaces, visto que é controlada pela magnitude da energia livre por unidade de área $(\gamma)$ das três interfaces envolvidas nesse fenômeno: sólido/gás $\left(\gamma_{\mathrm{SG}}\right)$, sólido/líquido $\left(\gamma_{\mathrm{SL}}\right)$ e líquido/gás $\left(\gamma_{\mathrm{LG}}\right)$. Limitações experimentais, todavia, permitem que somente seja possível medir diretamente, e com aceitável precisão, a magnitude de $\gamma_{L G}$. A elaboração intelectual de cientistas, todavia, foi capaz de correlacionar as grandezas $\gamma_{S G}, \gamma_{S L}$ e $\gamma_{L G}$ com variáveis diretamente mensuráveis, como o ângulo de contato $(\theta)$, ou com outras calculadas a partir do conhecimento de $\theta$ e $\gamma_{\mathrm{LG}}$, como o coeficiente de espalhamento (S) ou trabalho de adesão $\left(\mathrm{W}_{\mathrm{a}}\right)$. Zisman (1964) correlacionou $\gamma_{\mathrm{LG}} \operatorname{com} \cos \theta$, introduzindo o conceito de tensão superficial crítica de molhabilidade de sólidos por líquidos $\left(\gamma_{c}\right)$, ou seja, para todo sólido existe certo valor particular da variável $\gamma_{L G}$ que, abaixo do qual, o líquido molha o sólido completamente. Uma modalidade especial de flotação (Flotação Gama ou "Gamma Flotation") se baseia neste conceito (YARAR, 1988).

Uma vez que a magnitude das grandezas primárias $\left(\gamma_{S G}, \gamma_{S L}\right.$ e $\left.\gamma_{L G}\right)$ e secundárias $\left(\theta, S, W_{a}\right.$ e $\left.\gamma_{c}\right)$ que determinam a molhabilidade de apatita por água (ou ar) pode ser modificada pela ação de surfatantes, tal modificação, e também o seu controle, pode constituir uma importante ferramenta para engenheiros aprimorarem o desempenho de processos de flotação e filtragem.

Com base nas premissas apresentadas no decorrer deste capítulo, delineouse o objetivo geral desta tese, que é o de estudar a molhabilidade do mineral apatita, visando otimizar a seletividade da separação apatita/minerais de ganga por flotação. Para alcançá-lo, delinearam-se os seguintes objetivos secundários:

i. Executar medidas de tensão superficial $\left(\gamma_{L G}\right)$ de soluções água/metanol em diferentes proporções, almejando gerar subsídios para avaliar a influência de $\gamma_{L G}$ na magnitude de $\theta$;

ii. Determinar o ângulo de contato $(\theta)$, pelo método de ascensão capilar (tensiômetro), de partículas de apatita que tiveram suas superfícies modificadas pela adsorção de (a) oleato de sódio em diferentes concentrações ou (b) amido de milho e Berol ${ }^{\circledR} 867$; 
iii. Determinar o ângulo de contato $(\theta)$ ao longo dos planos basal (001) e frontal (010) do cristal de apatita que teve sua superfície modificada pela adsorção de oleato de sódio em diferentes concentrações, através do método da bolha cativa (goniômetro);

iv. Com base nas informações levantadas nos itens anteriores (i-iii), determinar a tensão superficial crítica de molhabilidade $\left(\gamma_{c}\right)$ da apatita previamente tratada com reagentes de flotação através de diagramas $\cos \theta$ versus $\gamma L G$ propostos por Zisman (1964);

v. Verificar o comportamento da recuperação de apatita previamente tratada com amido de milho e Berol ${ }^{\circledR} 867$ versus $\gamma_{L G}$, através de ensaios de Flotação Gama, determinando a tensão superficial crítica de molhabilidade da apatita, conforme proposto por Yarar (1988);

vi. Com base nos valores medidos de $\theta$ e $\gamma_{\mathrm{LG}}$, caracterizar a molhabilidade da apatita ("in natura" ou após condicionamento com reagentes de flotação) através do cálculo de outros parâmetros de molhabilidade: trabalho de adesão $\left(\mathrm{W}_{\mathrm{a}}\right)$ e coeficiente de espalhamento (S);

vii. Correlacionar ângulo de contato com a flotabilidade de partículas de apatita em ensaios de microflotação; 


\section{REVISÃO BIBLIOGRÁFICA}

\subsection{Energia Livre Interfacial por Unidade de Área $(\gamma)$}

Entre duas fases adjacentes, existe uma região tridimensional denominada "interfase" onde ocorre uma transição contínua das propriedades de uma fase às da outra. Uma vez que o comprimento e largura (área) de uma interfase são infinitamente maiores que sua espessura, seu volume pode ser desprezado e, por conveniência, o termo "interface" pode ser utilizado para designar uma fronteira geométrica e bidimensional entre duas fases que se encontram em contato (RABOCKAI, 1979). Por outro lado, o termo "superfície" corresponde a uma interface onde uma das fases é um gás, usualmente ar (ROSEN, 1989).

No caso de interfaces fluidas (líquido/gás e líquido/líquido), suas propriedades mecânicas podem ser relacionadas com as de uma membrana elástica hipotética que se encontra em permanente estado de tensão. Assim como uma mola que, dentro de certos limites, ao ser estendida, tende a voltar a sua posição inicial devido à ação de uma força elástica restauradora; interfaces fluidas comportam-se de maneira semelhante através da ação de uma "força restauradora" $(F)$ que atua ao longo de seu comprimento $L$, sempre se opondo a qualquer aumento da área interfacial (Fig. 1). De acordo com a Eq. (1), a razão entre a força restauradora $(F)$ e o comprimento do segmento de reta $(L)$ sobre o qual a mesma atua é denominada "tensão interfacial" $(\gamma)$, quando se trata da interface líquido/líquido ou "tensão superficial", quando se trata da interface líquido/gás. Em ambos os casos, $\gamma$ exibe as dimensões $\mathrm{N} / \mathrm{m}$ no SI ou dina/cm no sistema CGS (RABOCKAI, 1979; SOMORJAI, 1972).

$$
\gamma=\frac{\mathrm{F}}{\mathrm{L}}
$$




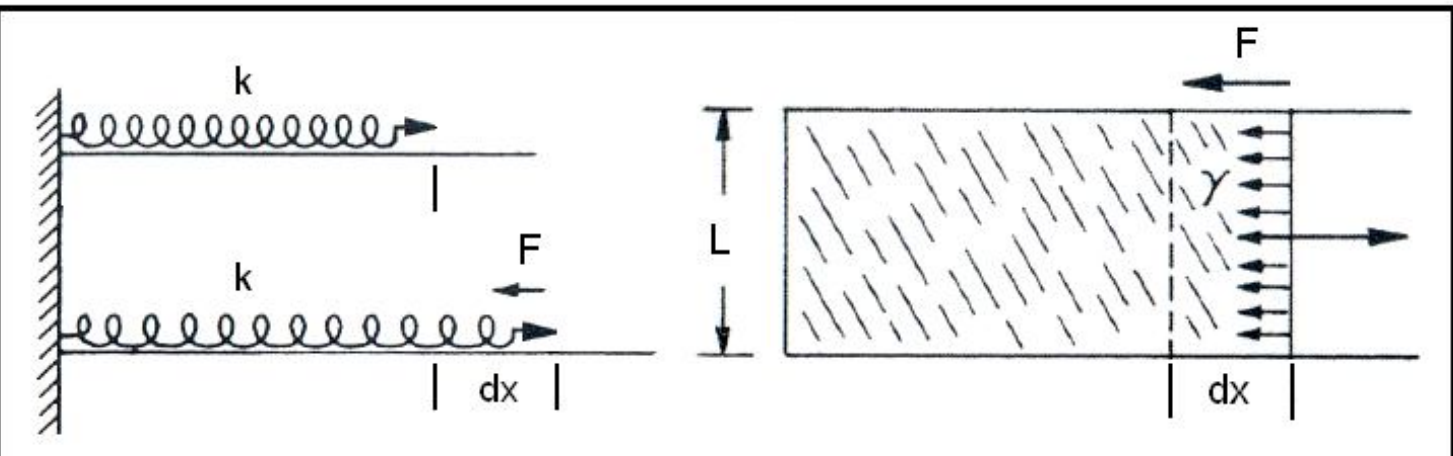

Figura 1 - Analogia entre as propriedades mecânicas da interface e as de uma mola (DE BRUYN; AGAR, 1962, p.111, adaptação nossa).

Uma vez que $\gamma$ se opõe a qualquer processo que resulte no aumento da área da interface, ela também pode ser definida como o trabalho (W) necessário para aumentar a área da interface de uma unidade, num processo isotérmico e reversível, de acordo com a relação matemática expressa pela Eq. (2). Neste caso, é mais coerente expressar a magnitude de $\gamma \mathrm{em} \mathrm{J} / \mathrm{m}^{2}$ no Sistema Internacional ou $\mathrm{erg} / \mathrm{cm}^{2}$ no Sistema CGS (SOMORJAI, 1972).

$$
\gamma=\frac{\mathrm{W}}{\mathrm{dA}}
$$

Onde:

$\gamma=$ Tensão superficial ou interfacial;

$W=$ Trabalho para aumentar a área da interface;

$\mathrm{dA}=$ Incremento diferencial da área da interface.

Por ser um processo termodinamicamente reversível, o trabalho realizado a pressão e temperatura constantes corresponderá a uma variação da energia livre do sistema e, conseqüentemente, $\gamma$ poderá ser definida como a variação da energia livre interfacial por unidade de área, de acordo com a Eq. (3) (SOMORJAI, 1972).

$$
\gamma=\left(\frac{\partial \mathrm{G}}{\partial \mathrm{A}}\right)_{\mathrm{T}, \mathrm{p}}
$$


A existência de uma tensão interfacial $(\gamma)$ entre duas fases adjacentes pode ser explicada em termos das forças de atração entre moléculas (ou átomos) que compõem as mesmas. Por exemplo, seja a água líquida em equilíbrio com seu vapor, onde as atrações entre moléculas são representadas por setas, conforme ilustrado na Fig. 2. Verifica-se, então, que a atração entre as moléculas localizadas no seio da fase líquida ("bulk") será muito diferente daquela que ocorre na região interfacial. No interior do líquido, a atração ocorrerá indiscriminadamente ao longo de todas as direções (conforme ilustram as setas), ocasionando um balanceamento entre as forças atrativas. Ao passo que, na interface líquido/gás, a atração será nãobalanceada em virtude da presença da fase gasosa, que é muito mais rarefeita. Disto resultará uma força na direção da fase líquida, fazendo com que o maior número possível de moléculas se desloque da interface para o interior do líquido e a superfície se contraia espontaneamente, adquirindo a menor área possível. Este fato explica por que gotículas de um líquido tendem a adquirir uma forma esférica (SHAW, 1975).

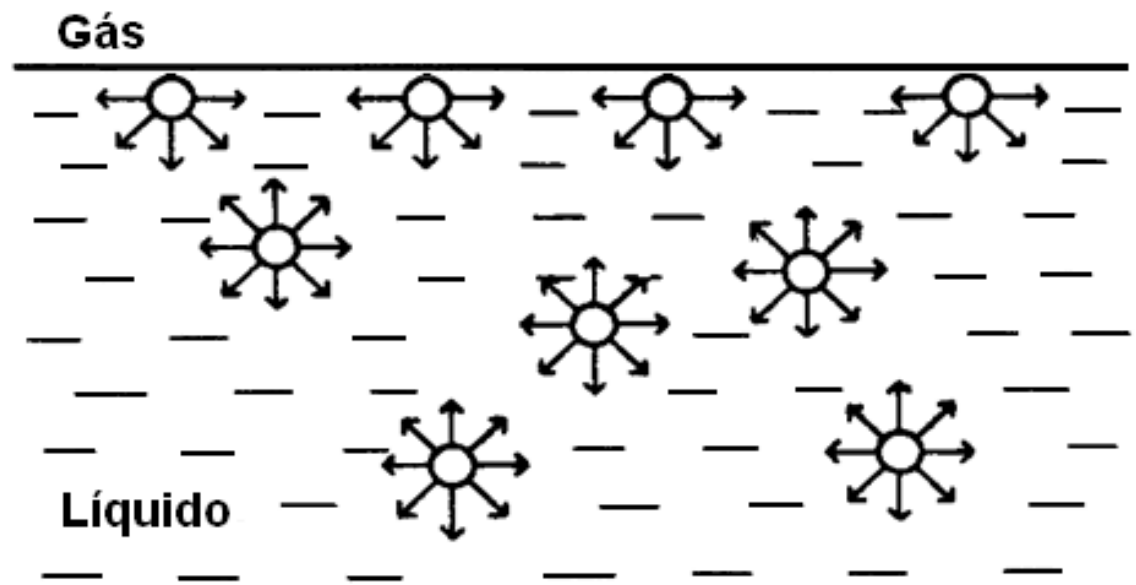

Figura 2 - Forças de atração entre moléculas na superfície e no interior de um líquido (SHAW, 1975, p.42, adaptação nossa).

Atrações intermoleculares responsáveis pela tensão (ou energia livre) superficial $(\gamma)$ de um líquido resultam de uma variedade de contribuições, como as interações íon-dipolo, dipolo-dipolo, dipolo-dipolo induzido, dipolo induzido-dipolo induzido (forças de dispersão ou forças de London) e pontes de hidrogênio. Informações a respeito de tais interações são apresentadas na Tab. 1. 
Tabela 1 - Interações intermoleculares (FORÇAS, 200?).

\begin{tabular}{|c|c|c|c|}
\hline Interação & Descrição & $\begin{array}{c}\text { Magnitude } \\
(\mathrm{kJ} / \mathrm{mol})\end{array}$ & Exemplo \\
\hline Íon-dipolo & $\begin{array}{c}\text { Interação por atração } \\
\text { eletrostática entre uma espécie } \\
\text { iônica e uma molécula que } \\
\text { possui dipolo permanente } \\
\text { (polar). }\end{array}$ & $1-70$ & $A$ \\
\hline Dipolo-dipolo & $\begin{array}{l}\text { Interação por atração } \\
\text { eletrostática entre duas } \\
\text { moléculas que possuem dipolo } \\
\text { permanente. }\end{array}$ & $0,1-10$ & \\
\hline $\begin{array}{l}\text { Dipolo-dipolo } \\
\text { induzido }\end{array}$ & $\begin{array}{l}\text { Uma molécula portadora de } \\
\text { dipolo permanente induz a } \\
\text { polarização em uma molécula } \\
\text { apolar vizinha, resultando em } \\
\text { uma interação por atração } \\
\text { eletrostática. }\end{array}$ & - & \\
\hline $\begin{array}{l}\text { Dipolo induzido- } \\
\text { dipolo induzido ou } \\
\text { forças de } \\
\text { dispersão }\end{array}$ & $\begin{array}{c}\text { Moléculas apolares } \\
\text { apresentam dipolos } \\
\text { instantâneos oriundos da } \\
\text { flutuação eletrônica causada } \\
\text { pelo movimento dos elétrons } \\
\text { em seus átomos constituintes. } \\
\text { Estes dipolos instantâneos } \\
\text { podem induzir a polarização } \\
\text { das moléculas apolares } \\
\text { adjacentes, resultando em } \\
\text { forças atrativas. }\end{array}$ & $0,1-2$ & $\mathrm{C}_{8} \mathrm{H}_{18}$ \\
\hline $\begin{array}{l}\text { Pontes de } \\
\text { hidrogênio }\end{array}$ & $\begin{array}{c}\text { É um tipo especial de } \\
\text { interação dipolo-dipolo entre } \\
\text { moléculas que apresentam } \\
\text { átomos de hidrogênio ligados a } \\
\text { átomos fortemente } \\
\text { eletronegativos como } \mathrm{F}, \mathrm{O} \text { e N. } \\
\text { Trata-se de uma interação } \\
\text { mais intensa que a dipolo- } \\
\text { dipolo. }\end{array}$ & $10-40$ & \\
\hline
\end{tabular}

Nota: $\mathrm{M}^{2+}$ representa um cátion metálico divalente.

Enquanto a contribuição devida às forças de London está presente em todos os materiais, as demais são dependentes da natureza das moléculas que interagem entre si (FOWKES, 1964). Por esta razão, Fowkes (1962; 1964) propôs que a energia livre superficial $(\gamma)$ de um líquido fosse representada pela soma de duas contribuições principais: interações "dispersivas" $\left(\gamma^{d}\right)$, ou seja, aquelas oriundas das 
forças de dispersão de London e as "não-dispersivas" $\left(\gamma^{n}\right)$ que engloba todas as demais, conforme expressa a Eq. (4).

$$
\gamma=\gamma^{\mathrm{d}}+\gamma^{\mathrm{n}}
$$

A Tab. 2 informa a magnitude da contribuição fornecida por "interações dispersivas" $\left(\gamma^{d}\right)$ e "não-dispersivas" $\left(\gamma^{n}\right)$ para a energia livre superficial de alguns líquidos puros. Analisando as informações contidas na Tab. 2, é importante ressaltar que:

i. Para hidrocarbonetos saturados, como é o caso do hexano, a energia livre superficial $(\gamma)$ é oriunda somente de "interações dispersivas", isto é, $\gamma=\gamma^{\mathrm{d}}$;

ii. Na água, a componente não-dispersiva é representada principalmente por contribuições do tipo pontes de hidrogênio, isto é, $\gamma^{\mathrm{n}}=51 \mathrm{erg} / \mathrm{cm}^{2}$;

iii. No mercúrio, as ligações metálicas representam a contribuição nãodispersiva, equivalendo à $\gamma^{n}=284 \mathrm{erg} / \mathrm{cm}^{2}$.

Tabela 2 - Energia livre superficial de líquidos e suas contribuições dispersivas e nãodispersivas $\left(20^{\circ} \mathrm{C}\right)$ (FOWKES, 1964).

\begin{tabular}{c|c|c|c}
\hline \hline \multirow{2}{*}{ Substância } & \multicolumn{3}{|c}{ Energia Livre Superficial (erg/cm $\mathbf{c}^{\mathbf{2}}$} \\
\cline { 2 - 4 } & $\gamma$ & $\gamma^{\mathbf{d}}$ & $\gamma^{\mathbf{n}}$ \\
\hline \hline Água & 72,8 & 21,8 & 51,0 \\
\hline Mercúrio & 484,0 & 200,0 & 284,0 \\
\hline Hexano & 18,4 & 18,4 & - \\
\hline \hline
\end{tabular}

Numa abordagem mais recente, conforme exposto na Eq. (5), van Oss; Chaudhury e Good (1987; 1989) sugerem que a energia livre superficial de líquidos e sólidos polares seja o somatório de duas contribuições: interações de longo alcance de Lifshitz-van der Waals $\left(\gamma^{\mathrm{LW}}\right)$ e interações ácido-base de Lewis $\left(\gamma^{\mathrm{AB}}\right)$.

$$
\gamma=\gamma^{\mathrm{LW}}+\gamma^{\mathrm{AB}}
$$

A principal diferença entre as componentes $\gamma^{\mathrm{d}}$ e $\gamma^{\mathrm{LW}}$ apresentadas nas Eqs. (4) e (5), respectivamente, se baseia no fato de que $\gamma^{\mathrm{LW}}$ engloba as contribuições devidas às interações dipolo-dipolo e dipolo-dipolo induzido, além daquela oriunda 
das forças de dispersão de London, uma vez que a teoria de Lifshitz considera que estas interações eletromagnéticas não agem independentemente (GOOD, 1993). Com relação a hidrocarbonetos saturados, entretanto, esta diferença é apenas conceitual, já que apenas interações de natureza dispersiva (dipolo induzido-dipolo induzido) ocorrem entre as moléculas, isto é, $\gamma=\gamma^{\mathrm{d}}=\gamma^{\mathrm{LW}}$.

A abordagem segundo a qual a energia livre superficial de um líquido é o somatório de contribuições relativas às interações moleculares existentes pode ser generalizada para as interfaces líquido/líquido e sólido/líquido. Segundo Fowkes (1962; 1963), a tensão na interface entre dois líquidos imiscíveis 1 e 2 ( $\left.\gamma_{12}\right)$, é a soma das tensões em cada fase adjacente. O diagrama apresentado na Fig. 3 ilustra o raciocínio desenvolvido por Fowkes, descrito a seguir:

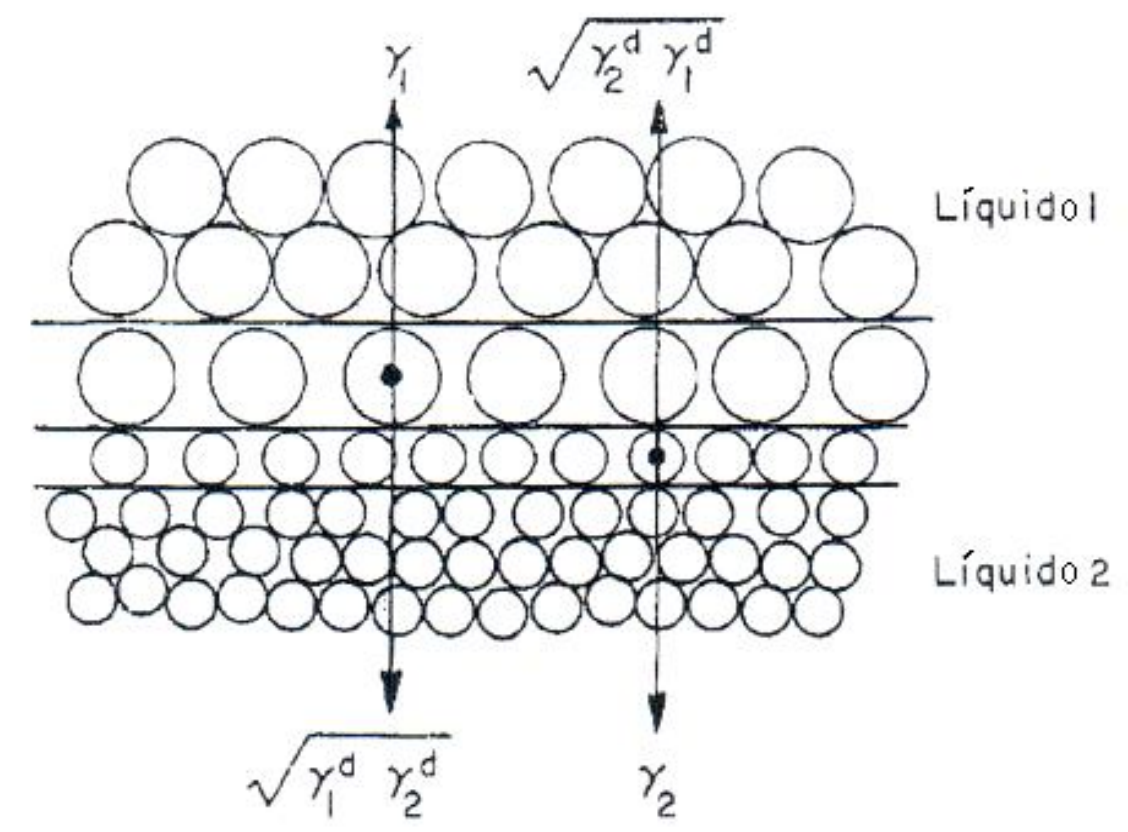

Figura 3 - Diagrama simplificado da interface entre duas fases condensadas 1 e 2 (FOWKES, 1963, p.2539, adaptação nossa).

i. As moléculas do líquido 1, situadas na região interfacial, são atraídas por aquelas do interior da mesma fase, resultando em uma tensão equivalente à tensão superficial $\gamma_{1}$, caso a fase 2 fosse um gás; 
ii. Entretanto, as moléculas interfaciais do líquido 1 são também atraídas pelas moléculas interfaciais do líquido 2 , o que resulta em uma redução de $\gamma_{1}$ dada pela média geométrica das contribuições das forças atrativas entre as diferentes moléculas, proposta por Girifalco e Good (1957);

iii. Fowkes ainda sugeriu que as interações, através da interface, podem ocorrer apenas entre forças do mesmo tipo existentes em cada fase. Portanto, para duas fases que interagem apenas por forças dispersivas a média geométrica será dada por $\left(\sqrt{\gamma_{1}^{\mathrm{d}} \gamma_{2}^{\mathrm{d}}}\right)$;

iv. As considerações (i-iii) feitas para a fase 1 são válidas também para a fase 2, e a energia livre interfacial $\gamma_{12}$ será dada pela Eq. (6):

$$
\gamma_{12}=\left(\gamma_{1}-\sqrt{\gamma_{1}^{\mathrm{d}} \gamma_{2}^{\mathrm{d}}}\right)+\left(\gamma_{2}-\sqrt{\gamma_{1}^{\mathrm{d}} \gamma_{2}^{\mathrm{d}}}\right)=\gamma_{1}+\gamma_{2}-2 \sqrt{\gamma_{1}^{\mathrm{d}} \gamma_{2}^{\mathrm{d}}}
$$

Tamai; Makuuchi e Suzuki (1967) consideraram a contribuição devida a interações não-dispersivas entre as fases 1 e 2, quando presentes, inserindo um termo de energia $I_{12}$ à Eq. (6) e obtendo a Eq. (7). Outros autores, como Owens e Wendt (1969) e Wu (1970), assumiram que a média geométrica também pode ser utilizada para expressar a contribuição de tais interações, conforme mostra a Eq. (8):

$$
\begin{gathered}
\gamma_{12}=\gamma_{1}+\gamma_{2}-2 \sqrt{\gamma_{1}^{\mathrm{d}} \gamma_{2}^{\mathrm{d}}}-\mathrm{I}_{12} \\
\gamma_{12}=\gamma_{1}+\gamma_{2}-2 \sqrt{\gamma_{1}^{\mathrm{d}} \gamma_{2}^{\mathrm{d}}}-2 \sqrt{\gamma_{1}^{\mathrm{n}} \gamma_{2}^{\mathrm{n}}}
\end{gathered}
$$

Empregando as componentes $\gamma^{\mathrm{LW}}$ e $\gamma^{\mathrm{AB}}$, a abordagem realizada por van Oss; Chaudhury e Good (1987; 1989) fornece a Eq. (9) para expressar a energia livre interfacial entre duas fases imiscíveis.

$$
\gamma_{12}=\gamma_{1}+\gamma_{2}-2 \sqrt{\gamma_{1}^{\mathrm{LW}} \gamma_{2}^{\mathrm{LW}}}-2 \sqrt{\gamma_{1}^{\mathrm{AB}} \gamma_{2}^{\mathrm{AB}}}
$$


Uma vez que a componente $\gamma^{\mathrm{AB}}$ pode ser expressa pela média geométrica do receptor $\left(\gamma^{+}\right)$de elétrons (ácido de Lewis) e do doador $\left(\gamma^{-}\right)$de elétrons (base de Lewis), a Eq.(9) passa a ser expressa pela Eq.(10):

$$
\gamma_{12}=\gamma_{1}+\gamma_{2}-2 \sqrt{\gamma_{1}^{\mathrm{LW}} \gamma_{2}^{\mathrm{LW}}}-2 \sqrt{\gamma_{1}^{+} \gamma_{2}^{-}}-2 \sqrt{\gamma_{1}^{-} \gamma_{2}^{+}}
$$

A Tab. 3 informa a magnitude da contribuição fornecida pelas componentes $\gamma^{\mathrm{LW}}, \gamma^{\mathrm{AB}}, \gamma^{+}$e $\gamma^{-}$para a energia livre superficial de alguns líquidos puros.

Tabela 3 - Componentes da energia livre superficial de alguns líquidos (GOOD, 1993).

\begin{tabular}{c|c|c|c|c|c}
\hline \multirow{2}{*}{ Líquido } & \multicolumn{5}{|c}{ Energia livre superficial e suas componentes $\left(\mathbf{e r g} / \mathbf{c m}^{2}\right)$} \\
\cline { 2 - 6 } & $\gamma$ & $\gamma^{\mathbf{L W}}$ & $\gamma^{\mathbf{A B}}$ & $\gamma^{+}$ & $\gamma^{-}$ \\
\hline Água & 72,8 & 21,8 & 51,0 & 25,5 & 25,5 \\
\hline Formamida & 58,0 & 39,0 & 19,0 & 2,28 & 39,6 \\
\hline Clorofórmio & 27,15 & 27,15 & 0,0 & 3,8 & 0,0 \\
\hline Diiodometano & 50,8 & 50,8 & $\cong 0,0$ & - & - \\
\hline \hline
\end{tabular}

Nota: os valores de $\gamma^{+}$e $\gamma^{-}$foram baseados na convenção de referência: $\gamma_{\text {água }}^{+} \gamma_{\text {água. }}^{-}$

Segundo Fowkes (1964), a componente $\gamma^{d} L$ de um líquido polar (fase $L$ ) pode ser determinada através de medidas de energia livre interfacial utilizando um hidrocarboneto saturado como fase de referência (fase $H$ ). Uma vez que apenas interações de dispersão estão presentes no hidrocarboneto, $\gamma_{H}=\gamma_{H}^{d}$ e a Eq. (8) se reduz à Eq. (11)

$$
\gamma_{L H}=\gamma_{L}+\gamma_{H}-2 \sqrt{\gamma_{L}^{d} \cdot \gamma_{H}}
$$

Assim, conhecendo-se os valores de $\gamma_{L H}$ e $\gamma_{H}$, a magnitude da componente $\gamma_{L}^{d}$ pode ser calculada utilizando-se a Eq. (11), enquanto que a magnitude da componente $\gamma^{n} L$ pode ser obtida através da Eq. (4), subtraindo-se $o$ valor de $\gamma^{d} L$ da energia livre superficial do líquido de interesse $\gamma_{\mathrm{L}}$. 
Os valores da energia livre superficial de líquidos e energia livre interfacial entre dois líquidos imiscíveis podem ser determinados experimentalmente através de diferentes métodos, como o da placa de Wilhelmy (seção 2.6), por exemplo. Por outro lado, valores de energias livres superficiais (e suas componentes) e também interfaciais, quando envolvem uma fase sólida, são difíceis de serem obtidos através de medidas diretas, uma vez que seria necessário estender ou contrair a superfície de um sólido, sem introduzir tensões no interior da fase (GOOD; GIRIFALCO; KRAUS, 1958). Neste sentido, métodos indiretos são empregados.

Fowkes (1964) sugeriu a determinação da componente dispersiva da energia livre interfacial do sólido $\left(\gamma_{s}^{d}\right)$ através de medidas de energia livre de adsorção, calores de adsorção ou calores de imersão. Entretanto, os métodos indiretos envolvendo medidas de ângulo de contato $\theta$ são os mais empregados devido à relativa facilidade de se realizar estas medidas com superfícies sólidas cuidadosamente preparadas (MOY; LI, 1992).

Em um sistema composto por uma gota de líquido sobre uma superfície sólida, em meio gasoso (Fig. 4), o ângulo de contato $\theta$ é definido como o ângulo formado entre uma reta tangente ao perfil da gota e outra tangente à interface sólido/líquido, ambas originando do ponto de contato entre as três fases envolvidas sólido/líquido/gás (DRZYMALA, 1994).

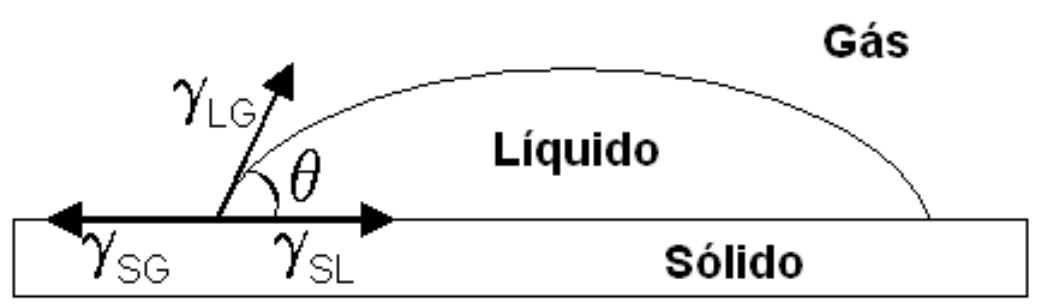

Figura 4 - Representação do ângulo de contato entre uma gota de líquido e a superfície de um sólido em um meio gasoso.

As energias livres interfaciais $\gamma_{S G}, \gamma_{S L}$ e $\gamma_{L G}$ são relacionadas ao ângulo de contato através da equação de Young (Eq. (12)). No equilíbrio, a fase gasosa se encontra saturada pelo vapor da fase líquida e o valor de $\gamma_{S v}$ é menor que o de $\gamma_{S}$ devido à adsorção física de moléculas do líquido sobre a superfície do sólido, 
resultando em um filme de pressão superficial $\prod_{e}=\gamma_{s}-\gamma_{s v}$. (ADAMSON,1982 apud DRZYMALA, 1994).

$$
\gamma_{S}-\Pi_{e}=\gamma_{S L}+\gamma_{L V} \cos \theta
$$

Em sistemas envolvendo sólidos de baixa energia e líquidos de alta energia $\left(\gamma_{L}>\gamma_{S}\right)$ e $\theta>0$, Пe é considerado negligenciável e $\gamma_{S}=\gamma_{S V}$ (FOWKES, 1964; GOOD,1993) e a equação de Young é expressa conforme a Eq. (13). A premissa apresentada por Fowkes (1964) é a de que um fluido de alta energia não pode reduzir a energia superficial de um material de baixa energia e um ângulo de contato maior que zero é uma evidência de que $\gamma_{L}>\gamma_{S}$. Entretanto, esta regra é válida para sólidos que interagem por forças dispersivas somente, como é o caso de partículas de apatita "recobertas" por surfatantes (ânions oleato ou sarcosinato de alquila).

$$
\gamma_{\mathrm{SV}}=\gamma_{\mathrm{SL}}+\gamma_{\mathrm{LV}} \cos \theta
$$

Das quatro variáveis contidas na Eq. (13), apenas os valores de $\gamma_{\mathrm{LV}}$ e $\theta$ podem ser obtidos através de medidas diretas. Em um grande número de trabalhos publicados, o termo $\gamma_{S L}$ da equação de Young é substituído por uma das Eqs. de (5) a (10) e o valores da energia superficial do sólido e suas componentes são determinados utilizando-se uma série de líquidos cujos valores de $\gamma_{\mathrm{LV}}, \gamma_{\mathrm{L}}^{\mathrm{d}}, \gamma_{\mathrm{L}}^{\mathrm{n}}, \gamma^{\mathrm{LW}}{ }_{\mathrm{L}}$, $\gamma_{L}^{A B}, \gamma_{L}^{+}$e $\gamma_{L}^{-}$são conhecidos. A Tab. 4 apresenta algumas dessas equações combinadas - Eqs. (14) a (16) - com suas respectivas referências.

Tabela 4 - Equações combinadas para o cálculo de energia livre superficial de sólidos e

\begin{tabular}{|c|c|}
\hline Equação Combinada & Referência \\
\hline$\gamma_{L}(\cos \theta+1)+\prod_{e}=2\left(\gamma_{S}^{d} \gamma_{L}^{d}\right)^{1 / 2}+2\left(\gamma_{S}^{n} \gamma_{L}^{n}\right)^{1 / 2}$ & Jańczuk et al. (1996) \\
\hline$\gamma_{\mathrm{L}}(\cos \theta+1)+\Pi_{\mathrm{e}}=2\left(\gamma_{\mathrm{S}}^{\mathrm{LW}} \gamma_{\mathrm{L}}^{\mathrm{LW}}\right)^{1 / 2}+2\left(\gamma_{\mathrm{S}}^{+} \gamma_{\mathrm{L}}^{-}\right)^{1 / 2}+2\left(\gamma_{\mathrm{S}}^{-} \gamma_{\mathrm{L}}^{+}\right)^{1 / 2}$ & $\begin{array}{l}\text { Good (1993); Jańczuk et } \\
\text { al. (1996) }\end{array}$ \\
\hline$\gamma_{\mathrm{H}}-2\left(\gamma_{\mathrm{S}}^{\mathrm{d}} \gamma_{\mathrm{H}}\right)^{1 / 2}=\gamma_{\mathrm{W}}-2\left(\gamma_{\mathrm{S}}^{\mathrm{d}} \gamma_{\mathrm{W}}^{\mathrm{d}}\right)^{1 / 2}-\mathrm{I}_{\mathrm{SW}}+\gamma_{\mathrm{HW}} \cos \theta$ & $\begin{array}{l}\text { Tamai; Makuuchi e } \\
\text { Suzuki (1967); Raichur; } \\
\text { Wang e Parekh (2001). }\end{array}$ \\
\hline
\end{tabular}
suas componentes a partir de medidas de ângulo de contato.

Nota: os índices L, S, H e W nas Eqs. (14) a (16) correspondem às fases: líquido, sólido, hidrocarboneto e água, respectivamente. 


\subsection{Molhabilidade}

O termo "molhabilidade", em seu conceito mais amplo, refere-se ao deslocamento de um fluido por outro sobre uma superfície líquida ou sólida (ROSEN, 1989). Entretanto, uma vez que o processo de flotação envolve as fases sólido/líquido/gás, tal termo será aqui aplicado ao deslocamento de ar por água (ou solução aquosa) sobre uma superfície sólida. Quando um sólido é completamente molhado por água ele é dito "hidrofílico", enquanto que um sólido "hidrofóbico" é aquele parcialmente molhado por água e que possui afinidade por substâncias apolares ou lipofílicas como o ar atmosférico e substâncias graxas (LEJA, 1982).

Termodinamicamente, a molhabilidade é uma função das magnitudes relativas das energias livres por unidade de área $(\gamma)$ das três interfaces envolvidas nesse fenômeno: sólido/gás ( $\left.\gamma_{S G}\right)$, sólido/líquido $\left(\gamma_{S L}\right)$ e líquido/gás $\left(\gamma_{L G}\right)$ (OWENS; WENDT, 1969). Segundo Rosen (1989), para que o líquido se espalhe espontaneamente sobre o sólido, e o molhe, a energia livre interfacial do sistema deve diminuir durante o processo em que uma unidade de área da interface sólido/gás é substituída por outra do tipo sólido/líquido.

Tomando como exemplo um sistema composto por uma gota de líquido em equilíbrio com seu vapor sobre a superfície plana de um sólido, uniformemente polida e limpa, sob valores constantes de temperatura e pressão (Fig. 5); verifica-se que:

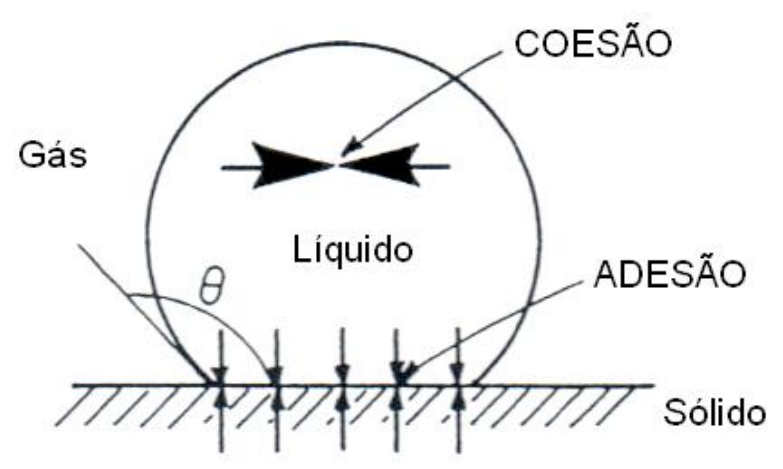

Figura 5 - Efeito do trabalho de coesão do líquido e do trabalho de adesão do líquido ao sólido sobre a molhabilidade do sólido (LASKOWSKI, 1986, p.190, adaptação nossa). 
i. As magnitudes de $\gamma_{L V}, \gamma_{S V}$ e $\gamma_{S L}$ são relacionadas ao trabalho de adesão do líquido ao sólido $\left(W_{a}\right)$ e ao trabalho de coesão do líquido $\left(W_{c}\right)$, através das Eqs. (17) e (18) desenvolvidas por Dupré (LEJA, 1982; GOOD, 1993).

$$
\begin{gathered}
\mathrm{W}_{\mathrm{a}}=\gamma_{\mathrm{SV}}+\gamma_{\mathrm{LV}}-\gamma_{\mathrm{SL}} \\
\mathrm{W}_{\mathrm{c}}=2 \gamma_{\mathrm{LV}}
\end{gathered}
$$

Onde:

$\mathbf{W}_{\mathbf{a}}$ é o trabalho hipotético requerido para destruir uma interface sólido/líquido, originando com isto duas novas interfaces: líquido/gás e sólido/gás.

$\mathbf{W}_{\mathbf{c}}$ é trabalho hipotético requerido para dividir em duas partes uma coluna de líquido com seção de área unitária de $1 \mathrm{~cm}^{2}$, gerando duas interfaces líquido/gás.

ii. O líquido se espalhará espontaneamente sobre o sólido quando as forças de adesão sólido/líquido forem maiores que as de coesão no líquido, ou seja, quando $W_{a}>W_{c}$. A partir desta abordagem, Harkins (1952 apud LEJA 1982) introduziu o "coeficiente de espalhamento" $S$, definido pelas Eqs. (19) e (20):

$$
\begin{gathered}
S=W_{a}-W_{c} \\
S=\gamma_{S V}-\gamma_{S L}-\gamma_{L V}=-\Delta G
\end{gathered}
$$

Quando $S$ é positivo, a variação da energia livre do sistema $(\Delta G)$ é negativa e o sólido será molhado completamente pelo líquido. Por outro lado, quando $S$ é negativo, o líquido molhará parcialmente o sólido e assumirá formas para as quais a energia livre do sistema seja mínima (RABOCKAI, 1979). É evidente que a molhabilidade é favorecida em sistemas envolvendo sólidos de alta energia livre superficial e líquidos de baixa energia livre superficial (OWENS; WENDT, 1969). 
iii. Devido às limitações experimentais de se medir diretamente as magnitudes de $\gamma_{S V}$ e $\gamma_{S L}$, o trabalho de adesão $W_{a}$ e o coeficiente de espalhamento $S$ necessitam ser avaliados indiretamente através de medidas do ângulo de contato $\theta$ formado entre as fases sólida e líquida (ROSEN, 1989). Na seção 1.1, verificou-se que a magnitude de $\theta$ está relacionada aos valores das energias livres interfaciais $\gamma_{L V}, \gamma_{S V}$ e $\gamma_{S L}$ pela equação de Young (Eq. (13)):

$$
\gamma_{\mathrm{SV}}=\gamma_{\mathrm{SL}}+\gamma_{\mathrm{LV}} \cos \theta
$$

Substituindo $0 \gamma_{s v}$ dado pela Eq. (13) nas equações que expressam $W_{a}$ (Eq.17) e $S_{L / S}$ (Eq. 20), obtêm-se as Eqs. (21) e (22), respectivamente:

$$
\begin{gathered}
\mathrm{W}_{\mathrm{a}}=\gamma_{\mathrm{LV}}(\cos \theta+1) \\
\mathrm{S}=\gamma_{\mathrm{LV}}(\cos \theta-1)
\end{gathered}
$$

Verifica-se na Eq. (22) que quando $\theta=0^{\circ}$, então $S \geq 0$, ou seja, o líquido molha completamente o sólido. Se o líquido for água, o sólido é dito hidrofílico. Por outro lado, quando $\theta>0$, então $S<0$ e o sólido será parcialmente molhado pelo líquido e, seguindo o raciocínio para a água, o sólido é dito hidrofóbico. Assim, uma vez que a tendência do líquido de se espalhar sobre o sólido aumenta com o decréscimo da magnitude de $\theta$, a determinação do ângulo de contato é uma medida útil para se inferir a molhabilidade (ZISMAN, 1964; PADDAY, 1993).

iv. Em suma, se $W_{a} \geq W_{c}$, o coeficiente de espalhamento $S$ será positivo ou nulo, $\theta=0^{\circ}$, e o líquido se espalhará espontaneamente sobre o sólido, molhando-o. Se $W_{a}<W_{c}$, o coeficiente de espalhamento $S$ será negativo, e o líquido formará gotas ou lentes sobre o sólido com um ângulo de contato maior que zero $\left(\theta>0^{\circ}\right)($ ROSEN, 1989).

Fox e Zisman (1950; ZISMAN 1964) desenvolveram empiricamente uma técnica para avaliar a molhabilidade de sólidos. A partir do estudo do espalhamento 
de líquidos puros (série homóloga de n-alcanos) sobre sólidos de baixa energia, eles encontraram que o gráfico de cosseno do ângulo de contato $(\cos \theta)$ versus a tensão superficial do líquido $\left(\gamma_{\mathrm{LV}}\right)$ resultava em uma relação linear. $O$ intercepto da reta em $\cos \theta=1$ foi denominado "tensão crítica de molhabilidade do sólido" ( $\left.\gamma_{c}\right)$ (Fig. 6). Líquidos que apresentam $\gamma_{L V}$ menor que 0 valor de $\gamma_{c}$ molharão 0 sólido completamente.

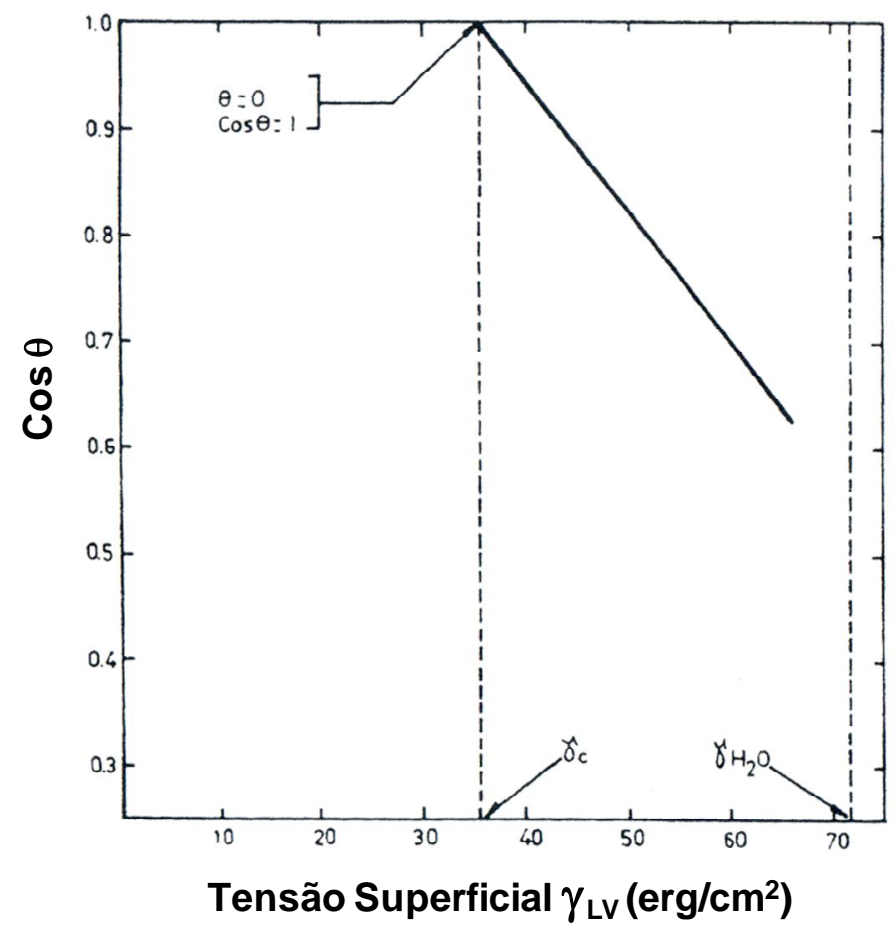

Figura 6 - Representação do conceito de tensão crítica de molhabilidade de Zisman (OZCAN, 1992, p.192, adaptação nossa).

Torna-se importante esclarecer o conceito de "sólidos de alta energia" e "sólidos de baixa energia". Segundo Fox, Hare e Zisman (1955), o primeiro grupo é composto por sólidos de alto ponto de fusão, tais como o diamante, quartzo e a maioria dos metais, que apresentam altos valores de energia livre superficial (na faixa de centenas de erg $/ \mathrm{cm}^{2}$ ). Por outro lado, o segundo grupo é de sólidos de baixo ponto de fusão, tais como polímeros orgânicos e ceras, que apresentam valores de energia livre superficial variando na faixa de $25-100 \mathrm{erg} / \mathrm{cm}^{2}$. 
Segundo Zisman (1964), o gráfico de $\cos \theta$ versus $\gamma_{\mathrm{LV}}$ para uma superfície de baixa energia geralmente fornece uma reta, a menos que as moléculas do líquido formem ligações de hidrogênio com o sólido; pois neste caso observou-se uma curvatura.

A utilização de uma série homóloga de líquido não é estritamente necessária se pequenos desvios dos dados são aceitáveis. De acordo com Parekh e Aplan (1985), este fato é de particular importância em sistemas minerais, nos quais líquidos com relativamente altas energias livre superficiais $\left(>\sim 30 \mathrm{erg} / \mathrm{cm}^{2}\right)$ são requeridos para a determinação de $\gamma_{\mathrm{c}}$.

Uma vez que o desempenho do processo de flotação é afetado pela intensidade da interação entre a água e os sólidos nela suspensos (LEJA, 1982), faz-se mister compreender a influência da molhabilidade em tal operação unitária de beneficiamento. Assim, maiores detalhes a respeito da aplicação da técnica desenvolvida por Zisman em sistemas minerais serão apresentados na próxima seção.

\subsubsection{Influência da molhabilidade na flotação}

No âmbito da tecnologia mineral, flotação é um processo de separação de minerais que é conduzido em meio aquoso e na presença de bolhas de gás. Em tal processo, partículas hidrofóbicas colidem e aderem às bolhas e são removidas do meio aquoso, enquanto partículas hidrofílicas permanecem suspensas no sistema, visto que colidem com as bolhas, mas não aderem às mesmas (LASKOWSKI, 1986).

A adesão de uma partícula a uma bolha de gás envolve a substituição de uma unidade de área da interface sólido/líquido por outra do tipo sólido/gás (Fig. 7), ou seja, um evento inverso ao da molhabilidade de um sólido por um líquido. Assim, baseando-se na abordagem desenvolvida na seção 1.2, tem-se que o retrocesso da fase líquida será espontâneo quando o coeficiente de espalhamento for negativo e, 
neste caso, a variação de energia livre do sistema é dada pela equação de Dupré (FUERSTENAU; CHANDER, 1986):

$$
\Delta \mathrm{G}=\gamma_{\mathrm{SG}}-\gamma_{\mathrm{SL}}-\gamma_{\mathrm{LG}}
$$

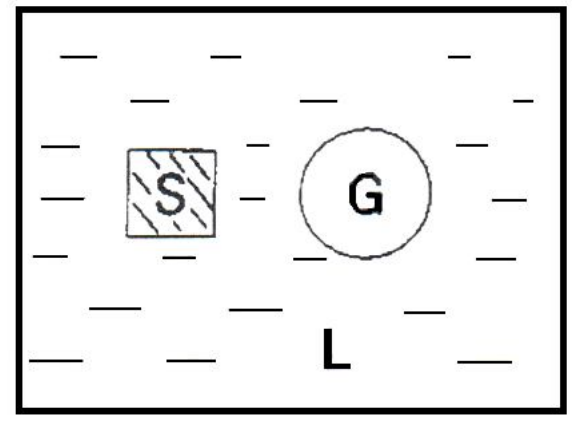

Estado Inicial

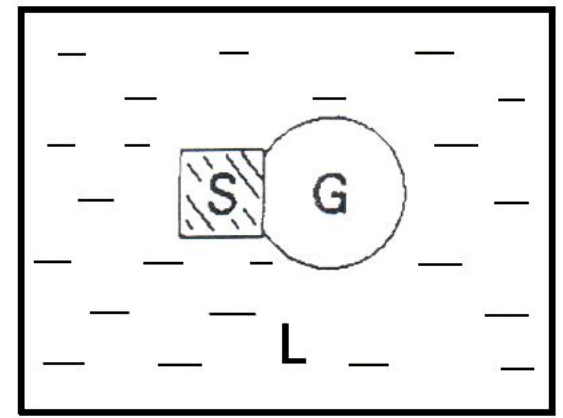

Estado Final

Figura 7 - Adesão partícula/bolha no processo de flotação (LASKOWSKI, 1986, p.191, adaptação nossa).

Segundo Leja (1982), o ângulo de contato formado entre uma partícula mineral aderida a uma bolha de gás em um meio aquoso (Fig. 8) está diretamente relacionado ao ângulo de contato estabelecido entre uma gota do mesmo líquido e a superfície; podendo, portanto, ser definido pela equação de Young (Eq. (13) apresentada na seção 1.1).

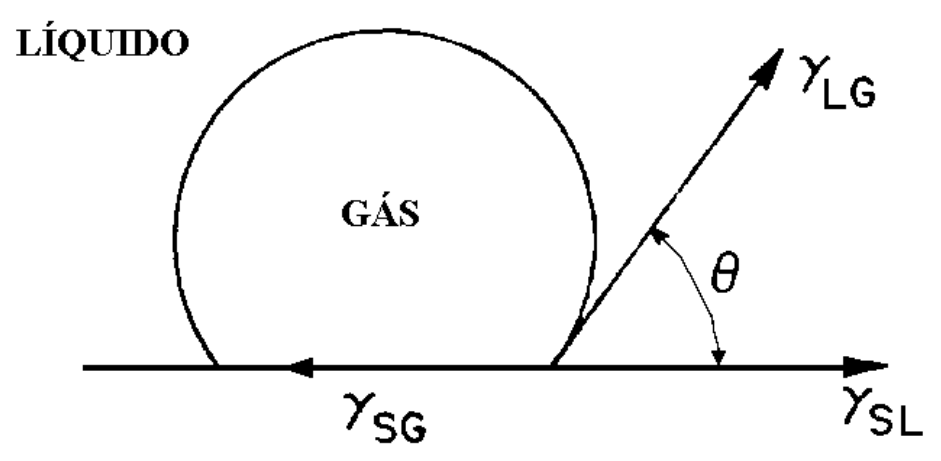

\section{SóLIDO}

Figura 8 - Representação do ângulo de contato entre uma bolha de gás e um sólido disperso em um líquido (FUERSTENAU; URBINA, 1987, p.27, adaptação nossa). 
Combinando-se a equação de Young com a Eq.(23), obtém-se a Eq. (24) que exprime, através de variáveis diretamente mensuráveis $\theta$ e $\gamma(\mathrm{LV}$, as condições termodinâmicas pelas quais um sólido vai $\left(\Delta G_{S / G}^{a}<0\right)$ ou não vai $\left(\Delta G_{S / G}^{a}>0\right)$ aderir a uma bolha de gás (DRZYMALA, 1994).

$$
\Delta \mathrm{G}_{\mathrm{S} / \mathrm{G}}^{\mathrm{a}}=\gamma_{\mathrm{LG}}(\cos \theta-1)
$$

Verifica-se na Eq. (24) que o critério termodinâmico para a formação do agregado partícula/bolha $\left(\Delta \mathrm{G}_{\mathrm{S} / \mathrm{G}}^{\mathrm{a}}<0\right)$ somente ocorrerá quando o ângulo de contato for maior que zero, ou seja, quando a partícula que se deseja flotar for hidrofóbica.

De acordo com Laskowski (1986), a estrita interpretação do chamado "critério termodinâmico" é que quanto mais negativa for a magnitude de $\Delta \mathrm{G}_{\mathrm{S} / \mathrm{G}}^{\mathrm{a}}$, maior será a "probabilidade" de ocorrer a flotação. Portanto, para uma partícula flotar, não basta que o retrocesso da fase líquida de sua superfície com a subseqüente adesão da bolha de gás seja termodinamicamente favorável, mas outros critérios também devem ser satisfeitos, tais como (RALSTON; DUKHIN; MISHCHUK, 2002; FINCH; DOBBY, 1990, LEAL FILHO; RODRIGUES; RALSTON, 2002):

i. a partícula precisa colidir com a bolha;

ii. o adelgaçamento do filme aquoso existente entre bolha e partícula e sua subseqüente ruptura deve ocorrer dentro de um intervalo de tempo (tempo de indução) menor que o tempo de colisão;

iii. o agregado partícula/bolha deve ser suficientemente estável para suportar as forças de cisalhamento existentes na célula de flotação.

Colisão entre partículas e bolhas (i), adesão entre ambas (ii) e preservação do agregado partícula/bolha (iii) são considerados como eventos ou sub-processos que controlam o processo de coleta de partículas por bolhas. Deste modo, a eficiência de coleta $\left(E_{k}\right)$ é o produto das eficiências individuais dos três eventos: colisão $\left(E_{c}\right)$, adesão $\left(E_{a}\right)$ e preservação $\left(E_{p}\right)$, conforme a eq. 25 .

$$
E_{k}=E_{c} \cdot E_{a} \cdot E_{p}
$$


No processo de flotação, quando partículas hidrofóbicas formam um agregado estável com bolhas de ar e são transportadas para a camada de espuma, diz-se que tais partículas foram recuperadas por flotação verdadeira (true flotation). Todavia, partículas, independentemente do seu caráter hidrofóbico/hidrofílico, podem ser arrastadas para a camada de espuma pelo fluxo ascendente de polpa. Tal processo de transporte é chamado de arraste hidrodinâmico. Segundo Trahar (1981) o arraste hidrodinâmico é mais provável de acontecer com partículas menores que $50 \mu \mathrm{m}$.

A apatita, mineral em estudo, apresenta um caráter hidrofílico natural. Assim sendo, coletores de cadeia longa, tais como sabões de ácidos graxos de sódio $(\mathrm{RCOONa})$ e alquil sarcosinatos de sódio (RNRCOONa), são comumente empregados em circuitos industriais de flotação de fosfato com o intuito de converter o caráter naturalmente hidrofílico da apatita em hidrofóbico (maiores detalhes a respeito da hidrofilicidade da apatita e de sua interação com o coletor oleato de sódio serão apresentados na seção 1.3.2).

Coletores são substâncias tensoativas constituídas de um grupo polar ligado a uma cadeia hidrocarbônica apolar $(\mathrm{R})$, capazes de adsorver na interface mineral/solução e rebaixar a magnitude de sua energia livre interfacial de modo que o ângulo de contato se torne maior que zero $\left(\theta>0^{\circ}\right)$ (FUERSTENAU; CHANDER, 1986). Por outro lado, coletores de cadeia longa adsorvem não somente na interface apatita/solução, mas também na interface ar/solução. Deste modo, eles são capazes de rebaixar a magnitude da energia livre superficial da solução de flotação ( $\gamma\llcorner v)$. Como mostra a Tab. 5, valores típicos de $\gamma_{\mathrm{LV}}$ no estágio rougher do circuito industrial de flotação da Bunge, localizada em Cajati - SP, encontram-se na faixa de 36-39 $\mathrm{erg} / \mathrm{cm}^{2}$, enquanto que no estágio cleaner $\gamma_{\mathrm{Lv}}$ é um pouco maior $\left(38-40 \mathrm{erg} / \mathrm{cm}^{2}\right)$.

Tabela 5 - Características da solução de flotação e coletor usado no circuito de flotação da Bunge (LEAL FILHO et al, 2002).

\begin{tabular}{c|c|c|c|c}
\hline \multirow{2}{*}{ Coletor } & \multicolumn{4}{|c}{ Características da solução de flotação (estágio rougher) } \\
\cline { 2 - 5 } & $\mathbf{p H}$ & $\mathbf{p C a}$ & $\mathbf{p M g}$ & $\gamma_{\mathrm{Lv}}\left(\mathbf{e r g} / \mathbf{c m}^{2}\right){ }^{* *}$ ) \\
\hline \hline Alquil sarcosinato $\left({ }^{*}\right)$ & 10.5 & 3.3 & 3.8 & $\begin{array}{c}\text { Rougher: } 36-39 \\
\text { Cleaner: 38-40 }\end{array}$ \\
\hline
\end{tabular}

$\left(^{*}\right)$ Matéria ativa do Berol ${ }^{\star} 867$ (SCHRÖDER, 1986; BUTTNER, 1987). $\left(^{* *}\right)$ Método do anel de Du Noüy $\left(22-23^{\circ} \mathrm{C}\right)$. 
Uma vez que o valor do ângulo de contato de um sólido depende da magnitude da tensão superficial da solução na qual ele está imerso (ZISMAN, 1964), quanto menor a magnitude de $\gamma_{L V}$ em uma célula de flotação, maior será a molhabilidade das partículas de apatita pela solução, resultando em um aumento de sua hidrofilicidade e conseqüente decréscimo da recuperação. Neste sentido, o conceito de $\gamma_{c}$ desenvolvido por Zisman (seção 1.2) se torna uma ferramenta útil no estudo da molhabilidade no processo de flotação.

Além de diversos polímeros sólidos e carvão de diferentes "ranks", minerais recobertos por surfatantes geralmente exibem uma relação linear entre $\cos \theta$ e $\gamma_{L V}$ (YARAR, 1988; OZCAN, 1992). Parekh e Aplan (1985) mostraram que o conceito de tensão crítica de molhabilidade pode ser aplicado no estudo de superfícies minerais que tiveram seu caráter hidrofóbico induzido pela adsorção de coletores.

Partículas de minerais de ganga portadores de cálcio, tais como dolomita e calcita, interagem fortemente com coletores de cadeia longa, tais como alquil sarcosinato (SCHRÖDER, 1986; BUTTNER, 1987) e sabões de ácidos graxos (FINKELSTEIN, 1989; LU; DRELICH; MILLER, 1998). Em circuitos de flotação brasileiros, embora um agente modificador (amido) seja usado para aumentar a seletividade do processo de separação, altos teores de $\mathrm{MgO}$ e $\mathrm{CaO}$ provenientes de minerais de ganga carbonática ou $\mathrm{MgO}$ de silicatos (flogopita, olivina e piroxênio) são encontrados em concentrados de apatita. Se partículas de minerais de ganga, carbonatos ou silicatos, são capazes de flotar juntamente com aquelas de apatita por meio de flotação verdadeira (e não por arraste hidrodinâmico), certamente elas não são molhadas pela solução da flotação que contém os reagentes $\left(\theta>0^{\circ}\right)$.

Um procedimento desenvolvido por Yarar (1988), denominado "flotação gama" (gamma flotation), consiste em controlar $\gamma_{\mathrm{Lv}}$ tal que $\gamma_{c}$ do mineral que se deseja flotar satisfaça a condição $\gamma_{L V}>\gamma_{c}$, enquanto que os minerais que não se deseja flotar satisfaçam a condição $\gamma_{L V} \leq \gamma_{c}$, isto é, a recuperação seja nula. Segundo Ozcan (1992), o melhor método para comparar diferentes minerais com base em seus valores de $\gamma_{c}$ é aquele que usa o sistema metanol/água. Assim, o controle de $\gamma_{L v}$ é realizado usando soluções compostas de metanol $\left(\gamma_{L V}=22,7 \mathrm{erg} / \mathrm{cm}^{2}\right.$ a $\left.20^{\circ} \mathrm{C}\right) \mathrm{e}$ 
água $\left(\gamma_{\mathrm{LV}}=72,8 \mathrm{erg} / \mathrm{cm}^{2}\right.$ a $\left.20^{\circ} \mathrm{C}\right)$ em diferentes proporções. $\mathrm{O}$ valor de $\gamma_{c}$ para um mineral pode ser determinado por experimentos de flotação gama: $\gamma_{c}$ de um mineral é o valor de $\gamma L G$ no qual a recuperação atinge zero.

\subsection{Aspectos Cristaloquímicos da Apatita}

\subsubsection{Cristaloquímica da apatita}

A apatita, mineral da família dos sais semi-solúveis, cristaliza-se no sistema hexagonal e apresenta fórmula química geral $\mathrm{M}_{5}\left(\mathrm{AO}_{4}\right)_{3} \mathrm{~B}$, onde $\mathrm{M}$ é geralmente um cátion divalente, enquanto $\mathrm{AO}_{4} \mathrm{e} \mathrm{B}$ são ânions tri e monovalentes, respectivamente (HANNA; SOMASSUNDARAN, 1976).

A fluorapatita, $\mathrm{Ca}_{5}\left(\mathrm{PO}_{4}\right)_{3} \mathrm{~F}$, é o mineral abordado na presente tese e a distribuição dos átomos constituintes em sua estrutura cristalina pode ser visualizada na Fig. 9. Nota-se a presença de dois tipos de íons cálcio - $\mathrm{Ca}_{\|}$e $\mathrm{Ca}_{\|}$- diferindo em suas posições na rede cristalina. O plano de projeção da figura é perpendicular ao eixo cristalográfico $c$. Os íons $\mathrm{Ca}_{1}$ estão situados em eixos ternários $\mathrm{Z}$, perpendiculares a este plano, nas cotas $Z=0$ e $Z=1 / 2$ (assumindo $\circ$ plano de projeção em $Z=0$ ) e cada um destes íons coordena com 9 átomos de oxigênio. Átomos de fósforo ocorrem em planos de simetria existentes nas cotas $Z=1 / 4$ e $Z=$ $3 / 4$ e ligam as colunas $\mathrm{Ca}_{1}-\mathrm{O}$ através da formação de tetraedros $\mathrm{PO}_{4}{ }^{3-}$ com 4 átomos de oxigênio de colunas vizinhas. Desta forma, como pode ser observado na figura, estes elementos formam os contornos de hexágonos regulares, sendo os vértices ocupados por Caı (SLANSKY,1980). 


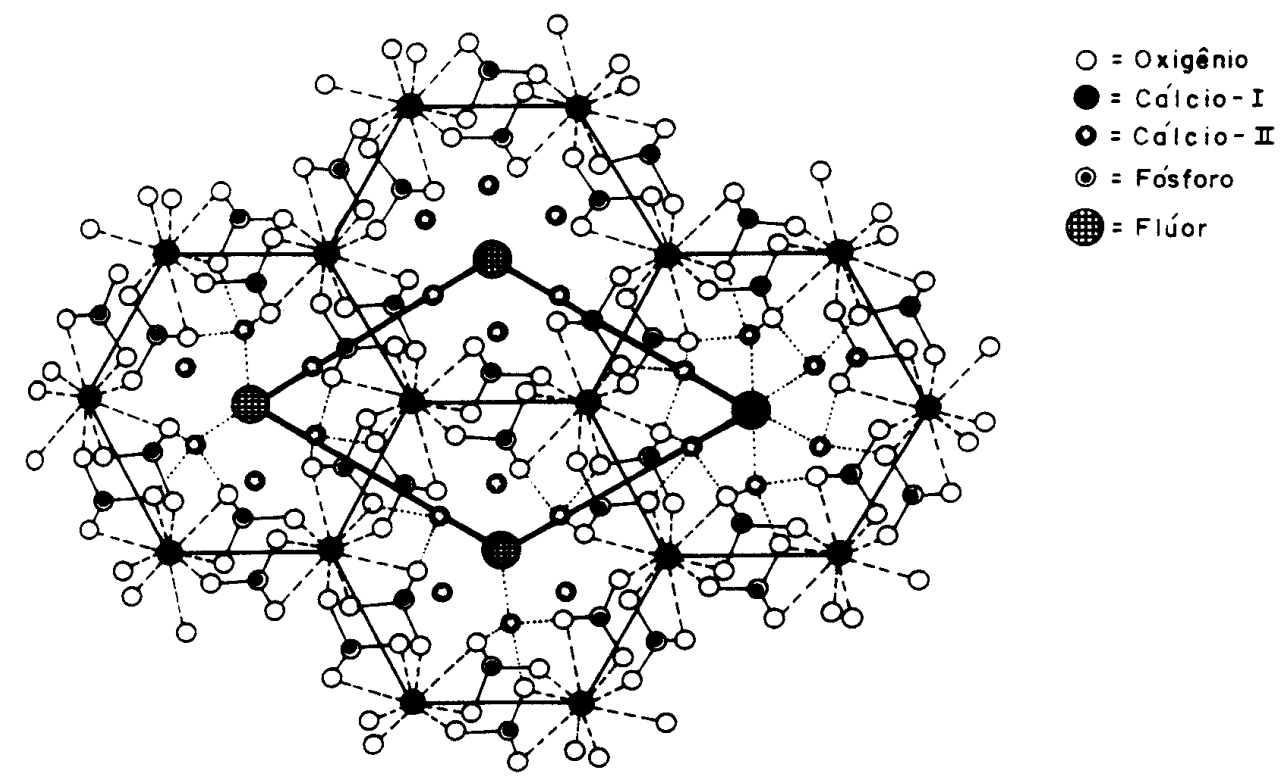

Figura 9 - Distribuição dos átomos formadores da fluorapatita em sua rede cristalina (SLANSKY,1980, p.27, adaptação nossa).

Os íons $\mathrm{F}^{-}$situam-se em eixos senários localizados no centro destes hexágonos. Os íons $\mathrm{Ca}_{\|}$ocorrem em planos perpendiculares a estes eixos senários, situados nas mesmas cotas dos íons flúor, ou seja, $Z=1 / 4$ e $Z=3 / 4$, e constituem os vértices de um triângulo equilátero. A cela unitária da fluorapatita constitui um prisma regular de base rombóide com os parâmetros de cela $a=b=9,37 \AA$ e $c=$ $6,88 \AA$ (Fig. 10) (SLANSKY,1980).

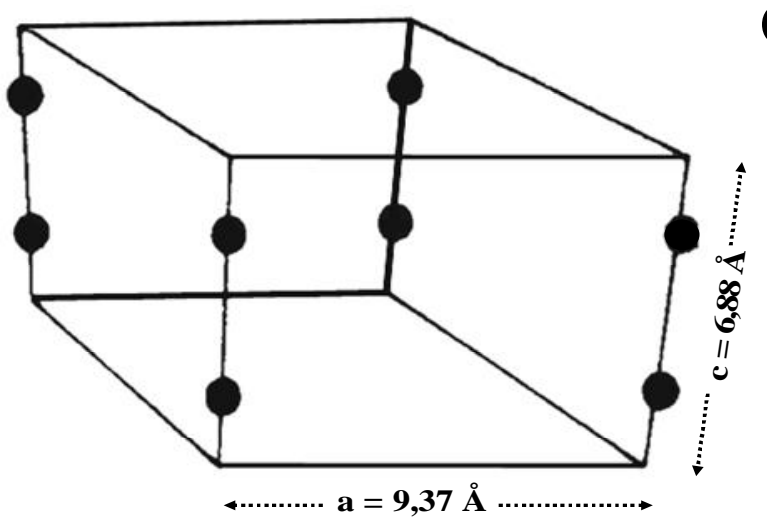

Flúor

Figura 10 - Representação da cela unitária da fluorapatita (SLANSKY,1980, p.27, adaptação nossa). 
A substituição parcial do $\mathrm{F}^{-}$, na fluorapatita, por $\mathrm{Cl}^{-}$ou $\mathrm{OH}^{-}$pode gerar as variedades cloroapatita e hidroxiapatita, respectivamente. As principais diferenças estruturais entre as três espécies ocorrem em virtude das diferentes localizações dos íons $\mathrm{F}^{-}, \mathrm{Cl}^{-}$e $\mathrm{OH}^{-}$ao longo do eixo senário, como pode ser observado na Fig. 11 (KANAZAWA, 1989).
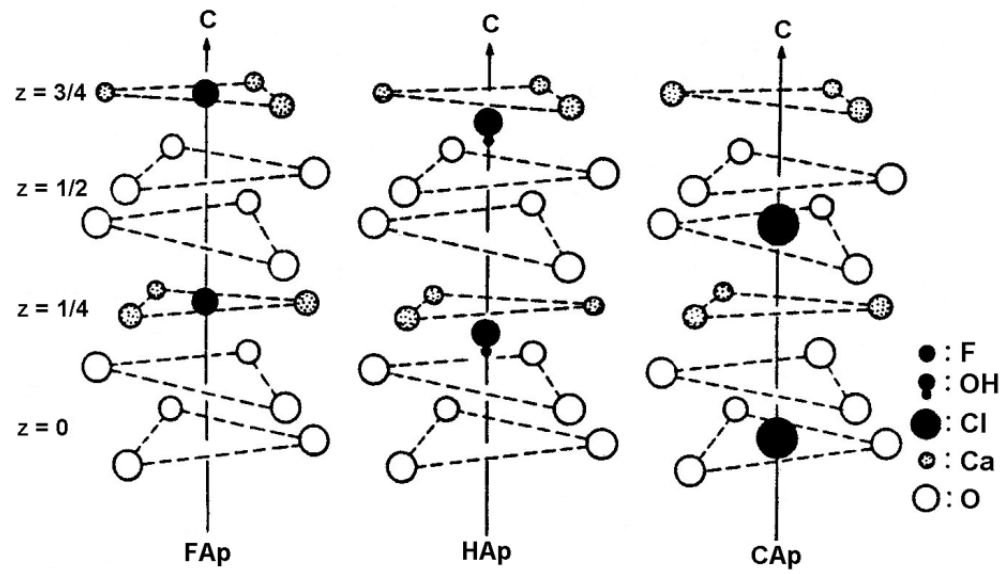

Figura 11 - Localização dos íons $\mathrm{B}\left(\mathrm{F}^{-}, \mathrm{OH}^{-}, \mathrm{Cl}^{-}\right)$na estrutura cristalina da apatita (KANAZAWA, 1989).

Uma variedade de outras substituições menores é possível na complexa estrutura cristalina da apatita (Tab. 6) e muitos destes elementos traços são importantes no tratamento de solos com fertilizantes fosfatados (KATCHMAN, 1961).

Tabela 6 - Substituições na rede cristalina da fluorapatita (KANAZAWA, 1989).

\begin{tabular}{c|c|c}
\hline \hline Posição & Fluorapatita & Substituições \\
\hline$M$ & $\mathrm{Ca}$ & $\mathrm{Pb}, \mathrm{Cd}, \mathrm{Sr}, \mathrm{Ni}, \mathrm{Eu}, \mathrm{Al}, \mathrm{Y}, \mathrm{La}, \mathrm{Ce}, \mathrm{Na}, \mathrm{K}$. \\
\hline $\mathrm{A}$ & $\mathrm{P}$ & $\mathrm{As}, \mathrm{V}, \mathrm{Cr}, \mathrm{Si}, \mathrm{C}, \mathrm{Al}, \mathrm{S}, \mathrm{Re}$. \\
\hline $\mathrm{B}$ & $\mathrm{F}$ & $\mathrm{OH}, \mathrm{Cl}, \mathrm{Br}, \mathrm{I}, \mathrm{O}, \mathrm{N}, \mathrm{CO}_{3}, \mathrm{H}_{2} \mathrm{O}, \square$ (vacância). \\
\hline \hline
\end{tabular}

Cristais perfeitos de apatita podem exibir hábito prismático e/ou acicular, onde as faces mais comuns são os planos frontais (100), (010), (110) e correlatos; os planos basais (001) e ainda planos intermediários (101), (011) e correlatos, conforme ilustra a Fig. 12. 


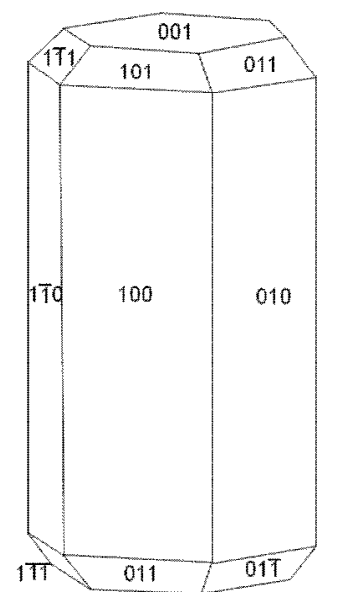

Figura 12 - Planos normalmente exibidos por cristais de fluorapatita (RAKOVAN, 2002, p.52, adaptação nossa).

A orientação cristalográfica predominante de partículas de apatita após cominuição pode ser avaliada através de microscopia ótica de luz polarizada. Sob nicóis cruzados, Leal Filho (1991) observou que, após moagem na usina de concentração, $21 \%$ das partículas de apatita da jazida de Cajati $(-417 \mu \mathrm{m}+44 \mu \mathrm{m})$ apresentavam plano basal predominante, enquanto que 68\% apresentavam plano frontal. Martins (2004), utilizando a mesma técnica com partículas de menor diâmetro $(-104 \mu \mathrm{m}+44 \mu \mathrm{m})$, observou que $(17 \pm 1) \%$ das partículas apresentavam plano basal predominante, enquanto que somente $(24 \pm 1) \%$ apresentavam plano frontal predominante.

A anisotropia exibida pela apatita no que diz respeito à distribuição espacial de seus constituintes fundamentais (átomos ou íons) faz com que algumas propriedades de relevância para a adsorção de reagentes de flotação sejam dependentes da orientação cristalográfica do seu cristal:

i. Tseng et al. (2006) reportaram indícios de que a dissolução do cristal de apatita na face frontal é mais intensa que na face basal;

ii. Leal Filho et al. (2000) reportou uma maior compatibilidade estereoquímica entre as distâncias entre grupos $\mathrm{OH}$ presentes nas moléculas de amido e as distâncias Ca-Ca existentes no plano frontal (010) apresentado pela apatita com relação ao seu plano basal (001).

iii. A partir de medidas de ângulo de contato, Martins (2004) observou que moléculas de amido se adsorvem preferencialmente no plano frontal em detrimento do basal. 


\subsubsection{Cristaloquímica da apatita versus molhabilidade}

Um sólido é dito hidrofílico quando é completamente molhado por água. Como mencionado na seção 1.2, a água se espalhará espontaneamente sobre a superfície de um dado sólido quando as forças de adesão forem maiores que as de coesão $\left(W_{a}>W_{c}\right)$ e, conseqüentemente, $\theta=0^{\circ}$. Segundo Fowkes (1967) apud Laskowski (1986), há três principais contribuições ao trabalho de adesão da água sobre o sólido:

$$
W_{a}=W_{a}^{d}+W_{a}^{h}+W_{a}^{i}
$$

Onde $W_{a}{ }^{d}$ é a contribuição das forças de dispersão, $W_{a}^{h}$ é a contribuição das ligações de hidrogênio entre as moléculas de água e grupos superficiais do sólido, e $W_{\mathrm{a}}{ }^{\mathrm{i}}$ é a contribuição devida à ionização na interface eletricamente carregada (forças atrativas coulombianas).

No que concerne à fluorapatita, os cátions $\mathrm{Ca}^{2+}$ encontram-se ligados ionicamente aos radicais aniônicos $\mathrm{PO}_{4}{ }^{3-}$ em sua estrutura cristalina e a fratura deste mineral dá origem a uma superfície rica em sítios iônicos e dipolos permanentes (SUN; FORSLING, 1991). Além disso, a presença de átomos de oxigênio em sua rede cristalina permite a formação de pontes de hidrogênio com as moléculas de água (Leal Filho, 1999). Portanto, a adesão da água à superfície da fluorapatita se dará através da contribuição de interações não-dispersivas $\left(W_{a}^{h}\right.$ e $\left.W_{a}^{i}\right)$, e dispersivas $\left(W_{a}{ }^{d}\right)$, resultando em consideráveis forças superficiais de hidratação que conferem ao mineral uma hidrofilicidade natural. Corroborando esta afirmação, Martins (2004) obteve $\theta=0^{\circ}$ para os planos basal (001) e frontal (010) apresentados por cristais de fluorapatita em contato com água, através de determinações de ângulo de contato pelo método da bolha cativa (goniômetro).

Para que partículas de fluorapatita sejam capazes de aderir a bolhas de ar e flotar, sua energia livre superficial necessita ser rebaixada através da adsorção de um agente surfatante. Assim sendo, coletores de cadeia longa, tais como sabões de ácidos graxos e de alquil sarcosinatos, sulfosuccinatos e sulfosuccinamatos, são 
comumente empregados em circuitos industriais de flotação de fosfato com o intuito de converter o caráter naturalmente hidrofílico da apatita em hidrofóbico (LEAL FILHO, 1999; BUTTNER,1987; PINTO; ARAUJO, 1990).

Três mecanismos de interação para o sistema oleato de sódio/minerais da família dos sais semi-solúveis foram reportados pelos autores Fuerstenau e Chander (1986) e Finkelstein (1989), e amplamente comentados por Leal Filho (1999): quimissorção, reação de superfície e precipitação na solução.

Quimissorção constitui uma interação química entre o coletor e sítios metálicos (cálcio e/ou magnésio) superficiais da rede cristalina. Trata-se de uma adsorção específica e, portanto, de difícil dessorção: possível apenas com lixiviação ácida, como se faz na Flórida (WIEGEL, 1999). Tal interação é de grande interesse para flotação, devido sua maior seletividade comparada aos outros dois mecanismos de adsorção. Por ser uma interação direta coletor/sítio interfacial, espera-se que ocorra em monocamada e, quanto mais compacta esta for, maior o caráter hidrofóbico resultante do sistema coletor/partícula mineral (MILLER, 2002). Segundo este mesmo autor, o seguinte modelo de coordenação entre oleato e fluorita ilustrado na Fig. 13 é proposto, baseando-se na relação 2:1 (sítios cálcio da fluorita:carboxilato) encontrada nos resultados obtidos em ensaios de adsorção.

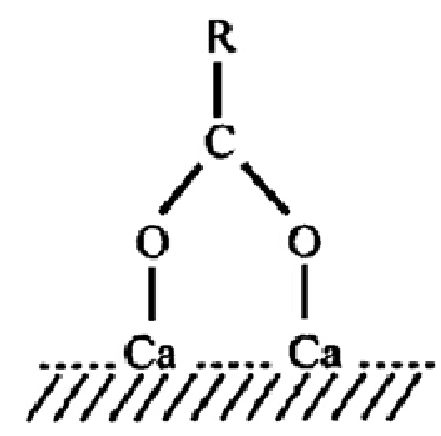

(Sistema carboxilato/fluorita)

Figura 13 - Modelo de coordenação oleato/fluorita (MILLER, 2002, p. 250, adaptação nossa).

Em virtude da solubilidade natural que caracteriza os minerais semi-solúveis, cátions metálicos de sua rede cristalina (principalmente $\mathrm{Ca}^{2+} \mathrm{e} \mathrm{Mg}^{2+}$ ) são liberados 
para o meio aquoso, reagindo com o coletor a uma distância muito próxima à superfície, formando um sal hidrofóbico (FINKELSTEIN,1989). À medida que o limite de solubilidade deste sal é atingido, ocorre um aumento na densidade de empacotamento do precipitado superficial, inicialmente bidimensional, resultando em uma substância tridimensional; ou seja, uma "crosta" delgada que poderá recobrir a partícula mineral total ou parcialmente. Tal tipo de interação é denominado "reação de superfície" ou "precipitação superficial" e o precipitado hidrofóbico formado pode ser removido por água quente $\left(100^{\circ} \mathrm{C}\right)$, mas não por ultrassom (FINKELSTEIN,1989; LEAL FILHO,1999).

A precipitação em solução se caracteriza pela formação de sal coloidal, em solução, através da interação entre os ânions oleato e cátions metálicos oriundos da água de processo e/ou solubilidade dos minerais. Tal precipitado hidrofóbico se agrega às partículas minerais presentes seja por coagulação ou por aglomeração (FINKELSTEIN,1989; MILLER, 2002). Deste modo, a hidrofobização das partículas minerais é controlada pelos mecanismos previstos pela teoria DLVO. A adsorção é fraca, já que o sal coloidal agrega-se à superfície mineral por forças atrativas de van der Waals, e de fácil dessorção, podendo a remoção ser realizada por ultrassom e escrubagem (FINKELSTEIN,1989; LEAL FILHO,1999). Obviamente este mecanismo é pouco seletivo.

A precipitação de oleato de cálcio, tanto em solução quanto na superfície, é dependente de seu produto de solubilidade $\left(\mathrm{Kps}=10^{-15,6}\right)$ e do $\mathrm{pH}$ da solução. Assim sendo, somente quando o produto de solubilidade do oleato de cálcio for ultrapassado é que ocorrerá sua precipitação. Se a razão de dissolução e difusão dos cátions $\mathrm{Ca}^{2+}$ provenientes do mineral para o seio da solução for mais rápida que a difusão do coletor rumo à superfície, poderá ocorrer preferencialmente precipitação em solução em vez de reação de superfície (FUERSTENAU; CHANDER, 1986).

Torna-se importante ressaltar que os três mecanismos podem ocorrer ao mesmo tempo para um dado sistema oleato/mineral e a predominância de um deles determinará o grau de dessorção e o grau de hidrofobicidade da partícula mineral (LEAL FILHO, 1999; MILLER, 2002). 
As isotermas de adsorção de oleato em apatita, fluorita e calcita, reportadas por Lu, Drelich e Miller (1998) e apresentadas na Fig. 14, ilustram bem a ocorrência dos três mecanismos citados acima para o sistema oleato/sais semi-solúveis. Nestas isotermas, a variação da densidade de adsorção de ânions oleato na superfície dos minerais citados em função da concentração de equilíbrio do coletor mostra que:

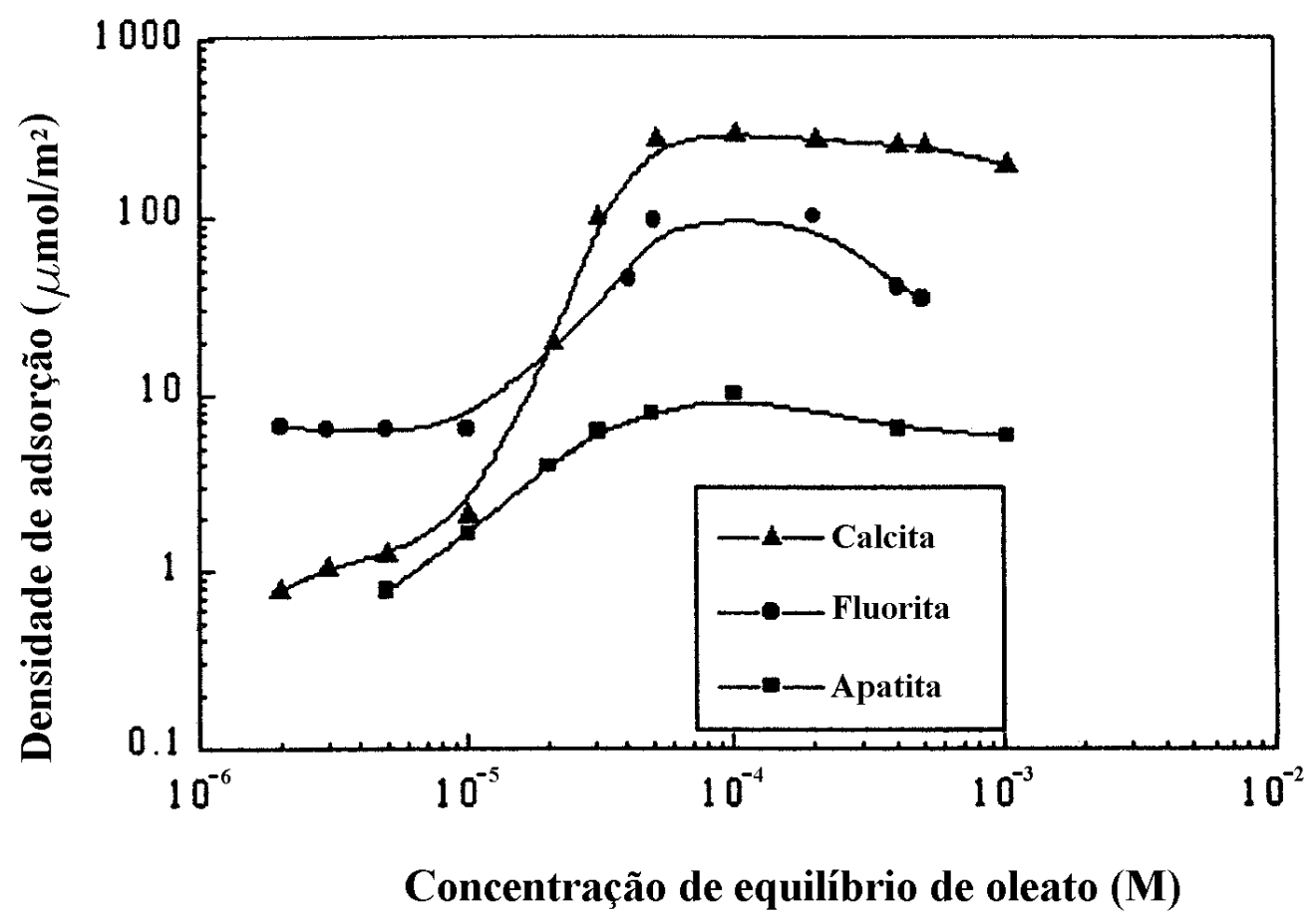

Figura 14 - Isotermas de adsorção de oleato em apatita, fluorita e calcita em pH=9,5 e temperatura 20 - 25ㅇ (LU; DRELICH; MILLER, 1998, p.467, adaptação nossa).

i. Em baixa concentração de equilíbrio de oleato $\left(<1.10^{-5} \mathrm{M}\right)$ a precipitação de oleato de cálcio não é favorecida e o mecanismo de adsorção predominante é o de quimissorção. A diferença na magnitude da densidade de adsorção de oleato para os três minerais foi atribuída à densidade superficial de sítios cálcio (Tab. 7). Neste sentido, fluorita é o mineral que sofre maior adsorção de oleato, seguida pelos minerais calcita e apatita. No caso específico da apatita, apesar da diferença ser pequena, presume-se que o oleato adsorverá preferencialmente no plano basal (001) com relação ao frontal (100). 
Tabela 7 - Densidade de sítios cálcio superficiais para fluorita, calcita e apatita (LU; DRELICH; MILLER, 1998, p.467, adaptação nossa).

\begin{tabular}{c|c}
\hline Superfície & Densidade de cálcio $\left(\boldsymbol{\mu m o l} / \mathbf{m}^{2}\right)$ \\
\hline \hline Fluorita (111) & 12,9 \\
\hline Calcita (101) & 8,24 \\
\hline Apatita (001) & 6,57 \\
\hline Apatita (100) & 5,15 \\
\hline
\end{tabular}

ii. Em concentrações de equilíbrio mais altas $\left(>1.10^{-4} \mathrm{M}\right)$, os mecanismos de precipitação superficial e precipitação em solução com subseqüente aglomeração assumem papel predominante. A solubilidade dos minerais passa a controlar a densidade de adsorção e, portanto, calcita (pKps = 8,4 ) sofre maior adsorção do coletor, seguida pelos minerais fluorita (pKps $=10,3)$ e apatita $(\mathrm{pKps}=118)$.

Tseng et al. (2006) reportaram as seguintes razões relativas de dissolução entre as diferentes direções cristalográficas exibidas por cristais de apatita em $\mathrm{pH}>3$ : [100]>[110]>[001]. Assim, na interação oleato/apatita por reação de superfície, presume-se que oleato adsorverá preferencialmente no plano frontal (100), seguido pelos planos intermediário (110) e basal (001), em decorrência da ordem decrescente de solubilidade.

\subsection{Determinação do Ângulo de Contato}

A determinação de ângulo de contato é uma ferramenta muito útil no estudo da molhabilidade de sólidos por líquidos e, portanto, de grande interesse na área de processamento mineral no que se refere às operações de flotação e filtragem. A magnitude de $\theta$ já é per se um indicativo da molhabilidade (ZISMAN, 1964; PADDAY, 1993) e, em sistemas envolvendo água como a fase líquida, ela indica o caráter hidrofílico/hidrofóbico do sólido. Além disto, outro aspecto de interesse do ângulo de contato é a sua relação, através da equação de Young (Eq. 13), com as tensões superficiais de sólidos $\gamma_{S V}$ e $\gamma_{S L}$, as quais não podem ser diretamente medidas. Tal relação, em conjunto com o conhecimento de $\gamma$ LV, possibilita a 
determinação de variáveis também importantes nos estudos de molhabilidade como o trabalho de adesão $\left(W_{\mathrm{a}}\right)$ e coeficiente de espalhamento $(\mathrm{S})$ do líquido sobre 0 sólido, conforme descrito na seção 1.2 .

Diversos métodos, diretos e indiretos, são empregados na determinação de $\theta$ e uma extensa revisão a respeito das técnicas de medida foi executada por Neumann e Good (1979).

A determinação direta do ângulo de contato em sistemas envolvendo minerais pode ser executada pelas técnicas da gota séssil ou da bolha cativa (Fig. 15), em que uma gota de líquido ou uma bolha de gás é posicionada na superfície mineral e $\theta$ é medido através da fase líquida, utilizando um goniômetro de contato (NEUMANN; GOOD, 1979). Ao se empregar a bolha cativa, o ângulo de avanço $\left(\theta_{\mathrm{a}}\right)$ da fase líquida é obtido pela medida contínua de $\theta$ durante a diminuição do tamanho da bolha com o auxílio de uma agulha conectada a uma seringa, enquanto que o ângulo de retrocesso $\left(\theta_{\mathrm{r}}\right)$ é obtido durante o aumento da bolha. O processo inverso é efetuado para determinar $\theta_{\mathrm{a}}$ e $\theta_{\mathrm{r}}$ quando se trata da gota séssil (GOOD, 1993).
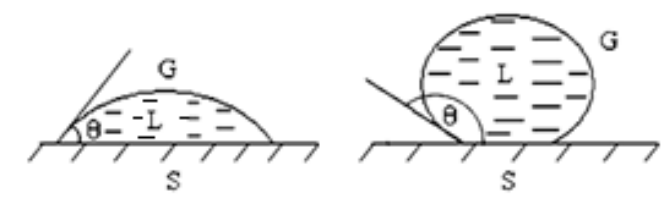

a

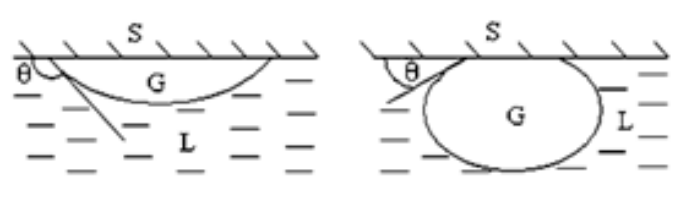

b

Figura 15 - Sistemas apresentando $\theta>0$; (a) gotas sésseis (b) bolhas cativas $(\mathrm{S}=$ sólido, $\mathrm{L}=$ líquido e $\mathrm{G}$ = gás) (NEUMANN; GOOD, 1979, p. 32, adaptação nossa).

Segundo Good (1993), os valores de $\theta_{\mathrm{a}}$ são sempre maiores que aqueles de $\theta_{r}$, resultando na histerese de ângulo de contato $H$, conforme indica a Eq. (27). Tal histerese ocorre devido à tendência a falta de idealidade apresentada pela superfície do sólido, por mais cuidadosa que tenha sido sua preparação (uma superfície ideal é totalmente plana, polida, impermeável e homogênea).

$$
\mathrm{H}=\theta_{\mathrm{a}}-\theta_{\mathrm{r}}
$$


Conforme comentado no parágrafo anterior, as duas técnicas descritas acima demandam, via de regra, superfícies planas, polidas, impermeáveis e homogêneas (KISSA, 1999). Entretanto, partículas minerais usualmente processadas em usinas de tratamento de minérios não apresentam uma superfície plana suficientemente grande para a determinação direta de $\theta$. Segundo Kissa (1999), há limitações e incertezas em se estimar a molhabilidade de materiais particulados a partir do ângulo de contato medido em uma superfície polida de um cristal do mesmo material de tamanho apropriado ou em uma superfície criada pela compactação do pó. Portanto, para se determinar $\theta$ de tais materiais, faz-se mister utilizar medições indiretas, como aquelas baseadas na ascensão capilar de líquidos em leitos de partículas que exibem diâmetro dentro da faixa de tamanho que se deseja estudar.

Para determinar ângulo de contato através do método da ascensão capilar, adota-se a abordagem que Washburn (1921) utilizou para descrever o movimento do menisco de um líquido (de viscosidade $\eta$, peso específico $\rho$ e tensão superficial $\gamma_{L G}$ ) que percola um tubo capilar em fluxo laminar e regime estacionário. Experimentalmente, as partículas minerais são empacotadas em um tubo de vidro fechado em sua extremidade inferior por um filtro (vidro sinterizado usualmente). $O$ tubo é colocado em contato com a superfície do líquido teste, sendo a razão de ascensão medida pela altura ou pela massa de líquido adquirida pelo leito de partículas em função do tempo (SIEBOLD et al., 2000). Nesta abordagem, os espaços vazios entre as partículas minerais são considerados como um conjunto de capilares de raio médio r e a razão de ascensão do líquido (dh/dt) é expressa pela lei de Poiseuille através da Eq. (28).

$$
\frac{d h}{d t}=\frac{r^{2} \Delta P}{8 \eta h}
$$

Onde h é a altura de ascensão do menisco do líquido no capilar no tempo t e $\Delta \mathrm{P}$ é a diferença entre a pressão capilar e a pressão hidrostática, conforme mostra a Eq. (29) (SIEBOLD et al., 2000). 


$$
\Delta P=\frac{2 \gamma_{L G} \cos \theta}{r}-\rho g h
$$

Onde $\theta$ é o ângulo de contato de avanço do líquido sobre o sólido. Assumindo que a pressão hidrostática pode ser negligenciada nos estágios iniciais do processo, quando $\mathrm{h}<<\mathrm{h}_{\mathrm{eq}}{ }^{1}$, a Eq. (29) pode ser reescrita na forma da Eq. (30).

$$
\Delta \mathrm{P}=\frac{2 \gamma_{\mathrm{LG}} \cos \theta}{\mathrm{r}}
$$

Para que a pressão capilar seja positiva, $\cos \theta$ tem de ser positivo e conseqüentemente a magnitude do ângulo de contato reside entre $0^{\circ}$ e $90^{\circ}$ (KISSA, 1999). A Eq (31) é obtida substituindo a Eq. (30) na Eq. (28):

$$
\frac{\mathrm{dh}}{\mathrm{dt}}=\frac{\mathrm{r} \gamma_{\mathrm{LG}} \cos \theta}{4 \eta \mathrm{h}}
$$

Da integração da Eq. (31) resulta a conhecida equação de Washburn (Eq.32):

$$
\frac{h^{2}}{t}=\frac{r \gamma_{L G} \cos \theta}{2 \eta}
$$

Ao se monitorar o ganho de massa $m$ do líquido percolado ao invés de sua altura h em função do tempo, a equação de Washburn passa a ser expressa pela Eq. (33):

$$
\frac{m^{2}}{t}=\frac{c \rho^{2} \gamma_{L G} \cos \theta}{\eta}
$$

Onde:

$\mathrm{m}$ = massa de líquido absorvido;

$\mathrm{t}$ = tempo gasto para a absorção;

\footnotetext{
${ }^{1}$ No equilíbrio, $\Delta \mathrm{P}=0$ e $\mathrm{h}_{\mathrm{eq}}$ é a altura máxima atingida pelo líquido (Siebold et al., 2000).
} 
$\rho=$ peso específico do líquido;

$\gamma=$ tensão superficial do líquido;

$\eta=$ viscosidade dinâmica do líquido;

$\theta$ = ângulo de contato de avanço;

$\mathrm{C}=$ constante

A constante c é dada pela Eq. (34):

$$
c=\frac{1}{2} \pi^{2} r^{5} n^{2}
$$

Onde $\mathrm{n}$ é o número de capilares de raio médio $r$ formados pelos espaços vazios entre as partículas empacotadas. Assim, o valor de c dependerá do tamanho das partículas e também do seu grau de empacotamento e deverá ser determinado experimentalmente, antes da medida do ângulo de contato, utilizando-se um líquido que molhe completamente as partículas $\left(\theta=0^{\circ}\right)$ (KRÜSS, 1994).

A equação de Washburn permite a determinação do ângulo de contato, um parâmetro físico-químico, a partir da medida de parâmetros físicos como a distância percolada por um líquido (h) em função do tempo (t). Presume-se, entretanto, que tal equação somente será válida se a hidrodinâmica do sistema for regida por forças capilares.

A hidrodinâmica da percolação da fase líquida através do leito de partículas pode ser avaliada através da determinação dos seguintes parâmetros adimensionais: Número de Reynolds (Re), Número de Weber $(\mathrm{We})$, Número de Bond (Bo) e Número de Capilar (Cap). Informações sobre tais parâmetros são apresentadas na Tab. 8. Nesta tabela, $r$ é o raio médio do capilar, $v$ é a velocidade do fluxo de líquido ascendente, assim como $\eta, \rho$ e $\gamma$ representam a viscosidade, peso específico e tensão superficial do líquido em ascensão, respectivamente. 
Tabela 8 - Parâmetros hidrodinâmicos usados para caracterizar o escoamento em meio poroso (LEJA, 1982).

\begin{tabular}{|c|c|c|c|}
\hline Parâmetro adimensional & Significado físico & \multicolumn{2}{|c|}{ Equação matemática } \\
\hline Número de Reynolds (Re) & $\mathrm{Re}=\frac{\text { Forças inerciais }}{\text { Forças viscosas }}$ & $\operatorname{Re}=\frac{2 r \rho . v}{\eta}$ & (35) \\
\hline Número de Weber (We) & We $=\frac{\text { Forças inerciais }}{\text { Forças capilares }}$ & $W e=\frac{2 r \rho . v^{2}}{\gamma_{L G}}$ & $(36)$ \\
\hline Número de Bond (Bo) & Bo $=\frac{\text { Força gravitacional }}{\text { Forçascapilares }}$ & $\mathrm{Bo}=\frac{(2 r)^{2} \rho \cdot g}{\gamma_{L G}}$ & $(37)$ \\
\hline Número de Capilar (Cap) & Cap $=\frac{\text { Forças viscosas }}{\text { Forçascapilares }}$ & $\mathrm{Cap}=\frac{\mathrm{We}}{\mathrm{Re}}=\frac{\eta \cdot \mathrm{v}}{\gamma_{\mathrm{LG}}}$ & (38) \\
\hline
\end{tabular}

Os números hidrodinâmicos indicarão:

i. Se o regime é laminar ou turbulento: uma vez que o método de ascensão capilar parte da premissa de que o fluxo ascendente do fluido deve ocorrer em regime laminar, então o Número de Reynolds deverá ser inferior a $1000(\operatorname{Re}<1000)$ para que uma determinação de $\theta$ pela equação de Washburn seja válida;

ii. A predominância das forças capilares sobre inerciais e gravitacionais: o movimento ascensional do líquido através do leito de partículas sofre a influência de forças inerciais nos instantes iniciais, e de forças gravitacionais nos instantes finais. Deste modo, dentro do intervalo de tempo em que a altura do líquido (ou massa) é determinada, as forças capilares deverão ser dominantes para que a equação de Washburn seja válida, ou seja, $\mathrm{We}<1$ e Bo $<1$, conforme ilustra a Fig.16;

iii. A predominância das forças capilares sobre viscosas: para que as forças capilares sejam dominantes, o Número Capilar deverá ser inferior a 1 $($ Cap $<1)$. 


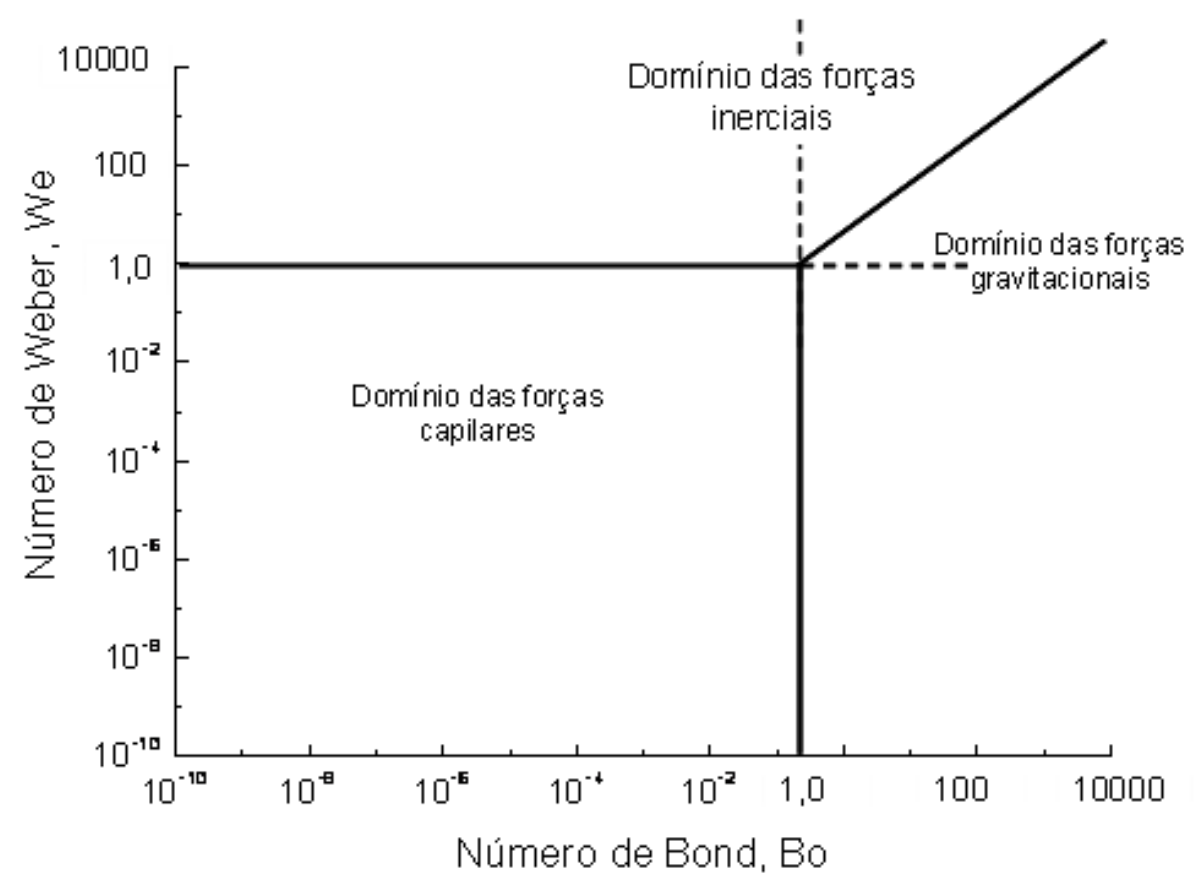

Figura 16 - Diagrama dos domínios hidrodinâmicos. 


\section{MATERIAIS E MÉTODOS}

\subsection{Obtenção, Preparação e Caracterização das Amostras de Apatita e Minério de Fosfato}

Minerais e minérios utilizados nesta tese foram:

i. Apatitas de gênese ígnea provenientes de duas diferentes localidades: Cajati - SP e Ipirá - BA (identificadas como "apatita-Cajati" e "apatitaIpirá", respectivamente);

ii. Minério de fosfato da jazida do Morro da Mina (Cajati-SP).

\subsubsection{Preparação e purificação das amostras de apatita}

A apatita-Cajati foi obtida através da purificação de amostra do minério denominado "Minério Calcítico Padrão" da jazida de Cajati-SP, enquanto que a apatita-Ipirá foi obtida através da purificação de cristais bem definidos, provenientes de Ipirá-BA. A preparação foi realizada como descrito abaixo:

i. As amostras foram britadas e cominuídas em gral de porcelana até que $100 \%$ de suas massas fossem passantes na peneira de $104 \mu \mathrm{m}(150$ mesh Tyler);

ii. Os produtos $-104 \mu \mathrm{m}$ foram então deslamados a úmido em peneira de 44 $\mu \mathrm{m}$ (325 mesh Tyler);

iii. Após deslamagem, os produtos $-104+44 \mu \mathrm{m}$ foram secados em estufa a $40^{\circ} \mathrm{C}$ e posteriormente submetidos a ensaio de separação densitária;

iv. A separação densitária foi realizada por ensaios de afunda-flutua em tetrabromoetano $(d=2,95)$, sob centrifugação;

v. Os produtos que afundaram em TBE foram exaustivamente lavados com acetona, álcool e água, nesta ordem, e secados em estufa a $40^{\circ} \mathrm{C}$. 
Posteriormente, as impurezas magnéticas da amostra apatita Cajati foram removidas em separador isodinâmico Frantz;

vi. A caracterização das amostras purificadas foi realizada por difratometria de raios $\mathrm{X}$ e análise química por WDS. Os resultados são sumarizados na Tab. 9.

Tabela 9 - Composição química das amostras de apatita.

\begin{tabular}{c|c|c|c|c|c|c|c}
\hline \hline Minerais & $\% \mathbf{P}_{2} \mathbf{O}_{5}$ & $\% \mathrm{CaO}$ & $\frac{\% \mathbf{C a O}}{\% \mathbf{P}_{\mathbf{2}} \mathbf{O}_{5}}$ & $\% \mathrm{~F}$ & $\% \mathrm{Fe}_{2} \mathbf{O}_{3}$ & $\% \mathbf{M g O}$ & $\% \mathrm{SiO}_{2}$ \\
\hline $\begin{array}{c}\text { Apatita } \\
\text { Cajati }\end{array}$ & 41,05 & 54,23 & 1,32 & 1,69 & 0,05 & 0,05 & 0,02 \\
\hline $\begin{array}{c}\text { Apatita } \\
\text { Ipirá }\end{array}$ & 40,40 & 55,38 & 1,37 & 2,74 & $0,07\left(^{*}\right)$ & 0,01 & 0,77 \\
\hline \hline
\end{tabular}

$\left(^{*}\right)$ Convertido a \% $\mathrm{Fe}_{2} \mathrm{O}_{3}$ a partir de valor inicial dado em \%FeO.

Como resultado dos procedimentos de preparação (cominuição e peneiramento) e purificação (separação densitária e magnética), obtiveram-se amostras de apatita com granulometria na faixa $-104+44 \mu \mathrm{m}$ que foram utilizadas em posteriores ensaios de microflotação e determinação de ângulo de contato pelo método da ascensão capilar.

\subsubsection{Obtenção e preparação de cristal de apatita}

Um cristal de apatita com planos e arestas bem definidos foi selecionado da amostra proveniente de Ipirá-BA. Os planos basal (001) e frontal (010) escolhidos foram cuidadosamente desbastados a úmido, utilizando lixas com as seguintes especificações: 100, 400, 1200 e 2400, nesta ordem. O acabamento foi realizado pelo polimento da amostra com pasta de diamante de $9 \mu \mathrm{m}$ e $6 \mu \mathrm{m}$, respectivamente (Fig. 17).

Após preparação da superfície do cristal, o mesmo foi utilizado em medidas de ângulo de contato pelo método da bolha cativa. 

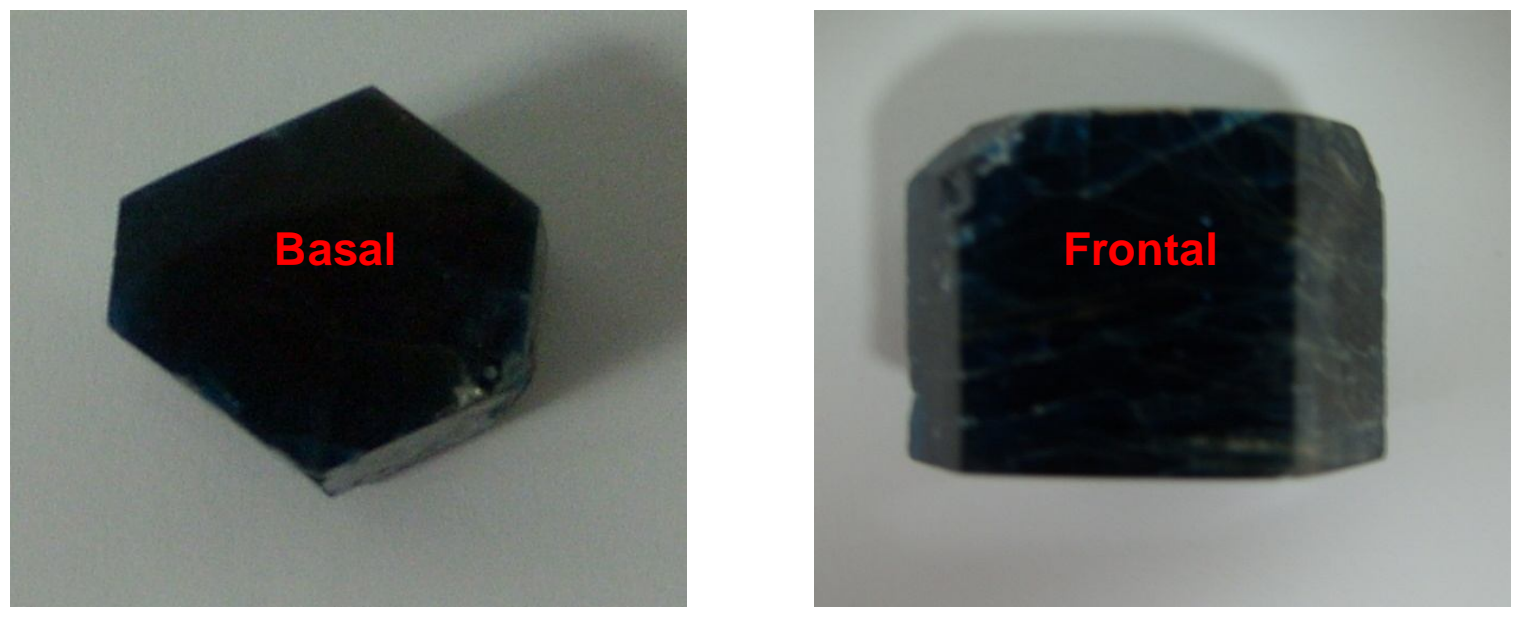

Figura 17 - Planos basal (001) e frontal (010) selecionados do cristal de apatita-Ipirá e polidos.

\subsubsection{Preparação e caracterização tecnológica do minério de fosfato}

Minério de fosfato oriundo da jazida de Cajati-SP foi amostrado no circuito de processamento (usina 320) após o mesmo ter sido submetido às etapas de moagem a úmido, separação magnética e deslamagem. Após espessamento da amostra, a mesma foi secada (temperatura $<60^{\circ} \mathrm{C}$ ) e homogeneizada. Informação a respeito de sua mineralogia é apresentada na Tab. 10, enquanto que composição química, distribuição granulométrica e grau de liberação são descritos na Tab. 11. O grau de liberação de apatita foi determinado por testes de afunda-flutua em líquidos de densidade conhecida, seguidos de microscopia óptica pelo Laboratório de Caracterização Tecnológica da Escola Politécnica da USP.

Tabela 10 - Mineralogia típica do minério de fosfato de Cajati - SP.

\begin{tabular}{c|c}
\hline Minerais & Teor (\%) \\
\hline Apatita & 12 \\
\hline Calcita & 70 \\
\hline Dolomita & 13 \\
\hline Silicatos & 4 \\
\hline Magnetita & 1 \\
\hline \hline
\end{tabular}


Tabela 11 - Composição química, distribuição granulométrica e grau de liberação da apatita na amostra de minério.

\begin{tabular}{c|c|c|c|c|c|c|c}
\hline \multirow{2}{*}{ Fração } & \multirow{2}{*}{$\begin{array}{c}\text { Grau de } \\
\text { liberação }\end{array}$} & $\begin{array}{c}\text { Massa } \\
(\%)\end{array}$ & \multicolumn{5}{|c}{ Composição química } \\
\cline { 4 - 8 } & & $\mathbf{P}_{2} \mathbf{O}_{5}$ & $\mathbf{C a O}$ & $\mathbf{M g O}$ & $\mathbf{S i O}_{2}$ & $\mathbf{F e}_{2} \mathbf{O}_{3}$ \\
\hline \hline$+208 \mu \mathrm{m}$ & $92 \%$ & 29,3 & 5,34 & 46,28 & 4,10 & 1,96 & 1,90 \\
\hline $\begin{array}{c}-208 \mu \mathrm{m} \\
+44 \mu \mathrm{m}\end{array}$ & $99 \%$ & 58,6 & 6,22 & 45,01 & 4,50 & 2,03 & 2,91 \\
\hline$-44 \mu \mathrm{m}$ & n.d. & 12,1 & 4,45 & 44,60 & 4,63 & 2,25 & 4,26 \\
\hline Total & - & 100,0 & 5,75 & 45,33 & 4,52 & 2,04 & 2,78 \\
\hline \hline
\end{tabular}

\subsubsection{Enriquecimento do minério de fosfato visando futuros ensaios de flotação gama}

Uma vez que o minério obtido é de baixo teor $\left(5,75 \%\right.$ de $\left.\mathrm{P}_{2} \mathrm{O}_{5}\right)$, tornou-se necessário concentrar apatita antes dos experimentos de flotação gama. Deste modo, 21 ensaios de flotação rougher foram realizados sob condições experimentais idênticas às condições adotadas no circuito industrial. Uma descrição detalhada desses experimentos é apresentada na seção 2.4. Flotação rougher produziu 1,89 $\mathrm{kg}$ de concentrado de apatita $\left(20,1 \%\right.$ de $\left.\mathrm{P}_{2} \mathrm{O}_{5}\right)$ cuja composição química e distribuição de tamanho de partículas são apresentadas na Tab. 12.

Tabela 12 - Composição química e distribuição granulométrica da amostra que alimentou a flotação gama.

\begin{tabular}{c|c|c|c|c|c|c|c}
\hline \hline \multirow{2}{*}{ Fração } & \multirow{2}{*}{$\begin{array}{c}\text { Massa } \\
(\%)\end{array}$} & \multicolumn{6}{|c}{ Composição química } \\
\cline { 3 - 8 } & $\mathbf{P}_{\mathbf{2}} \mathbf{O}_{5}$ & $\mathbf{C a O}$ & $\mathbf{M g O}$ & $\mathbf{S i O}_{2}$ & $\mathbf{F e}_{2} \mathbf{O}_{3}$ & $\mathbf{K}_{\mathbf{2}} \mathbf{O}$ \\
\hline \hline$+147 \mu \mathrm{m}$ & 32,7 & 32,1 & 53,7 & 2,90 & 0,81 & n.d. & n.d. \\
\hline $\begin{array}{c}-147 \mu \mathrm{m} \\
+37 \mu \mathrm{m}\end{array}$ & 56,6 & 15,2 & 47,5 & 4,07 & 1,08 & n.d. & n.d. \\
\hline$-37 \mu \mathrm{m}$ & 10,7 & 9,7 & 42,8 & 4,88 & 1,74 & n.d. & n.d. \\
\hline Total & 100,0 & 20,1 & 49,0 & 3,77 & 1,06 & 1,88 & 0,11 \\
\hline
\end{tabular}


De acordo com a mineralogia do minério (Tab. 10), ele contém somente um mineral portador de fósforo (apatita). Assim sendo, o teor de $\mathrm{P}_{2} \mathrm{O}_{5}$ em uma amostra pode ser usado para calcular o conteúdo de apatita presente na mesma. Além disso, o teor de $\mathrm{SiO}_{2}$ em uma amostra indica a presença de minerais de ganga da família dos silicatos.

Uma vez que há três minerais portadores de $\mathrm{Ca}$ (apatita, calcita e dolomita) no sistema mineralógico de Cajati, o teor total de cálcio (\%СаО amostra pode ser expresso como a soma de duas contribuições como apresentado na Eq. (39):

$$
\% \mathrm{CaO}_{\text {TOTAL }}=\% \mathrm{CaO}_{\mathrm{CARB}}+\% \mathrm{CaO}_{\mathrm{APA}}
$$

Onde:

$\% \mathrm{CaO}_{\text {CARB }}=$ Contribuição da dolomita e calcita (carbonatos) ao teor total de cálcio na amostra (\%СaO

$\% \mathrm{CaO}_{\mathrm{APA}}=$ Contribuição da apatita ao teor total de cálcio na amostra.

Visto que a apatita de Cajati apresenta uma razão \%CaO:\% $\mathrm{P}_{2} \mathrm{O}_{5}=1,32$ (Tab.

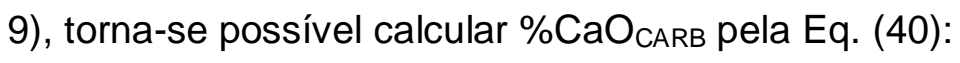

$$
\% \mathrm{CaO}_{\mathrm{CARB}}=\% \mathrm{CaO}_{\mathrm{TOTAL}}-\left(1,32 . \% \mathrm{P}_{2} \mathrm{O}_{5}\right)
$$

Para calcular a recuperação metalúrgica de apatita, carbonatos e silicatos em qualquer teste de flotação, os teores de $\mathrm{P}_{2} \mathrm{O}_{5}, \mathrm{CaO}_{\mathrm{CARB}}$ e $\mathrm{SiO}_{2}$ foram utilizados, respectivamente.

\subsection{Reagentes}

Água destilada foi utilizada nos ensaios de flotação rougher e microflotação, enquanto soluções compostas de metanol (grau analítico) e água deionizada $\left(\mathrm{pH}=5.8\right.$, condutividade elétrica $\left.=1.6 \times 10^{-6} \mathrm{~S} / \mathrm{cm}\right)$ foram usadas nos ensaios de 
flotação gama e nas medidas de ângulo de contato para a determinação da tensão crítica de molhabilidade $\left(\gamma_{c}\right)$. Densidade e viscosidade dinâmica das soluções água/metanol foram obtidas por interpolação de valores fornecidos pela literatura (GONZALEZ et al, 2007), enquanto os valores de energia livre superficial foram determinadas experimentalmente, como descrito na seção 2.6.

Os valores experimentais de energia livre superficial $\left(\gamma_{L V}\right)$ dos líquidos hexano, metanol e água (deionizada no Laboratório de Físico-Química de Interfaces -LFQI e no Centro de Tecnologia Mineral -CETEM) e das soluções água/metanol são apresentados na Tab. 13, onde se observa que os valores para os líquidos "puros" são muito semelhantes àqueles fornecidos pela base de dados do Tensiômetro K12. Deste modo, tais líquidos apresentam-se adequados para o uso.

Tabela 13 - Energia livre superficial, densidade e viscosidade dinâmica do hexano, metanol, água deionizada e soluções água/metanol $\left(20,0 \pm 0,1^{\circ} \mathrm{C}\right)$.

\begin{tabular}{c|c|c|c|c}
\hline \multirow{2}{*}{ Líquido } & \multicolumn{2}{|c|}{$\begin{array}{c}\text { Energia livre superficial } \\
\left(\mathbf{e r g} / \mathbf{c m}^{2}\right)\end{array}$} & $\begin{array}{c}\text { Densidade } \\
\left(\mathbf{g} / \mathbf{c m}^{3}\right)\end{array}$ & $\begin{array}{c}\text { Viscosidade } \\
(\mathbf{m P a} \mathbf{s})\end{array}$ \\
\cline { 2 - 5 } & Experimental & Literatura $\left(^{* *}\right)$ & $\left(^{* *}\right)$ & $\left(^{* *}\right)$ \\
\hline Hexano & $18,42 \pm 0,02$ & 18,4 & 0,661 & 0,326 \\
\hline Água (LFQI) & $\begin{array}{c}72,81 \pm 0,02 \\
72,90 \pm 0,02\left(^{*}\right)\end{array}$ & 72,8 & 0,998 & 1,002 \\
\hline Água (CETEM) & $72,86 \pm 0,02$ & 72,8 & 0,998 & 1,002 \\
\hline $\begin{array}{c}\text { Solução água/metanol } \\
(\% \text { metanol) }\end{array}$ & & & $\left(^{* * *}\right)$ & $\left(^{* * *}\right)$ \\
\hline 0,0 & $72,90 \pm 0,02$ & - & 0,998 & 1,003 \\
\hline 1,0 & $70,90 \pm 0,02$ & - & 0,992 & 1,057 \\
\hline 9,8 & $59,17 \pm 0,03$ & - & 0,972 & 1,522 \\
\hline 17,5 & $52,71 \pm 0,03$ & - & 0,955 & 1,730 \\
\hline 27,0 & $46,25 \pm 0,06$ & - & 0,934 & 1,799 \\
\hline 36,5 & $41,42 \pm 0,11$ & - & 0,914 & 1,727 \\
\hline 48,0 & $38,81 \pm 0,05$ & - & 0,890 & 1,534 \\
\hline 75,0 & $30,75 \pm 0,07$ & - & 0,837 & 0,989 \\
\hline 100,0 & $22,83 \pm 0,06$ & 22,7 & 0,792 & 0,585 \\
\hline \hline
\end{tabular}

$\left(^{*}\right)$ Águas deionizadas em dias diferentes.

$\left.{ }^{* *}\right)$ Base de dados do software do Tensiômetro K12.

$\left({ }^{* \star *}\right)$ González et al.(2007).

Nota: Os desvios apresentados correspondem ao desvio padrão resultante de uma série de três medidas em cada condição experimental (APÊNDICE 1). 
A Tab. 13 também apresenta as magnitudes de densidade e viscosidade dinâmica dos líquidos e soluções que, em conjunto com os valores experimentais de $\gamma_{L V}$, foram introduzidos na base de dados do Tensiômetro K12 para a realização das medidas de ângulo de contato pelo método da ascensão capilar (seção 2.7).

\subsubsection{Reguladores de pH}

Soluções de hidróxido de sódio e ácido clorídrico, ambas 10\%p/v foram utilizadas para o ajuste de $\mathrm{pH}$, sempre que necessário As soluções foram preparadas solubilizando $10,00 \pm 0,01 \mathrm{~g}$ de $\mathrm{NaOH}$ ou $\mathrm{HCl}$ (ambos de grau analítico) em água deionizada e avolumadas em balão de $100 \mathrm{~mL}$.

\subsubsection{Coletores}

Berol $^{\circledR} 867$ fornecido pela Akzo-Nobel foi utilizado nos ensaios de flotação rougher e no tratamento da superfície de partículas de apatita Cajati para a determinação do ângulo de contato pelo método da ascensão capilar. Soluções-mãe $1 \% \mathrm{p} / \mathrm{v}$ foram preparadas como segue:

i. $\quad 1,00 \pm 0,01 \mathrm{~g}$ de Berol $^{\circledR} 867$ era pesado em um béquer;

ii. Adicionavam-se $20 \mathrm{~mL}$ de água deionizada, solubilizando-se facilmente toda a massa sob agitação moderada. Em seguida, a solução era avolumada com água deionizada em balão de $100 \mathrm{~mL}$;

iii. Novas soluções eram preparadas imediatamente antes de serem usadas, para evitar degradação microbiológica. Por diluição da solução-mãe foram obtidas as concentrações requeridas nos ensaios.

Soluções de oleato de sódio em diferentes concentrações foram utilizadas nos ensaios de microflotação e no tratamento da superfície da apatita Ipirá para a determinação do ângulo de contato pelos métodos da bolha cativa e ascensão capilar. Soluções-mãe 1\% p/v foram preparadas como segue: 
i. $\quad 2,50 \pm 0,01 \mathrm{~g}$ de ácido oléico (Synth) eram pesados em um béquer;

ii. Sob agitação, adicionavam-se $20 \mathrm{~mL}$ de água deionizada e gotas de $\mathrm{NaOH} 10 \% \mathrm{p} / \mathrm{v}$ até $\mathrm{pH} \cong 11,0$ para realizar a saponificação. Em seguida, a solução era avolumada com água deionizada em balão de $250 \mathrm{~mL}$;

iii. Novas soluções eram preparadas imediatamente antes de serem usadas. Por diluição da solução-mãe foram obtidas as concentrações requeridas nos ensaios.

\subsubsection{Modificador}

Amido de milho (Amidex ${ }^{\circledR} 3001$ ) fornecido pela Corn Products foi utilizado nos ensaios de flotação rougher e na modificação da superfície de partículas de apatita Cajati para a determinação do ângulo de contato pelo método da ascensão capilar. Soluções-mãe $1 \%$ p/v foram preparadas como segue:

i. $\quad 2,50 \pm 0,01 \mathrm{~g}$ de amido eram pesados em um béquer;

ii. Sob agitação, adicionaram-se $30 \mathrm{~mL}$ de água deionizada e $5,0 \mathrm{~mL}$ de $\mathrm{NaOH} 10 \%$ p/v para gelatinizar a solução (relação amido:soda $=5: 1$ ). A solução era avolumada em balão de $250 \mathrm{~mL}$;

iii. Novas soluções-mãe eram preparadas imediatamente antes de serem usadas, para evitar degradação microbiológica. Por diluição da soluçãomãe foram obtidas as concentrações requeridas nos ensaios.

\subsection{Ensaios de Microflotação}

O tubo de Hallimond utilizado no sistema de microflotação possui 3,22 mm de diâmetro e uma placa porosa em sua base, necessária para produzir borbulhamento uniforme do gás $\mathrm{N}_{2}$ utilizado na flotação. A vazão do gás era controlada por uma válvula com a ajuda de um rotâmetro. O sistema pode ser visualizado na Fig. 18. 
Ensaios de microflotação foram realizados em tubo de Hallimond de $3,22 \mathrm{~cm}$ de diâmetro sob as seguintes condições: 1,00 $\pm 0,01 \mathrm{~g}$ da amostra de apatita Ipirá era condicionado com solução de oleato de sódio (nas concentrações $0,5,15,25$, 50 e $75 \mathrm{mg} / \mathrm{L} ; \mathrm{pH}=10,5$ e a $25^{\circ} \mathrm{C}$ ) por 1 minuto. Após condicionamento, flotação era realizada durante o período de 1 minuto com uma vazão de gás nitrogênio de 54,6 $\mathrm{cm}^{3} / \mathrm{min}$. Os produtos flotado e afundado eram secos e pesados. Os ensaios foram feitos em triplicata e a flotabilidade (recuperação) foi calculada através da razão entre a massa do produto flotado e a massa da alimentação, multiplicada por 100.

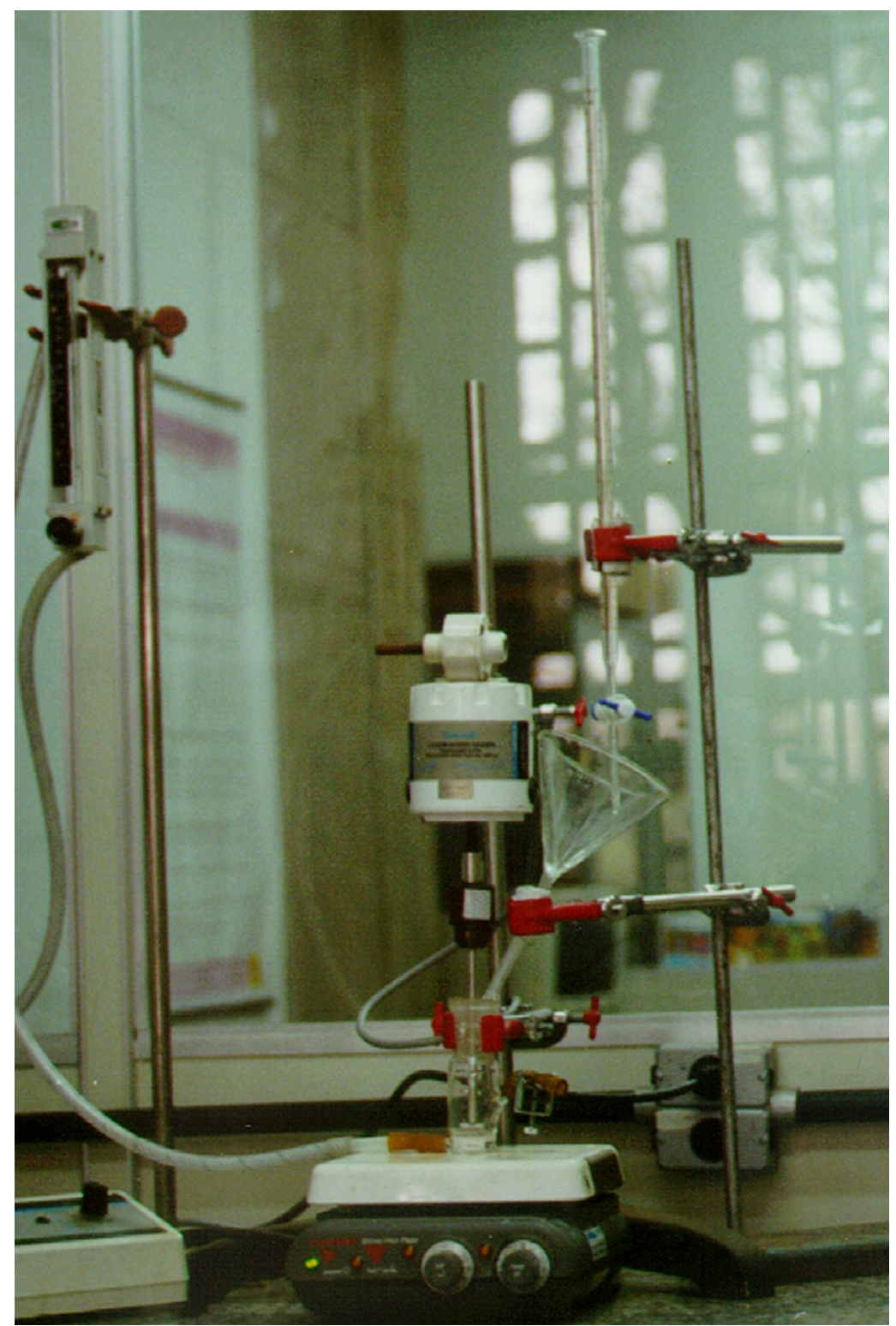

Figura 18 - Sistema de microflotação. 


\subsection{Enriquecimento do Minério de Fosfato por Flotação}

Foram realizados 21 ensaios de flotação rougher com o minério de fosfato caracterizado na Tab. 11 , a $22-23^{\circ} \mathrm{C}$ visando enriquecê-lo para, posteriormente, submetê-lo a ensaios de flotação gama (seção 2.5).

Os procedimentos experimentais foram semelhantes às condições de flotação adotadas na etapa rougher do circuito industrial:

i. $400,0 \mathrm{~g}$ de minério eram empolpados com $800 \mathrm{~mL}$ de água destilada, perfazendo uma porcentagem de sólidos da ordem de $33 \%$ em massa. A suspensão exibiu $\mathrm{pH}=9.1$;

ii. Adicionava-se o agente modificador Amidex ${ }^{\circledR} 3001$ ( $75 \mathrm{~g} / \mathrm{t}$ ou $\left.37,5 \mathrm{mg} / \mathrm{L}\right)$ e o $\mathrm{pH}$ da polpa era ajustado para $\mathrm{pH}=10,6 \mathrm{com} \mathrm{NaOH} 10 \% \mathrm{p} / \mathrm{v}$. O tempo de condicionamento do reagente era de 5 minutos;

iii. Após condicionamento com amido, uma quantidade adicional de água destilada $(800 \mathrm{~mL})$ era adicionada à suspensão perfazendo uma porcentagem de sólidos de $20 \%$ em massa. Coletor Berol ${ }^{\circledR} 867$ (100g/t ou $25 \mathrm{mg} / \mathrm{L}$ ) era adicionado ao sistema e condicionado por 2 minutos;

iv. Após condicionamento, o ar era admitido no sistema e a flotação executada até total exaustão da espuma;

v. Os produtos "flutuado" dos 21 ensaios $(1,89 \mathrm{~kg})$ foram secados a $40^{\circ} \mathrm{C}$, homogeneizados em pilha alongada e alíquotas de 100,0 gramas foram retiradas para a realização dos experimentos de flotação gama. Composição química e distribuição granulométrica de tal produto são apresentadas na Tab. 12, seção 2.1.4.

\subsection{Ensaios de Flotação Gama}

Ensaios de flotação gama foram realizados em duplicata, a $20^{\circ} \mathrm{C}$, como descrito a seguir: 
i. $\quad 100,0 \mathrm{~g}$ de concentrado rougher foram empolpados com $1,2 \mathrm{~L}$ de solução água/metanol desejada (\% metanol de 0,$0 ; 1,0 ; 9,8 ; 17,5 ; 27,0 ; 36,5 ; 48,0$; $75,0$ ou $100,0 \%)$. $\mathrm{O} \mathrm{pH}$ das suspensões encontrava-se na faixa de $9.4<\mathrm{pH}<9.6$, que se assemelha ao $\mathrm{pH}$ do estágio cleaner no circuito industrial de Cajati;

ii. Após 1 minuto de condicionamento, o ar era admitido no sistema e a flotação executada até total exaustão da espuma. Os produtos "flutuado" e "afundado" foram filtrados, secados, pesados e analisados quimicamente.

Para qualquer valor particular de energia livre superficial $\left(\gamma_{L V}\right)$, as recuperações de apatita $\left(R_{A P A}\right)$, carbonatos $\left(R_{C A R B}\right)$ e silicatos $\left(R_{S I L}\right)$ foram calculadas usando os teores de $\mathrm{P}_{2} \mathrm{O}_{5}, \mathrm{CaO}_{\text {CARB }}$ ou $\mathrm{SiO}_{2}$ nos produtos "flutuado" e "afundado", respectivamente. A eficiência de separação apatita/carbonatos

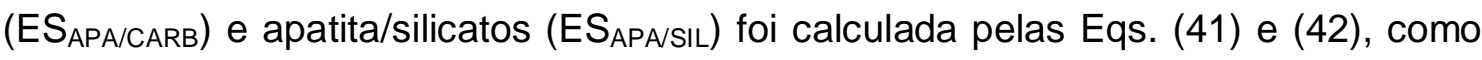
proposto por Schulz (1970).

$$
\begin{aligned}
& \mathrm{ES}_{\mathrm{APA} / \mathrm{CARB}}=\mathrm{R}_{\mathrm{APA}}-\mathrm{R}_{\mathrm{CARB}} \\
& \mathrm{ES}_{\mathrm{APA} / \mathrm{SIL}}=\mathrm{R}_{\mathrm{APA}}-\mathrm{R}_{\mathrm{SIL}}
\end{aligned}
$$

\subsection{Determinação de Energia Livre Superficial $\left(\gamma_{\mathrm{LV}}\right)$}

As energias livres superficiais $(\gamma\llcorner\mathrm{LV})$ dos líquidos utilizados nos ensaio de flotação gama e/ou nas medidas de ângulo de contato - água deionizada, hexano e soluções de diferentes proporções água/metanol - e da solução de flotação rougher foram determinadas no Tensiômetro K12, fabricado pela Krüss, pelo método de Wilhelmy. O método utiliza uma placa de platina de geometria definida e superfície rugosa. A borda inferior da placa é colocada em contato com a superfície do líquido, que avança sobre a mesma, puxando-a para seu interior em decorrência da "força de Wilhelmy" $\left(F_{w}\right)$. Tal força é contrabalançada e medida pelo tensiômetro quando 
este retorna a placa a sua posição inicial (superfície do líquido). $O$ valor de $\gamma_{\llcorner V}$ do líquido é determinado automaticamente pelo aparelho através da Eq. (43). Para se usar tal equação, o valor de $\theta$ deve ser zero. A rugosidade e a limpeza cuidadosa da placa garantem este requisito (KRÜSS, 1994).

$$
\gamma_{L V}=\frac{F_{W}}{L \cdot \cos \theta}
$$

Onde $L$ é o perímetro da placa molhada pelo líquido e $\theta$ é o ângulo de contato.

As medidas foram executadas a $20,0 \pm 0,1{ }^{\circ} \mathrm{C}$, em triplicata. $\mathrm{O}$ equipamento foi programado para realizar 50 medidas dentro de um período de 400 segundos. Os resultados são os valores médios das 15 últimas medidas.

\subsection{Determinação de Ângulo de Contato pelo Método da Ascensão Capilar}

Medidas de ângulo de contato foram realizadas em triplicata e a $20,0 \pm 0,1^{\circ} \mathrm{C}$ no Tensiômetro K12, fabricado pela Krüss, pelo método de ascensão capilar. Uma quantidade definida da amostra $(3,0000 \pm 0,0001 \mathrm{~g})$ era cuidadosamente empacotada em uma cubeta de vidro de geometria cilíndrica, fechada em sua extremidade inferior por uma placa de vidro sinterizado. Um filtro de papel era colocado entre esta placa e a amostra para evitar o entupimento dos poros com as partículas, conforme ilustra a Fig. 19.

A cubeta, preenchida com partículas de apatita, era colocada em contato com a superfície do líquido teste, sendo a razão de ascensão do mesmo medida pela massa adquirida pelo sistema cubeta/leito de partículas ao ser percolado pelo líquido em função do tempo (Fig. 20). Tal massa era monitorada por eletro-balança embutida no tensiômetro K12. O ângulo de contato era automaticamente 
determinado pelo software do aparelho, utilizando a equação de Washburn (Eq. 33), após a determinação da constante c.

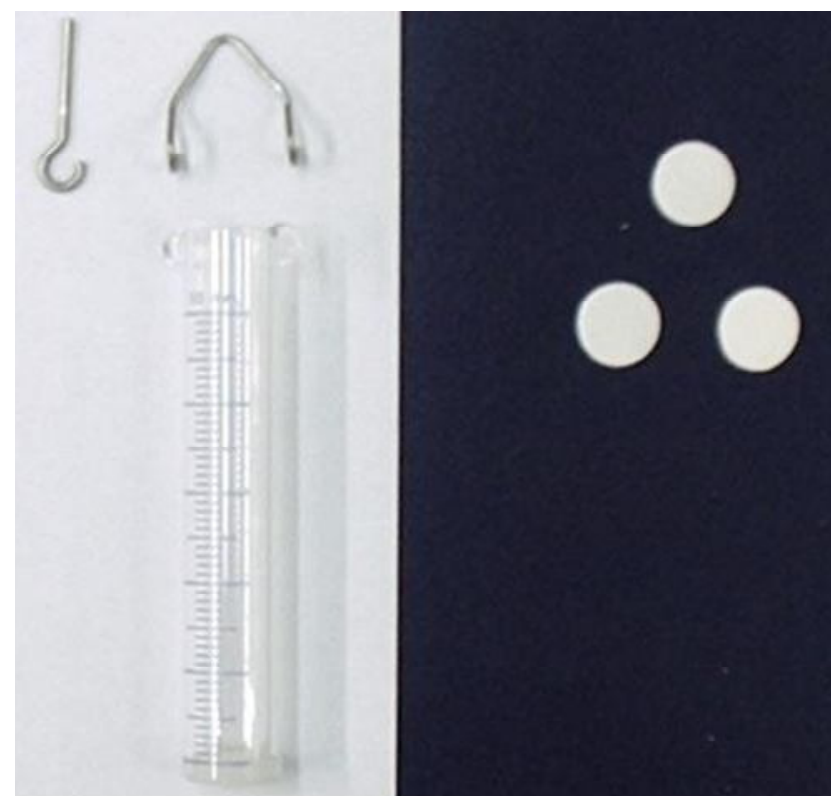

Figura 19 - Cubeta de vidro para empacotamento da amostra e papéis de filtro.

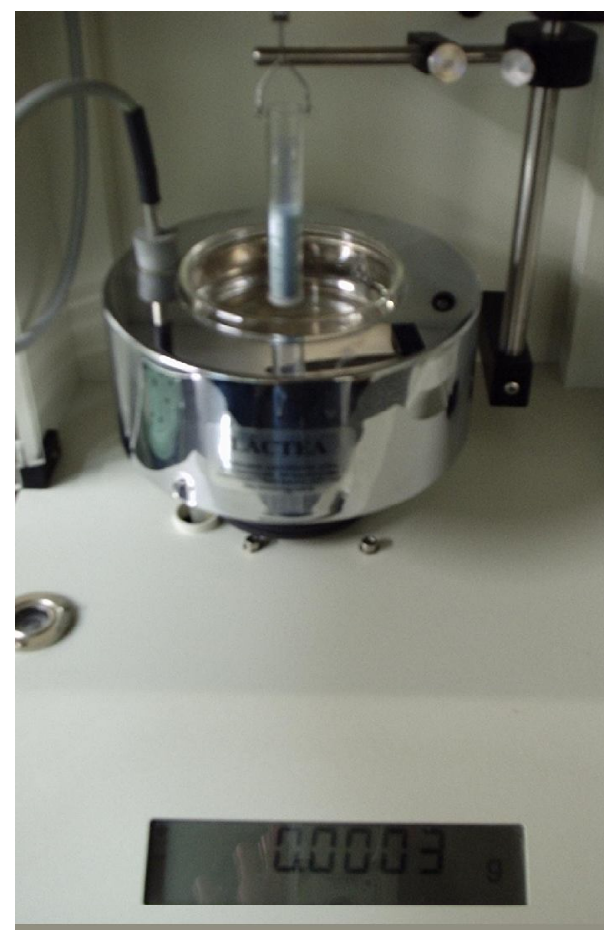

Figura 20 - Determinação do ângulo de contato utilizando o tensiômetro K12. 
Na determinação da constante $\mathrm{c}$ e dos ângulos de contato, os valores de $\mathrm{m}^{2} / \mathrm{t}$ foram obtidos por regressão linear, de acordo com o método dos mínimos quadrados, aplicada a uma seção da curva $\mathrm{m}^{2}$ versus $\mathrm{t}$ delimitada pelo intervalo de tempo de $t_{0}=2$ a $t_{f}=15$ segundos, conforme pode ser visualizado na Fig. 21. Este intervalo de tempo foi escolhido buscando garantir uma regressão com mínima variação do coeficiente angular, uma vez que:

i. Para tempos de contato muito curtos, não há garantias de que o sistema se encontre em regime laminar e tenha atingido o estado estacionário devido a variações instantâneas de $\mathrm{dm} / \mathrm{dt}$. Neste caso, a equação de Washburn se tornaria inválida (SZEKELY, NEUMANN, CHUANG, 1971). Segundo estes mesmos autores, resultados experimentais significativos somente poderiam ser obtidos a partir de 1-2 segundos após o início do processo de ascensão capilar. A presença da placa de vidro sinterizado e do filtro de papel colabora para a variação $\mathrm{de} \mathrm{dm} / \mathrm{dt}$ nos instantes iniciais da medida.

ii. Para tempos de contato muito longos, $\mathrm{dm} / \mathrm{dt}$ tende a zero devido à saturação dos capilares pelo líquido. Considerar pontos próximos a esta região resultaria em provável geração de erros.

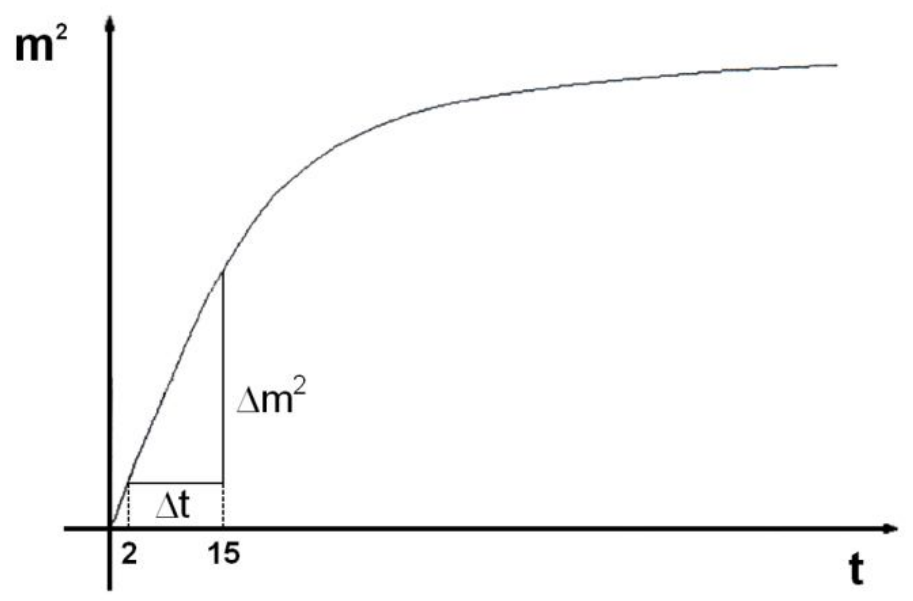

Figura 21 - Representação esquemática de uma curva da massa adquirida pelo leito de partículas ao ser percolado pelo líquido em função do tempo. 


\subsubsection{Determinação de ângulo de contato da apatita-Ipirá pré-tratada com oleato de sódio}

A superfície das partículas de apatita Ipirá foram modificadas pela adsorção de oleato de sódio ( $\mathrm{NaOl}$ ) nas concentrações $0,5,15,25$ e $75 \mathrm{mg} / \mathrm{L}$. Assim, 30,0 g da amostra eram condicionadas com a solução de $\mathrm{NaOl}\left(\mathrm{pH}=10,5\right.$ e a $25^{\circ} \mathrm{C}$ ) por 1 minuto e, em seguida, com água deionizada por 2 minutos. A amostra era filtrada, secada a $40^{\circ} \mathrm{C}$ em estufa com ventilação e armazenada em frascos selados.

Para a determinação da constante c, partículas de apatita sem prévia adsorção de oleato foram cuidadosamente empacotas para garantir reprodutibilidade das medidas. Os seguintes líquidos foram utilizados, considerando $\theta=0^{\circ}$ :

i. Hexano, por possuir baixa energia livre superficial $\left(\gamma\left\llcorner v=18,4 \mathrm{erg} / \mathrm{cm}^{2}\right)\right.$;

ii. Água, por ser capaz de molhar as partículas de apatita em função de seu caráter hidrofílico natural, conforme reportado por Martins (2004).

As medidas de ângulo de contato foram executadas através do avanço de água deionizada como a fase líquida, visando ao estudo da influência da adsorção do coletor oleato sobre a molhabilidade da apatita.

\subsubsection{Determinação de ângulo de contato da apatita-Cajati pré-tratada com amido de milho e Berol ${ }^{\circledR} 867$}

As medidas de ângulo de contato foram realizadas com soluções de água/metanol nas concentrações de metanol (v/v) de 0,0\%; 1,0\%; 9,8\%; $27,0 \%$; $48,0 \% ; 75,0 \%$ e $100,0 \%$, visando à determinação da tensão crítica de molhabilidade $\left(\gamma_{c}\right)$ da apatita Cajati pré-tratada com amido de milho e Berol ${ }^{\circledR} 867$.

A modificação da superfície das partículas minerais foi realizada a $20^{\circ} \mathrm{C}$ seguindo procedimentos experimentais semelhantes aos adotados na flotação 
rougher do minério também proveniente de Cajati (seção 2.4), conforme descrito a seguir:

i. $\quad 30,0 \mathrm{~g}$ da amostra foram condicionadas por 5 minutos em $\mathrm{pH}=10,6 \mathrm{com}$ Amidex ${ }^{\circledR} 3001$ (37,5 mg/L) em uma concentração de sólidos de 33\% em massa;

ii. Em seguida, água destilada foi adicionada a suspensão perfazendo uma concentração de sólidos de $20 \%$. O coletor Berol ${ }^{\circledR} 867$ (25 mg/L) foi então condicionado por 2 minutos em $\mathrm{pH}=10,6$;

iii. Após condicionamento com os reagentes, a suspensão foi filtrada e a tensão superficial do líquido foi determinada pelo método descrito na seção 2.6. A amostra de apatita foi lavada com água deionizada por 1 minuto e meio, filtrada, secada a $40^{\circ} \mathrm{C}$ em estufa com ventilação e armazenada em frasco selado para posteriores medidas de ângulo de contato.

A constante c foi determinada com a amostra de apatita previamente condicionada com os reagentes de flotação, utilizando-se hexano como a fase líquida percolante.

\subsubsection{Hidrodinâmica da percolação da fase líquida através do leito de partículas}

Para caracterizar a hidrodinâmica da percolação das soluções água/metanol através do leito de partículas de apatita previamente tratadas com amido de milho e Berol $^{\circledR} 867$, foram determinados os seguintes parâmetros adimensionais: Número de Reynolds (Re), Número de Weber (We), Número de Bond (Bo) e Número de Capilar (Cap).

O Número de Reynolds é dado pela Eq. (35) (WASHBURN, 1921), onde o termo $v$ representa a velocidade média de ascensão do fluido no capilar de raio $r$.

$$
R e=\frac{2 r \rho}{\eta} v
$$


Considerando-se que o fluxo se encontra em regime estacionário, a partir dos valores dos tempos $t_{0}$ (inicial) e $t_{f}$ (final) e das correspondentes alturas de ascensão de líquido $h_{0}$ (inicial) e $h_{f}$ (final), a velocidade média $v$ do escoamento pode ser calculada utilizando a Eq. (44).

$$
v=\frac{h_{f}-h_{0}}{t_{f}-t_{0}}
$$

A velocidade de ascensão de fluido no capilar também pode ser expressa pela Eq. (31) descrita na seção 1.4, cuja integração conduz ao resultado expresso pela Eq. (45).

$$
\begin{gathered}
\frac{d h}{d t}=\frac{r \gamma_{L G} \cos \theta}{4 \eta h} \\
h_{f}^{2}-h_{0}^{2}=\frac{r \gamma_{L G} \cos \theta}{2 \eta}\left(t_{f}-t_{0}\right)
\end{gathered}
$$

A Eq. (45) pode ser reescrita de modo a representar a velocidade média do escoamento, de acordo com a Eq. (46).

$$
\frac{h_{f}-h_{0}}{t_{f}-t_{0}}=\frac{r \gamma_{L G} \cos \theta}{2 \eta\left(h_{f}+h_{0}\right)}
$$

Combinando as Eqs. (44) e (46) com a Eq. (35) obtém-se as Eqs. (47) e (48), respectivamente.

$$
\begin{aligned}
& R e=\frac{2 r \rho}{\eta} \cdot \frac{h_{f}-h_{0}}{t_{f}-t_{0}} \\
& R e=\frac{r^{2} \rho \gamma_{L G} \cos \theta}{\eta^{2}\left(h_{f}+h_{0}\right)}
\end{aligned}
$$


Uma vez conhecidos os valores das alturas inicial $\left(h_{0}\right)$ e final $\left(h_{f}\right)$ de líquido no capilar em cada condição experimental, é possível a resolução do sistema formado pelas Eqs.(47) e (48), determinando o valor do Número de Reynolds e do raio médio do capilar.

Conhecendo-se o valor do raio médio do capilar $r$ e da velocidade de ascensão do líquido $\mathrm{v}$, os demais parâmetros adimensionais foram calculados.

Uma vez que a determinação experimental de $\theta$ foi baseada no ganho de massa versus tempo, monitorado por eletro-balança, e não na altura versus tempo, foi necessário fazer uma correlação entre as massas de líquido percolado $\mathrm{m}_{0}$ e $\mathrm{m}_{\mathrm{f}}$, obtidos dentro do intervalo de tempo $t_{0}=2 \mathrm{~s}$ e $t_{f}=15 \mathrm{~s}$, com as alturas dos meniscos $h_{0}$ e $h_{f}$ referentes ao mesmo intervalo. Como ponto de partida, foi calculada a porosidade do leito de partículas $\left(\varepsilon_{\mathrm{L}}\right)$, que representa a fração volumétrica do meio poroso ocupada pelo liquido, de acordo com a Eq. (49)

$$
\varepsilon_{\mathrm{L}}=1-\frac{\mathrm{m}_{\mathrm{s}}}{\mathrm{AL} \rho_{\mathrm{s}}}
$$

Em que $m_{s}$ representa a massa de sólidos; $A$ é a área da seção transversal do leito; L é a altura do leito poroso e $\rho_{\mathrm{s}}$ é a densidade do sólido.

Para uma determinada altura de ascensão (h), é possível escrever a Eq. (50), em que $V_{s, h}$ representa o volume efetivo de sólidos; $V_{L, h}$ representa o volume de líquido, e $\mathrm{V}_{T, \mathrm{~h}}$ representa o volume total, na altura $\mathrm{h}$.

$$
\mathrm{V}_{\mathrm{s}, \mathrm{h}}+\mathrm{V}_{\mathrm{L}, \mathrm{h}}=\mathrm{V}_{\mathrm{T}, \mathrm{h}}
$$

A Eq. (50) pode ser reescrita na forma da Eq. (51) que, isolando a variável h, conduz à Eq. (52).

$$
\left(1-\varepsilon_{L}\right) A h+V_{L, h}=A h
$$




$$
h=\frac{V_{L, h}}{\varepsilon_{L} A}
$$

O termo $\mathrm{V}_{\mathrm{L}, \mathrm{h}}$ é calculado a partir dos dados de ascensão capilar obtidos para cada condição experimental, através da definição de massa específica, mostrada pela Eq. (53).

$$
\mathrm{V}_{\mathrm{L}, \mathrm{h}}=\frac{\mathrm{m}_{\mathrm{L}, \mathrm{h}}}{\rho_{\mathrm{L}}}
$$

Onde $m_{L, h}$ é a massa de líquido presente no capilar, determinada experimentalmente, a uma altura h e $\rho_{\mathrm{L}}$ é a massa específica do líquido utilizado.

\subsection{Determinação de Ângulo de Contato pelo Método da Bolha Cativa}

O procedimento experimental consistiu de medidas diretas de ângulo de contato, envolvendo bolhas de ar posicionadas sobre as superfícies polidas do mineral em contato com a fase líquida, realizadas em um goniômetro Ramé-Hart pertencente ao Laboratório de Química de Superfície do CETEM/CNPq. Os procedimentos experimentais foram executados para os planos basal (001) e frontal (010) da apatita-Ipirá e são apresentados a seguir:

\subsubsection{Determinação de ângulo de contato no sistema apatita/ar/água}

O modus operandi dos ensaios é descrito a seguir:

i. Após a limpeza da superfície, o cristal era imerso em um béquer de vidro contendo a solução de oleato na concentração desejada $(0,5,1525$ ou 75 $\mathrm{mg} / \mathrm{L}$ ) e $\mathrm{pH}=10,5$, sendo condicionado pelo período de 1 minuto e a $25^{\circ} \mathrm{C}$; 
ii. Após condicionamento, a amostra era lavada com água para retirar o excesso de reagente e imersa em um béquer de vidro contendo água deionizada. Nota: o cristal era o tempo todo manipulado com uma pinça de aço inoxidável, tomando-se o cuidado de não tocar nos planos selecionados, para evitar contaminação;

iii. Uma bolha de ar cativa era colocada sobre a superfície a ser analisada (plano basal ou frontal) com o auxílio de uma agulha conectada a uma micro-seringa. Os ângulos de contato de avanço foram medidos em ambos os lados do perfil da bolha, em triplicata, e a $20^{\circ} \mathrm{C}$.

iv. As superfícies eram devidamente renovadas entre um ensaio e outro, através do polimento com alumina de $3 \mu \mathrm{m}$ e pasta de diamante de $1 \mu \mathrm{m}$ e posterior lavagem exaustiva das mesmas com água deionizada. A limpeza era aferida medindo-se o ângulo de contato com água deionizada (a superfície limpa da apatita apresentava $\theta=0^{\circ}$ ).

\subsubsection{Determinação de ângulo de contato no sistema apatita/ar/solução água:metanol}

O modus operandi dos ensaios é descrito a seguir:

i. Após a limpeza da superfície, o cristal era imerso em um béquer de vidro contendo a solução de oleato na concentração de $75 \mathrm{mg} / \mathrm{L}$ e pH =10,5, sendo condicionado pelo período de $1 \mathrm{~min}$. e a $25^{\circ} \mathrm{C}$;

ii. Após condicionamento, a amostra era lavada com água deionizada para retirar o excesso de reagente e imersa em um béquer de vidro contendo a solução água/metanol na concentração de metanol desejada $(0,0 \% ; 1,0 \%$; $9,8 \% ; 27,0 \% ; 48,0 \% ; 75,0 \%$ ou $100,0 \%(v / v))$.

iii. Uma bolha de ar cativa era colocada sobre a superfície a ser analisada (plano basal ou frontal) com o auxílio de uma agulha conectada a uma micro-seringa. Os ângulos de contato de avanço foram medidos em ambos os lados do perfil da bolha, em triplicata, e a $20^{\circ} \mathrm{C}$. 
v. As superfícies foram devidamente renovadas entre um ensaio e outro, através do polimento com alumina de $3 \mu \mathrm{m}$ e pasta de diamante de $1 \mu \mathrm{m}$ e posterior lavagem exaustiva das mesmas com água deionizada. A limpeza era aferida medindo-se o ângulo de contato com água deionizada (a superfície limpa da apatita apresentava $\theta=0^{\circ}$ ). 


\section{RESULTADOS E DISCUSSÃO}

\section{1 Ângulo de Contato da Apatita-Ipirá Pré-tratada com Oleato de Sódio}

\subsubsection{Método da ascensão capilar (tensiômetro)}

A determinação do ângulo de contato $(\theta)$ pela percolação de líquidos através de leito de partículas demanda prévio conhecimento do valor da constante $\mathrm{c}$, de acordo com a equação de Washburn (Eq. 33):

$$
\frac{m^{2}}{t}=\frac{c \rho^{2} \gamma_{L G} \cos \theta}{\eta}
$$

Para que a constante c possa ser determinada pela equação de Washburn é necessário utilizar um líquido capaz de molhar completamente as partículas, isto é, que seja satisfeita a condição $\theta=0^{\circ}$.

Uma vez que era necessário realizar determinações de $\theta$ utilizando partículas de apatita com (5-75mg/L) e sem (0mg/L) prévia adsorção de oleato de sódio, optouse por determinar o parâmetro c com partículas de apatita "in natura", isto é, sem prévia adsorção de oleato. Para satisfazer a condição $\theta=0^{\circ}$, trabalhou-se com:

i. Água deionizada, em virtude da hidrofilicidade natural apresentada pelo mineral apatita (MARTINS, 2004);

ii. Hexano, o qual é indicado na literatura por apresentar uma baixa energia livre superficial: $\gamma$ LV $=18,4 \mathrm{erg} / \mathrm{cm}^{2}$ (RULLISON, 1996?).

Os valores da constante $\mathrm{c}$ obtidos pela percolação de água e hexano no leito de partículas de apatita-Ipirá "in natura" são apresentados na Tab 14. Embora se tenha visualmente observado que ambos os líquidos molharam as partículas, saturando completamente o leito, pode-se verificar na Tab. 14 que a velocidade de 
ascensão da água é da ordem de $20 \%$ maior que a do hexano, ocasionando um valor mais alto para a constante $\mathrm{c}$.

Tabela 14 - Valores de c obtidos com hexano e com água deionizada $\left(20,0 \pm 0,2^{\circ} \mathrm{C}\right)$.

\begin{tabular}{c|c|c}
\hline \hline Líquido & $\begin{array}{c}\text { Velocidade de ascensão do líquido }\left(\mathbf{x 1 0 ^ { - 2 }}\right), \\
\mathbf{c m} / \mathbf{s}\end{array}$ & $\begin{array}{c}\text { Constante } \mathbf{c}\left(\mathbf{x 1 0 ^ { - 6 }}\right), \\
\mathbf{c m}^{\mathbf{5}}\end{array}$ \\
\hline \hline Hexano & $11,38 \pm 0,28$ & $7,4404 \pm 0,0499$ \\
\hline Água & $13,79 \pm 0,01$ & $9,2198 \pm 0,0741$ \\
\hline \hline
\end{tabular}

Nota: Os desvios apresentados correspondem ao desvio padrão resultante de uma série de três medidas em cada condição experimental (APÊNDICE 2).

A maior velocidade de percolação da água através do leito de partículas $\left(\sim 1,4 \times 10^{-3} \mathrm{~cm} / \mathrm{s}\right)$ comparada com a do hexano $\left(\sim 1,1 \times 10^{-3} \mathrm{~cm} / \mathrm{s}\right)$ indica uma mais intensa interação água/apatita versus hexano/apatita, visto que:

i. A adesão água/apatita e espalhamento de tal líquido sobre o mesmo mineral ocorreriam por decorrência de interações dispersivas e não dispersivas, conforme discutido na seção 1.3.2;

ii. A adesão hexano/apatita, "mutatis mutandis", somente por interações de natureza dispersiva.

Conhecendo-se as magnitudes de c (Tab 14), tornou-se possível realizar a determinação do ângulo de contato de avanço $\left(\theta_{\mathrm{a}}\right)$ entre água deionizada e as amostras de apatita-Ipirá pré-tratadas com oleato de sódio. Os valores de $\theta_{\mathrm{a}}$ obtidos, utilizando-se as constantes medidas com água $\left(c_{a}\right)$ e com hexano $\left(c_{h}\right)$, são apresentados na Tab. 15.

Tabela 15 - Ângulo de contato de avanço de água sobre apatita-Ipirá em função da concentração de oleato de sódio e da constante c $\left(20,0 \pm 0,0^{\circ} \mathrm{C}\right)$.

\begin{tabular}{c|c|c}
\hline \hline \multirow{2}{*}{$\begin{array}{c}\text { Oleato de sódio } \\
(\mathbf{m g} / \mathbf{L})\end{array}$} & \multicolumn{2}{|c}{ Ângulo de contato de avanço (graus) } \\
\cline { 2 - 3 } & $\mathbf{c}_{\mathrm{a}} \mathbf{= 9 , 2 1 9 8 . 1 0 ^ { - 6 } \mathbf { c m } ^ { \mathbf { 5 } }}$ & $\mathbf{c}_{\mathbf{h}}=\mathbf{7 , 4 4 0 4 . 1 0 ^ { - 6 } \mathbf { c m } ^ { \mathbf { 5 } }}$ \\
\hline 0 & $6,1 \pm 0,9$ & - \\
\hline 5 & $41,0 \pm 1,2$ & $20,6 \pm 2,9$ \\
\hline 15 & $62,5 \pm 0,7$ & $55,1 \pm 0,9$ \\
\hline 25 & $77,0 \pm 0,5$ & $73,9 \pm 0,6$ \\
\hline 75 & $89,9 \pm 0,0$ & $89,9 \pm 0,0$ \\
\hline \hline
\end{tabular}

Nota: Os desvios apresentados correspondem ao desvio padrão resultante de uma série de três medidas em cada condição experimental (APÊNDICE 3). 
Observa-se na Tab. 15 que:

i. Para partículas que não sofreram prévia adsorção de oleato de sódio (0mg/L), o valor de $\theta_{\mathrm{a}}$ não pôde ser determinado ao se utilizar a constante determinada com hexano $\left(c_{h}\right)$, uma vez que, nesta condição experimental, a água percola o leito com uma velocidade maior que a do hexano (Tab.14);

ii. Os valores de ângulo de contato obtidos com $c_{a}$ são maiores que aqueles obtidos com $\mathrm{c}_{\mathrm{h}}$ e as diferenças diminuem à medida que se aumenta a concentração de oleato de sódio de $0 \mathrm{mg} / \mathrm{L}$ até $75 \mathrm{mg} / \mathrm{L}$. Tal comportamento, em conjunto com a constatação realizada em (i), sugere que o hexano somente é indicado para ser utilizado na determinação da constante c de sólidos que apresentam caráter hidrofóbico mais pronunciado (sólidos de baixa energia), como é o caso das partículas de apatita condicionadas com $25-75 \mathrm{mg} / \mathrm{L}$ de oleato de sódio. Para sólidos que exibem menor caráter hidrofóbico, como é o caso da apatita "in natura" (sem prévia adsorção de oleato de sódio), o uso da água para determinar a constante c é mais adequado;

iii. Independentemente do líquido utilizado na determinação da constante c, a magnitude de $\theta_{\mathrm{a}}$ cresceu de aproximadamente $0^{\circ}$ a valores próximos de $90^{\circ}$ quando se aumentou a concentração de oleato de sódio de $0 \mathrm{mg} / \mathrm{L}$ para $75 \mathrm{mg} / \mathrm{L}$ nos ensaios de adsorção executados em etapa prévia à determinação de $\theta_{\mathrm{a}}$;

iv. Com base na constatação exarada no item (iii), pode-se afirmar que existe uma relação de causa-efeito entre um aumento da concentração de oleato de sódio (no tratamento da superfície da apatita antes da determinação de $\theta_{\mathrm{a}}$ ) e aumento da hidrofobicidade desse mineral, evidenciada pelo aumento da magnitude de $\theta_{\mathrm{a}}$. Este comportamento é ilustrado na Fig. 22;

v. A adsorção de oleato de sódio em apatita foi capaz de transformar seu caráter naturalmente hidrofílico $\left(\theta_{\mathrm{a} .} \sim 0^{\circ}\right)$ em hidrofóbico $\left(\theta_{\mathrm{a} \cdot}>0^{\circ}\right)$, fazendo jus à denominação de agente coletor. 


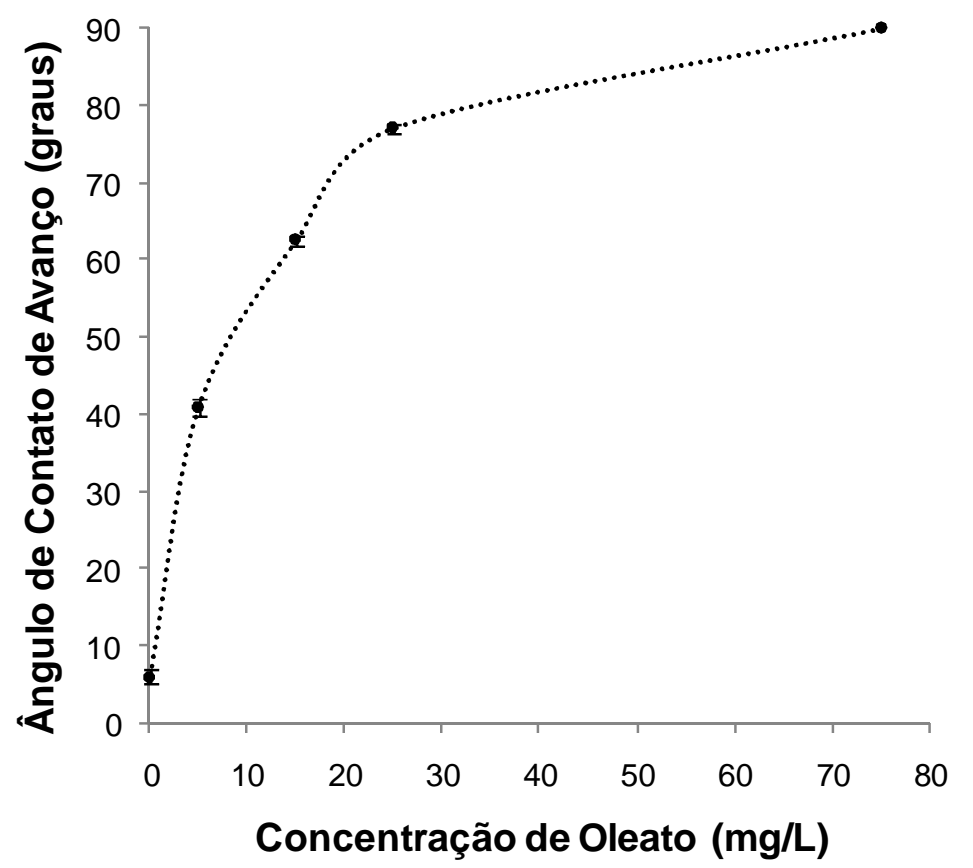

Figura 22 - Ângulo de contato de avanço da água deionizada sobre partículas de apatitaIpirá em função da concentração de oleato $\left(20,0 \pm 0,0{ }^{\circ} \mathrm{C}\right)$

A transformação do caráter naturalmente hidrofílico da apatita em hidrofóbico como conseqüência da interação entre suas partículas e oleato de sódio é corroborada não somente pelo aumento do ângulo de contato versus concentração de coletor (Tab. 16, Fig. 22), mas também por:

i. Menores trabalhos de adesão $\left(\mathrm{W}_{\mathrm{a}}\right)$ entre água e apatita (Tab. 16, Fig 23), calculados através da Eq. (21);

ii. Valores mais negativos para o coeficiente de espalhamento da água sobre apatita (Tab. 16, Fig. 24), calculados através da Eq. (22);

Torna-se importante ressaltar que os desvios apresentados para os valores de $W_{\mathrm{a}}\left(\sigma_{\mathrm{Wa}}\right)$ e $\mathrm{S}\left(\sigma_{\mathrm{S}}\right)$ correspondem à propagação dos desvios-padrões das variáveis $\gamma_{\mathrm{LV}}\left(\sigma_{\gamma}\right)$ e $\theta_{\mathrm{a}}\left(\sigma_{\theta}\right)$, calculados a partir das Eqs. (54) e (55), respectivamente.

$$
\sigma_{\mathrm{Wa}}=\sqrt{\sigma_{\gamma}^{2}(1+\cos [\theta])^{2}+\gamma^{2} \sigma_{\theta}^{2} \operatorname{sen}[\theta]^{2}}
$$




$$
\sigma_{\mathrm{S}}=\sqrt{\sigma_{\gamma}^{2}(-1+\cos [\theta])^{2}+\gamma^{2} \sigma_{\theta}^{2} \operatorname{sen}[\theta]^{2}}
$$

Tabela 16 - Ângulo de contato $\left(\theta_{a}\right)$, trabalho de adesão $\left(W_{a}\right)$ e coeficiente de espalhamento (S) de água sobre apatita-Ipirá em função da concentração de oleato de sódio utilizada na adsorção $\left(20,0 \pm 0,0^{\circ} \mathrm{C}\right)$.

\begin{tabular}{c|c|c|c}
\hline \hline $\begin{array}{c}\text { Oleato de sódio } \\
(\mathbf{m g} / \mathbf{L})\end{array}$ & $\begin{array}{c}\text { Ângulo de contato de } \\
\text { avanço (graus) }\end{array}$ & $\begin{array}{c}\mathbf{W}_{\mathbf{a}} \\
\left(\mathbf{e r g} / \mathbf{c m}^{2}\right)\end{array}$ & $\begin{array}{c}\mathbf{S} \\
\left(\mathbf{e r g} / \mathbf{c m}^{2}\right)\end{array}$ \\
\hline \hline 0 & $6,1 \pm 0,9$ & $145,2 \pm 0,1$ & $-0,4 \pm 0,1$ \\
\hline 5 & $41,0 \pm 1,2$ & $127,8 \pm 1,0$ & $-17,9 \pm 1,0$ \\
\hline 15 & $62,5 \pm 0,7$ & $106,4 \pm 0,8$ & $-39,2 \pm 0,8$ \\
\hline 25 & $77,0 \pm 0,5$ & $89,1 \pm 0,6$ & $-56,5 \pm 0,6$ \\
\hline 75 & $89,9 \pm 0,0$ & $72,9 \pm 0,0$ & $-72,7 \pm 0,0$ \\
\hline \hline
\end{tabular}

Nota: Os desvios apresentados para $\theta_{\mathrm{a}}$ correspondem ao desvio padrão resultante de uma série de três medidas em cada condição experimental (APÊNDICE 3).

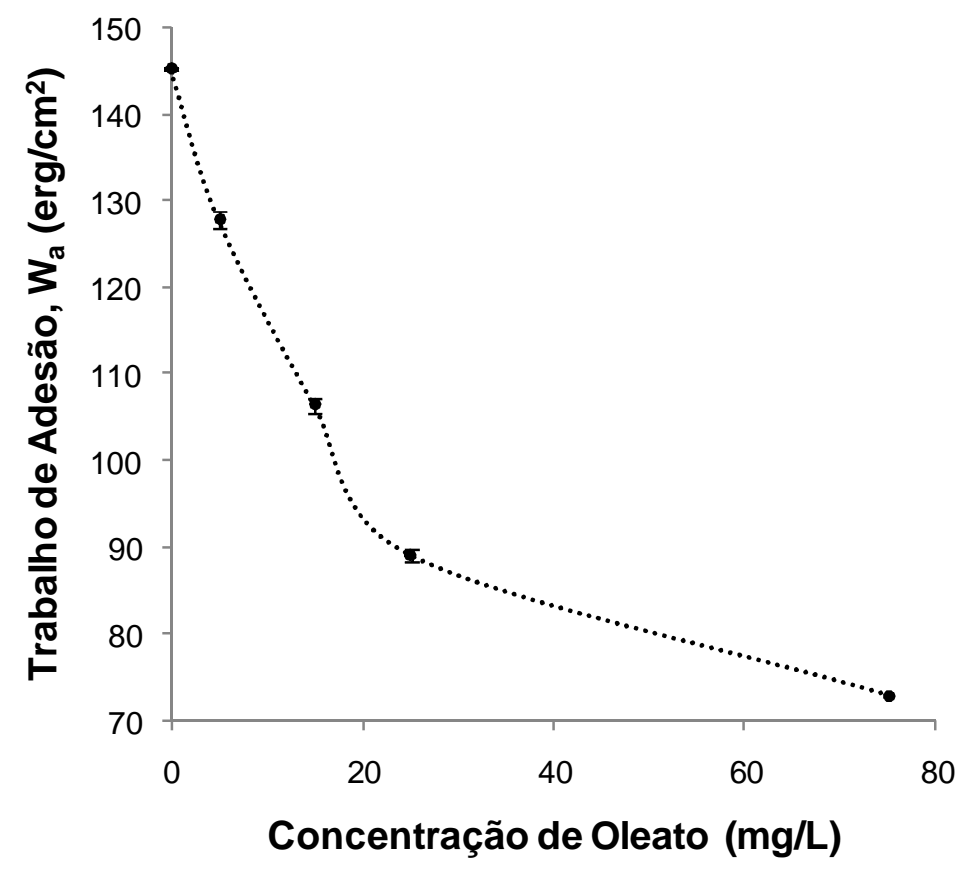

Figura 23 - Trabalho de adesão da água sobre apatita-Ipirá versus concentração de oleato de sódio utilizada na adsorção $\left(20,0 \pm 0,0^{\circ} \mathrm{C}\right)$. 


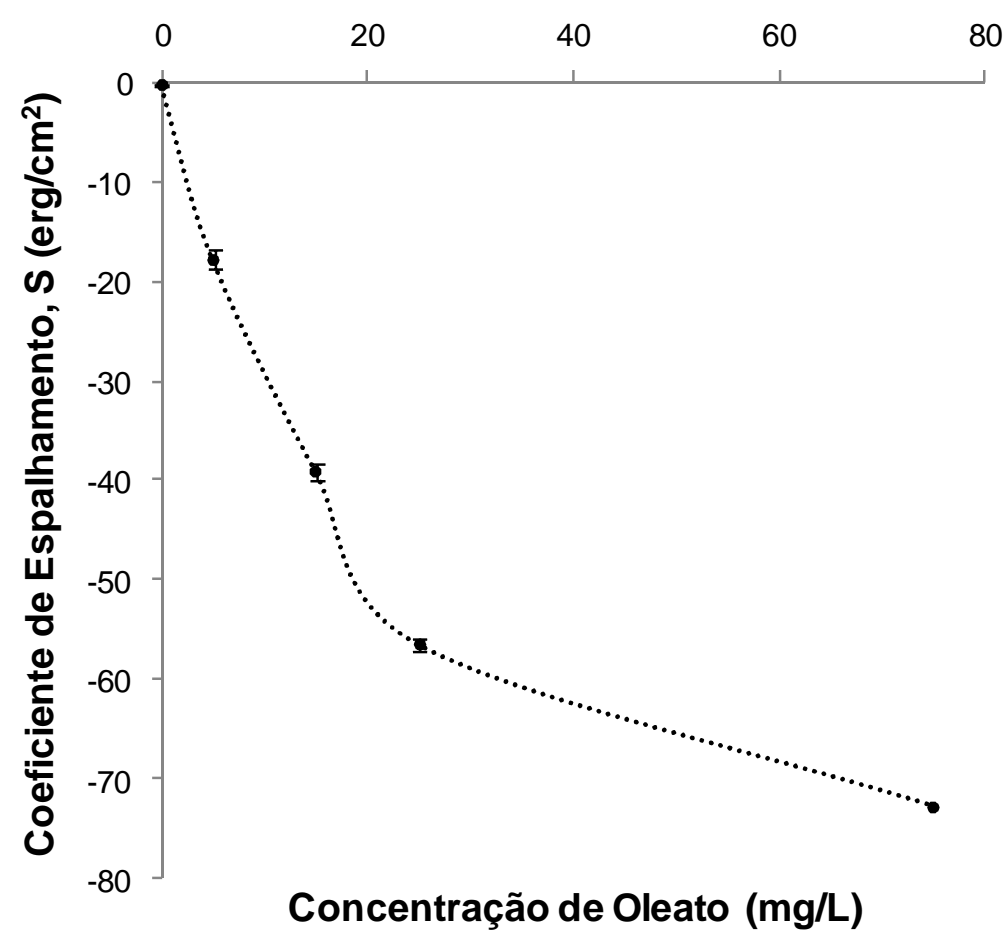

Figura 24 - Coeficiente de espalhamento da água sobre apatita-Ipirá versus concentração de oleato de sódio utilizada na adsorção $\left(20,0 \pm 0,0^{\circ} \mathrm{C}\right)$.

Observa-se nas figuras 23 e 24 que a superfície do mineral apatita, à medida que sofre crescente acúmulo de espécies oleato (adsorção), exibe tendência de se comportar como se fosse a superfície de um sólido de baixa energia, como a parafina $\left(\mathrm{Wa}=47 \mathrm{erg} / \mathrm{cm}^{2} ; \mathrm{S}=-98 \mathrm{erg} / \mathrm{cm}^{2}\right)$.

\subsubsection{Método da bolha cativa (goniômetro de contato)}

Através do método da bolha cativa foram determinados os valores de ângulo de contato de avanço para os planos basal (001) e frontal (010) apresentados pelo cristal de apatita-Ipirá, em função da concentração de oleato de sódio utilizada em seu pré-tratamento. Os resultados são apresentados na Tab. 17 e Fig. 25, enquanto os resultados de $\mathrm{W}_{\mathrm{a}}$ e S são apresentados nas Figs. 26 e 27. 
Tabela 17 - Ângulo de contato entre água e os planos basal e frontal do cristal de apatitaIpirá, em função da concentração de oleato de sódio utilizada na adsorção $\left(20^{\circ} \mathrm{C}\right)$.

\begin{tabular}{c|c|c|c}
\hline \multirow{2}{*}{ Oleato (mg/L) } & \multirow{2}{*}{ Oleato (mol/L) } & \multicolumn{2}{|c}{$\theta_{\mathrm{a}}$ (graus) } \\
\cline { 3 - 4 } & & Plano basal (001) & Plano frontal (010) \\
\hline \hline 0 & 0,0 & $0,0 \pm 0,0$ & $0,0 \pm 0,0$ \\
\hline 5 & $1,8 \times 10^{-5}$ & $23,8 \pm 1,3$ & $49,2 \pm 1,4$ \\
\hline 15 & $5,4 \times 10^{-5}$ & $33,6 \pm 0,6$ & $63,3 \pm 0,2$ \\
\hline 25 & $9,0 \times 10^{-5}$ & $60,6 \pm 0,3$ & $69,6 \pm 0,2$ \\
\hline 75 & $2,7 \times 10^{-4}$ & $68,5 \pm 0,3$ & $81,7 \pm 0,4$ \\
\hline \hline
\end{tabular}

Nota: Os desvios apresentados correspondem ao desvio padrão resultante de uma série de três medidas em cada condição experimental (APÊNDICE 3).

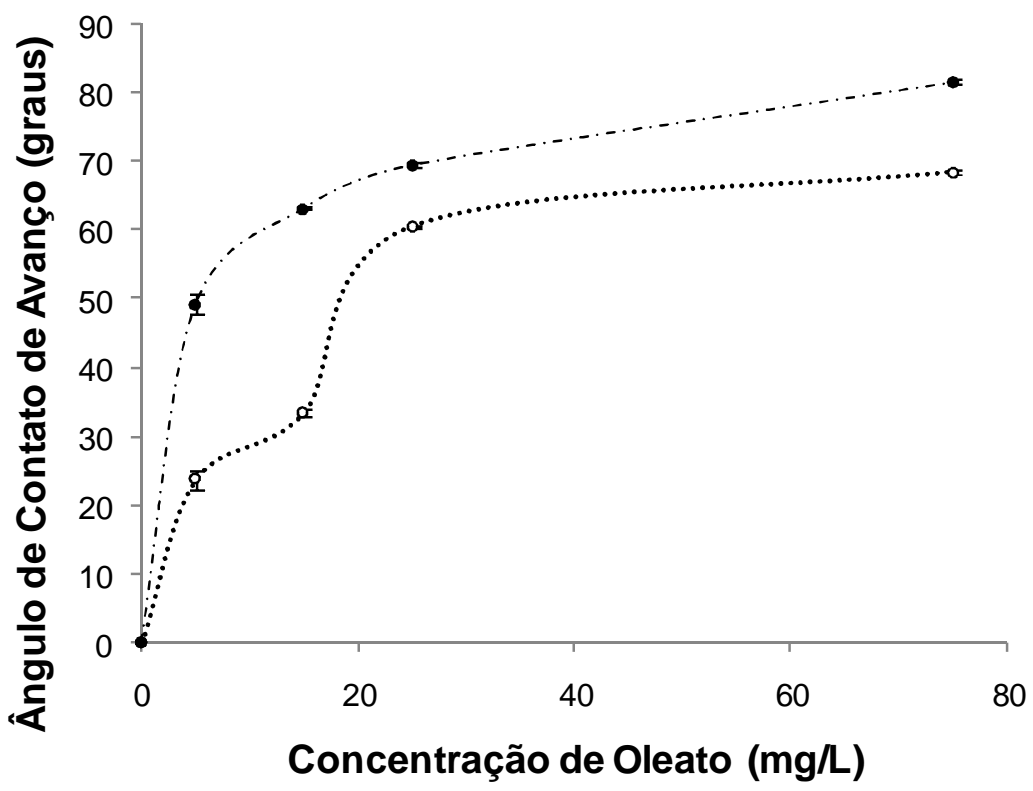

Plano basal $\quad \cdots \rightarrow$ Plano frontal

Figura 25 - Ângulo de contato de avanço da água sobre planos basal e frontal do cristal de apatita-Ipirá, em função da concentração de oleato de sódio $\left(20^{\circ} \mathrm{C}\right)$. 


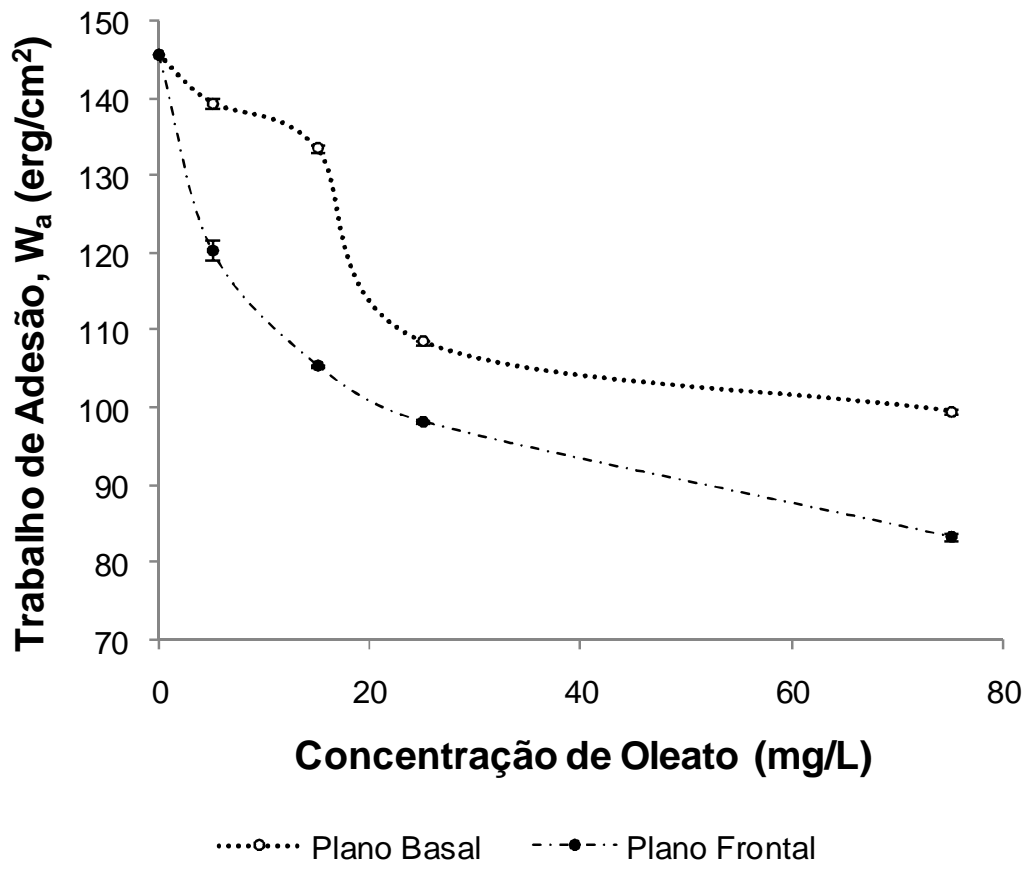

Figura 26 - Trabalho de adesão da água nos planos basal e frontal do cristal de apatitaIpirá, em função da concentração de oleato de sódio $\left(20^{\circ} \mathrm{C}\right)$.

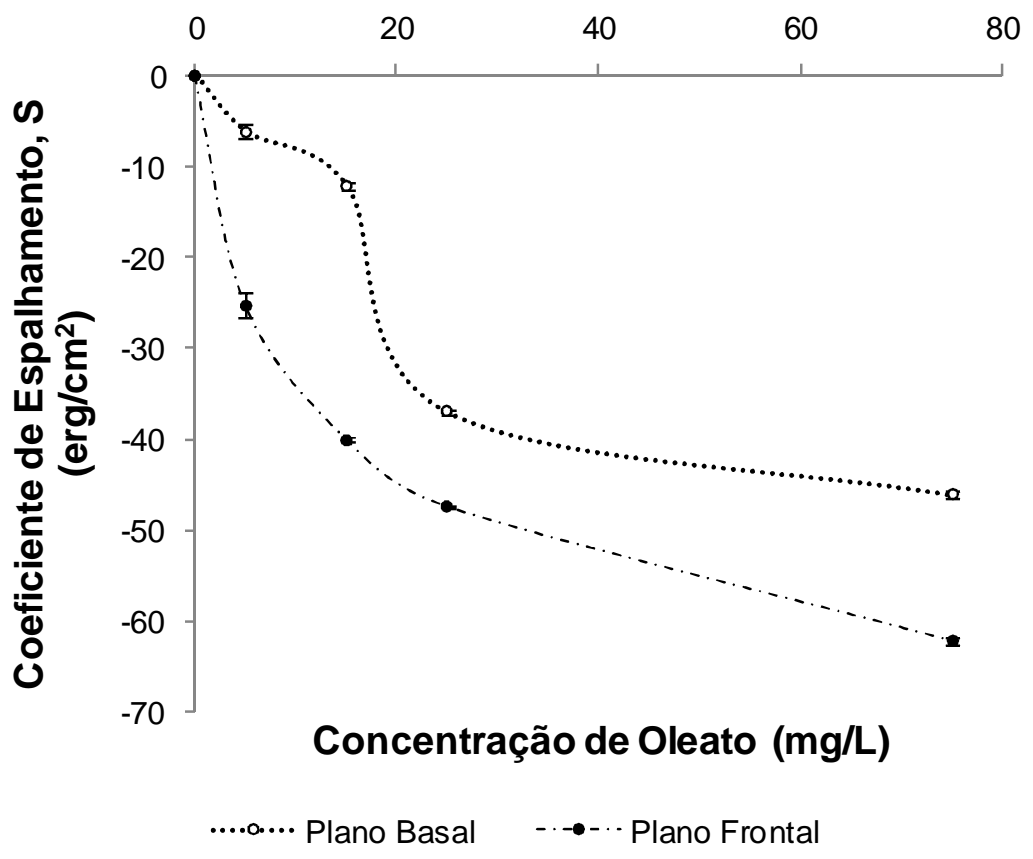

Figura 27 - Coeficiente de espalhamento da água sobre planos basal e frontal do cristal de apatita-Ipirá, em função da concentração de oleato de sódio $\left(20^{\circ} \mathrm{C}\right)$. 
Verifica-se na Tab. 17 e nas Figs. 25 a 27 que:

i. O experimento realizado sem a prévia adsorção de oleato de sódio (concentração $=0 \mathrm{mg} / \mathrm{L}$ ) comprovou a hidrofilicidade natural do mineral apatita. Segundo os valores obtidos: $\theta=0^{\circ}, \mathrm{W}_{\mathrm{a}}=\mathrm{W}_{\mathrm{c}}=2 \times 72,9 \mathrm{erg} / \mathrm{cm}^{2}=$ $145,8 \mathrm{erg} / \mathrm{cm}^{2}$ e $\mathrm{S}=0$, a água se espalha espontaneamente sobre os planos basal e frontal do cristal de apatita, molhando-os completamente;

ii. A magnitude de $\theta$ cresce com o aumento da concentração de oleato de sódio utilizada no pré-tratamento da superfície da apatita, independentemente de o plano ser basal ou frontal. Os valores de $\mathrm{W}_{\mathrm{a}}$ se tornam menores, enquanto os de $S$ mais negativos. Em ambos os casos, as faces (001) e (010) do cristal de apatita apresentam tendência de se comportarem como se fossem a superfície de um sólido de baixa energia, como a parafina $\left(\mathrm{Wa}=47 \mathrm{erg} / \mathrm{cm}^{2} ; \mathrm{S}=-98 \mathrm{erg} / \mathrm{cm}^{2}\right)$.

iii. Os valores de ângulo de contato determinados para o plano basal são menores que os determinados para o plano frontal em todas as concentrações de oleato de sódio utilizadas no pré-tratamento da superfície do cristal;

iv. Após condicionamento com oleato de sódio, mediram-se maiores ângulos de contato sobre o plano frontal do que sobre o plano basal. Tais resultados indicam que o coletor adsorveu preferencialmente sobre a orientação cristalográfica (010) em detrimento da (001), promovendo um caráter hidrofóbico mais pronunciado no plano frontal em comparação com o plano basal. Martins (2004), utilizando a técnica da bolha cativa para a medição do ângulo de contato, observou a mesma tendência com a apatita proveniente de Cajati;

De acordo com o que informa a Eq. 56, para que ocorra a precipitação do oleato de cálcio, é necessário que a concentração de cálcio em solução multiplicada pelo quadrado da concentração do ânion oleato seja maior que o produto de solubilidade do oleato de cálcio ( $\mathrm{pKps}=-15,60$, de acordo com Fuerstenau e Chander (1986)).

$$
\left[\mathrm{Ca}^{2+}\right] \times[\mathrm{RCOO}]^{2}>2,51 \times 10^{-16}
$$


No pré-tratamento do cristal de apatita com oleato de sódio, o cristal era imerso em solução $(\mathrm{pH}=10,5)$ que continha o ânion oleato na concentração desejada, condicionando-se por 1 minuto. Imaginemos que neste curtíssimo intervalo de tempo a dissolução do cristal de apatita fosse capaz de fazer com que a concentração de cálcio na solução chegasse a $5 \times 10^{-8} \mathrm{M}$. Uma vez que a concentração de oleato variou entre $5,0 \mathrm{mg} / \mathrm{L}\left(1,8 \times 10^{-5} \mathrm{M}\right)$ e $75 \mathrm{mg} / \mathrm{L}\left(2,7 \times 10^{-4} \mathrm{M}\right)$, então teríamos os valores dos produtos de solubilidade apresentados na Tab. 18, onde a precipitação de oleato de cálcio na interface apatita/solução seria mais provável de ocorrer nas concentrações mais altas $(25 \mathrm{mg} / \mathrm{L}$ e $75 \mathrm{mg} / \mathrm{L})$, mas não nas mais baixas (5mg/L e $15 \mathrm{mg} / \mathrm{L})$.

A literatura informa que o ânion oleato pode interagir com sítios cálcio que ocorrem na interface apatita/solução por quimissorção ou precipitação na superfície (FINKELSTEIN, 1989; LU, DRELICH, MILLER, 1998). Deste modo, espera-se que, para concentrações mais altas de coletor, a precipitação na superfície ocorra preferencialmente no plano (010) em detrimento do (001). Isto porque o plano frontal apresenta maior solubilidade que o basal, como reportou Tseng (2006). Os resultados apresentados na Fig. 25 corroboram esta tendência.

Tabela 18 - Previsão da precipitação de oleato de cálcio em solução a partir de uma concentração hipotética de cálcio de $\left[\mathrm{Ca}^{2+}\right]=5 \times 10^{-8} \mathrm{M}$.

\begin{tabular}{|c|c|c|c|}
\hline $\begin{array}{l}\text { Concentração de } \\
\text { Oleato (mg/L) }\end{array}$ & $\begin{array}{l}\text { Concentração } \\
\text { de oleato }(\mathrm{M})\end{array}$ & {$\left[\mathrm{Ca}^{2+}\right] \times\left[\mathrm{RCOO}^{-}\right]^{2}$} & $\begin{array}{l}\text { Previsão de } \\
\text { Precipitação }\end{array}$ \\
\hline 5 & $1,8 \times 10^{-5}$ & $1,6 \times 10^{-17}$ & $\begin{array}{l}1,6 \times 10^{-17}<2,5 \times 10^{-16} \\
\text { Não ocorre precipitação }\end{array}$ \\
\hline 15 & $5,4 \times 10^{-5}$ & $1,5 \times 10^{-16}$ & $\begin{array}{l}1,5 \times 10^{-16}<2,5 \times 10^{-16} \\
\text { Não ocorre precipitação }\end{array}$ \\
\hline 25 & $9,0 \times 10^{-5}$ & $4,1 \times 10^{-16}$ & $\begin{array}{l}4,1 \times 10^{-16}>2,5 \times 10^{-16} \\
\text { Ocorre precipitação }\end{array}$ \\
\hline 75 & $2,7 \times 10^{-4}$ & $3,6 \times 10^{-15}$ & $\begin{array}{l}3,6 \times 10^{-15}>2,5 \times 10^{-16} \\
\text { Ocorre precipitação }\end{array}$ \\
\hline
\end{tabular}

Por outro lado, uma vez que, para concentrações mais baixas de coletor, a interação oleato/apatita deve ocorrer predominantemente através do mecanismo de quimissorção; espera-se que o plano (001) apresente maior ângulo de contato do 
que o (010) após terem sido ambos pré-tratados com oleato de sódio, em virtude de o plano basal possuir maior densidade de íons cálcio do que o frontal (LU, DRELICH, MILLER, 1998). Nesta tese, talvez as concentrações de oleato utilizadas no pré-tratamento da apatita não foram suficientemente pequenas para corroborar este último mecanismo.

\subsubsection{Comparação dos métodos utilizados na determinação do ângulo de contato}

Na presente tese, dois métodos foram utilizados na determinação de ângulo de contato de avanço de água sobre amostras de apatita-Ipirá pré-tratadas com oleato de sódio:

i. $O$ método direto da bolha cativa (MBC), utilizado na determinação de $\theta_{a}$ dos planos basal (001) e frontal (010) apresentados pela apatita;

ii. $\quad$ método indireto da ascensão capilar (MAC), utilizado na determinação de $\theta_{\mathrm{a}}$ de partículas de apatita na faixa de $-140+44 \mu \mathrm{m}$.

Os resultados são apresentados na Tab. 19, a título de comparação.

Tabela 19 - Ângulos de contato de avanço de água sobre amostras de apatita pré-tratadas com oleato de sódio, determinados pelos métodos da ascensão capilar e da bolha cativa.

\begin{tabular}{c|c|c|c}
\hline \hline \multirow{2}{*}{$\begin{array}{c}\text { Concentração de } \\
\text { Oleato (mg/L) }\end{array}$} & \multirow{2}{*}{$\begin{array}{c}\theta_{\mathrm{a}} \text { (graus) - Método } \\
\text { da ascensão capilar }\end{array}$} & \multicolumn{2}{|c}{$\theta_{\mathrm{a}}$ (graus) - Método da bolha cativa } \\
\cline { 3 - 4 } & & Plano basal (001) & Plano frontal (010) \\
\hline \hline 0 & $6,1 \pm 0,9$ & $0,0 \pm 0,0$ & $0,0 \pm 0,0$ \\
\hline 5 & $41,0 \pm 1,2$ & $23,8 \pm 1,3$ & $49,2 \pm 1,4$ \\
\hline 15 & $62,5 \pm 0,7$ & $33,6 \pm 0,6$ & $63,3 \pm 0,2$ \\
\hline 25 & $77,0 \pm 0,5$ & $60,6 \pm 0,3$ & $69,6 \pm 0,2$ \\
\hline 75 & $89,9 \pm 0,0$ & $68,5 \pm 0,3$ & $81,7 \pm 0,4$ \\
\hline \hline
\end{tabular}

Nota: Os desvios apresentados correspondem ao desvio padrão resultante de uma série de três medidas em cada condição experimental (APÊNDICE 3). 
Nos experimentos realizados sem a prévia adsorção de oleato de sódio (concentração $=0 \mathrm{mg} / \mathrm{L}$ na Tab. 19), foram obtidos ângulos de $0^{\circ}$ com $0 \mathrm{MBC}$, independentemente da natureza do plano (basal ou frontal), e ângulos de $\sim 6^{\circ} \mathrm{com}$ o MAC. Também se observou, com a utilização do MAC, uma maior dificuldade de se obter ângulos próximos de zero, visto que pequenas variações de $\mathrm{m}^{2} / \mathrm{t}$ acarretam em grandes variações nas determinações de $\theta$ pela Eq. 33, haja vista os maiores desvios apresentados para os menores valores de $\theta_{a}$ obtidos pelo MAC. De fato, uma vez que $\cos 0^{\circ}=1,00$ e $\cos 10^{\circ}=0,99$, uma variação de $10^{\circ}$ no ângulo de contato é facilmente obtida com muito pequenas variações de $\mathrm{m}^{2} / \mathrm{t}$.

Ainda na Tab. 19 temos que:

i. Os valores de ângulo de contato obtidos pelo MBC tenderam a ser menores que aqueles obtidos pelo MAC, todavia é importante ressaltar que 0 último apresenta valor de $\theta$ relativo a todos os possíveis planos exibidos pelas partículas de apatita, enquanto o MBC informa a magnitude de $\theta$ em dois planos particulares;

ii. As magnitudes de $\theta_{\mathrm{a}}$ obtidas para o plano frontal através do MBC se assemelham mais àquelas obtidas para as partículas de apatita com o MAC. De fato, Leal Filho (1999) e Martins (2004) reportaram uma maior porcentagem de partículas de apatita apresentando predominantemente planos (010) com relação a planos (001) em uma dada distribuição granulométrica.

A diferença nos valores de ângulo de contato obtidos via MAC versus MBC pode ser devida às diferenças inerentes dos métodos de determinação empregados, conforme exposto a seguir:

i. Apesar das amostras de apatita apresentarem a mesma procedência (Ipirá), o MBC demandou um cristal com superfícies planas e cuidadosamente polidas, enquanto no MAC foram utilizadas partículas que apresentavam superfície irregular, podendo acarretar em maior histerese de ângulo de contato;

ii. No MBC, os ângulos de contato foram determinados em planos cristalográficos definidos (basal e frontal) apresentando uma área 
superficial exposta muito menor que a dos diversos planos expostos das partículas de apatita utilizadas no MAC;

iii. No MBC, a superfície da apatita já se encontrava em contato com o meio aquoso quando recebeu uma bolha de ar para ser executada a medida de $\theta_{\mathrm{a}}$; enquanto que no MAC, o avanço da água sobre o leito de partículas desloca a fase gasosa dos capilares, molhando uma superfície outrora seca.

Gutierrez-Rodriguez (apud KISSA, 1999), realizando medidas de ângulo de contato em carvão, indicou a existência de três tipos de sítios superficiais: fortemente hidrofóbicos, fracamente hidrofóbicos e hidrofílicos. Kissa (1999) comparou o MBC ao Método da Gota Séssil (MGS), que apresenta similaridade com o MAC, visto que, em ambos os métodos, a fase aquosa avança sobre uma fase sólida que estava em prévio contato com o ar. Seguindo a argumentação de Kissa (1999), temos:

i. No caso do MAC (análogo ao MGS), a percolação da água através de um leito de partículas secas sofrerá a influência dos três tipos de sítios (fortemente hidrofóbicos, fracamente hidrofóbicos e hidrofílicos), resultando em mais altos valores de $\theta_{\mathrm{a}}$;

ii. No caso do MBC, uma vez que a superfície do sólido já estava previamente em contato com a água, alguma umidade residual em torno de sítios fracamente hidrofóbicos facilitaria o avanço do líquido (água) sobre a superfície da partícula, resultando em menores valores de $\theta_{\mathrm{a}}$.

Os valores de ângulo de contato apresentados na Tab. 19, embora distintos em função do método empregado em sua medida (MBC) ou determinação (MAC), fornecem importantes informações a respeito da molhabilidade:

i. $\quad \mathrm{OMBC}$ permitiu o conhecimento da magnitude de $\theta_{\mathrm{a}}$ para os planos basal (001) e frontal (010) do cristal de apatita, possibilitando avaliar a diferença de molhabilidade apresentada por ambos;

ii. O MAC permitiu a determinação de $\theta_{a}$ de uma população de partículas de apatita que apresentavam tamanho $(-140+44 \mu \mathrm{m})$ típico da alimentação da flotação em circuitos industriais brasileiros. Mais ainda, uma vez que o valor de $\theta_{\mathrm{a}}$ determinado pelo MAC se refere a todos os planos 
apresentados por uma população de partículas, o conhecimento de $\theta_{a}$ medido por tal método possibilita avaliar a molhabilidade da apatita em condições experimentais mais próximas da prática industrial.

\subsection{Flotabilidade da Apatita-Ipirá}

A resposta à flotação apresentada pela apatita-Ipirá em função da concentração e oleato de sódio foi investigada através de ensaios de microflotação. Os resultados são apresentados na Tab. 20, onde se pode observar que:

Tabela 20 - Flotabilidade de apatita-Ipirá em função da concentração de oleato de sódio $\left(\mathrm{pH}=10,5\right.$ e $\left.25^{\circ} \mathrm{C}\right)$.

\begin{tabular}{c|c}
\hline \hline Concentração de Oleato $(\mathbf{m g} / \mathbf{L})$ & Flotabilidade (\%) \\
\hline 0 & $3 \pm 0$ \\
\hline 5 & $35 \pm 2$ \\
\hline 15 & $55 \pm 3$ \\
\hline 25 & $71 \pm 1$ \\
\hline 50 & $80 \pm 3$ \\
\hline 75 & $90 \pm 2$ \\
\hline \hline
\end{tabular}

Nota: Os desvios apresentados correspondem ao desvio padrão resultante de uma série de três medidas em cada condição experimental.

i. Na ausência do coletor, a apatita apresentou baixa flotabilidade (3\%). Sabendo-se que em tal condição o mineral apresenta $\theta_{\mathrm{a}}$ próximo de zero (Tab. 16), a baixa resposta à flotação pode ser explicada pelo arraste hidrodinâmico;

ii. A flotabilidade de apatita cresceu com o aumento da concentração de oleato de sódio, atingindo um valor máximo de $90 \%$ quando se executou a microflotação com uma concentração de coletor de $75 \mathrm{mg} / \mathrm{L}$. Nesta concentração, o ângulo de contato da apatita era de $90^{\circ}$ (Tab. 16);

iii. A baixíssima molhabilidade das partículas de apatita $\left(\theta \sim 90^{\circ}\right.$; $\mathrm{W}_{\mathrm{a}}=72,9 \mathrm{erg} / \mathrm{cm}^{2}$ e $\mathrm{S}=-72,7 \mathrm{erg} / \mathrm{cm}^{2}$ ) na presença de $75 \mathrm{mg} / \mathrm{L}$ de oleato de sódio, aliada a condições hidrodinâmicas (LEAL FILHO et al., 2006) 
adequadas ao tamanho das mesmas $(-104 \mu \mathrm{m}+44 \mu \mathrm{m})$ durante os ensaios de microflotação, contribuíram para a obtenção de uma flotabilidade de $90 \%$.

O comportamento da flotabilidade da apatita versus ângulo de contato de avanço determinado pelo método de ascensão capilar é ilustrado na Fig. 28, onde se pode verificar uma relação de causa-efeito entre altos ângulos de contato e alta flotabilidade.

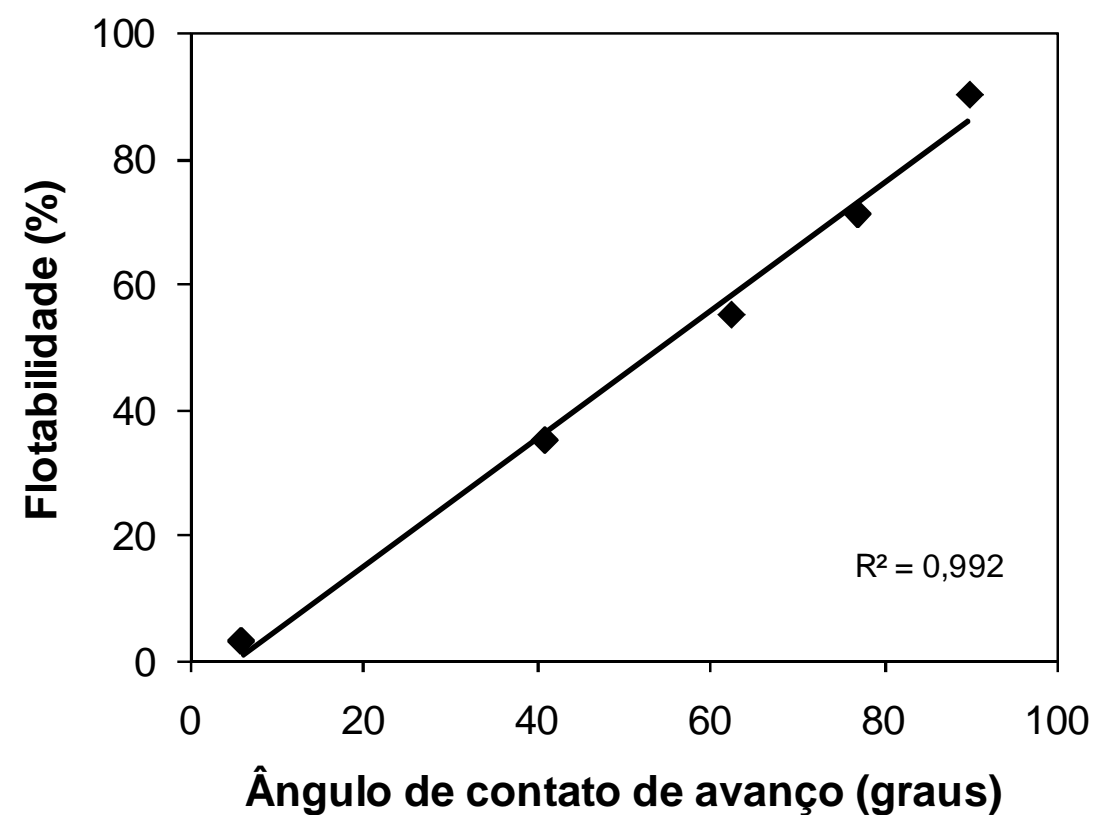

Figura 28 - Flotabilidade da apatita Ipirá versus ângulo de contato de avanço.

\subsection{Tensão Superficial Crítica de Molhabilidade da Apatita-Ipirá Pré- tratada com Oleato de Sódio}

Os valores de ângulo de contato, molhabilidade e flotabilidade da apatita em função da concentração e oleato de sódio (seções 3.1 e 3.2) mostraram que: 
i. À medida que se aumenta a concentração do coletor na solução (de 0mg/L a $75 \mathrm{mg} / \mathrm{L})$, aumenta-se sua concentração na interface apatita/solução (adsorção positiva);

ii. Ao aumentar paulatinamente a adsorção do coletor na interface apatita/solução, em função do aumento da concentração do mesmo na solução; provoca-se uma diminuição gradual da molhabilidade das partículas do mineral, que tende a valores que caracterizam sólidos de baixa energia, como a parafina;

iii. A baixa molhabilidade das partículas de apatita provocada pela adsorção de oleato de sódio, aliada a condições hidrodinâmicas adequadas à colisão, adesão e preservação do agregado partícula bolha conduzem a alta flotabilidade em ensaios de microflotação.

Com base nas informações apresentadas e discutidas no parágrafo anterior, pode-se erroneamente deduzir que aumentos na concentração de oleato de sódio sempre acarretarão em aumento de recuperação de apatita, desde que se trabalhe em concentração inferior à concentração crítica de formação de micelas do coletor. O erro de raciocínio se baseia no fato de que coletores de cadeia longa, como o oleato de sódio, adsorvem não somente na interface mineral/solução, mas também na interface ar/solução, reduzindo consideravelmente a magnitude de $\gamma$ LV. Como se viu na seção 1.2, se a magnitude de $\gamma_{L V}$ for reduzida para valores abaixo de certo valor crítico denominado "tensão superficial crítica de molhabilidade", a solução tende a molhar o mineral, revertendo a tendência de redução da molhabilidade através do aumento da concentração de coletor na interface mineral/solução.

Os valores de ângulo de contato de avanço $\left(\theta_{\mathrm{a}}\right)$ apresentados na seção 3.1 foram obtidos utilizando-se água deionizada sem a presença de coletor, que havia sido utilizado somente no pré-tratamento da superfície da apatita. Tal modus operandi, todavia, não traduz a realidade de um experimento de flotação, onde a solução apresenta energia livre superficial por unidade de área $(\gamma\llcorner v)$ inferior à da água pura na mesma temperatura. Isto ocorre porque o processo é conduzido com água que contém espécies coletoras em solução. Deste modo, torna-se importante 
avaliar a influência da energia livre superficial por unidade de área da fase líquida $(\gamma \mathrm{LV})$ sobre a magnitude de $\theta_{\mathrm{a}}$.

Ângulos de contato de avanço $\left(\theta_{\mathrm{a}}\right)$ foram determinados pelo método da bolha cativa nos planos basal e frontal do cristal de apatita-Ipirá em função de $\gamma_{\mathrm{LV}}$ de soluções água/metanol preparadas em várias concentrações. Antes da execução dessas medidas, o cristal de apatita tinha sido condicionado com oleato de sódio (75mg/L) por 1 minuto. Os resultados são apresentados na Tab. 21 e Fig. 29, onde se pode verificar que a magnitude de $\theta_{\mathrm{a}}$ decresce com a diminuição de $\gamma_{\mathrm{LV}}$ da fase líquida tanto para o plano basal quanto para o frontal do cristal de apatita, como previsto por Zisman (1964). Observa-se também que, a partir de um determinado valor de $\gamma_{\mathrm{LV}}$ - denominado tensão crítica de molhabilidade $\left(\gamma_{\mathrm{C}}\right)$ - a fase líquida passa a molhar completamente a superfície da apatita, ou seja, $\theta=0^{\circ}$.

Tabela 21 - Ângulo de contato dos planos basal e frontal do cristal de apatita-Ipirá (prétratados com oleato $=75 \mathrm{mg} / \mathrm{L})$, em função da energia livre superficial da fase líquida $\left(20^{\circ} \mathrm{C}\right)$.

\begin{tabular}{c|c|c|c}
\hline \hline \multicolumn{2}{c|}{ Solução água/metanol } & \multicolumn{2}{c}{ Ângulo de contato de avanço (graus) } \\
\hline$\%$ metanol & $\gamma_{\text {Lv }}\left(\mathbf{e r g} / \mathbf{c m}^{2}\right)$ & Plano basal (001) & Plano frontal (010) \\
\hline \hline 0,0 & $72,86 \pm 0,02$ & $68,5 \pm 0,3$ & $81,7 \pm 0,4$ \\
\hline 1,0 & $70,90 \pm 0,02$ & $65,9 \pm 0,1$ & $78,0 \pm 0,1$ \\
\hline 9,8 & $59,17 \pm 0,03$ & $56,9 \pm 0,2$ & $67,5 \pm 0,1$ \\
\hline 27,0 & $46,25 \pm 0,06$ & $40,5 \pm 0,1$ & $48,1 \pm 0,2$ \\
\hline 48,0 & $38,81 \pm 0,05$ & $28,4 \pm 0,1$ & $33,5 \pm 0,2$ \\
\hline 75,0 & $30,75 \pm 0,07$ & $0,0 \pm 0,0$ & $0,0 \pm 0,0$ \\
\hline 100,0 & $22,83 \pm 0,06$ & $0,0 \pm 0,0$ & $0,0 \pm 0,0$ \\
\hline \hline
\end{tabular}

Nota: Os desvios apresentados correspondem ao desvio padrão resultante de uma série de três medidas em cada condição experimental (APÊNDICES 1 e 3). 


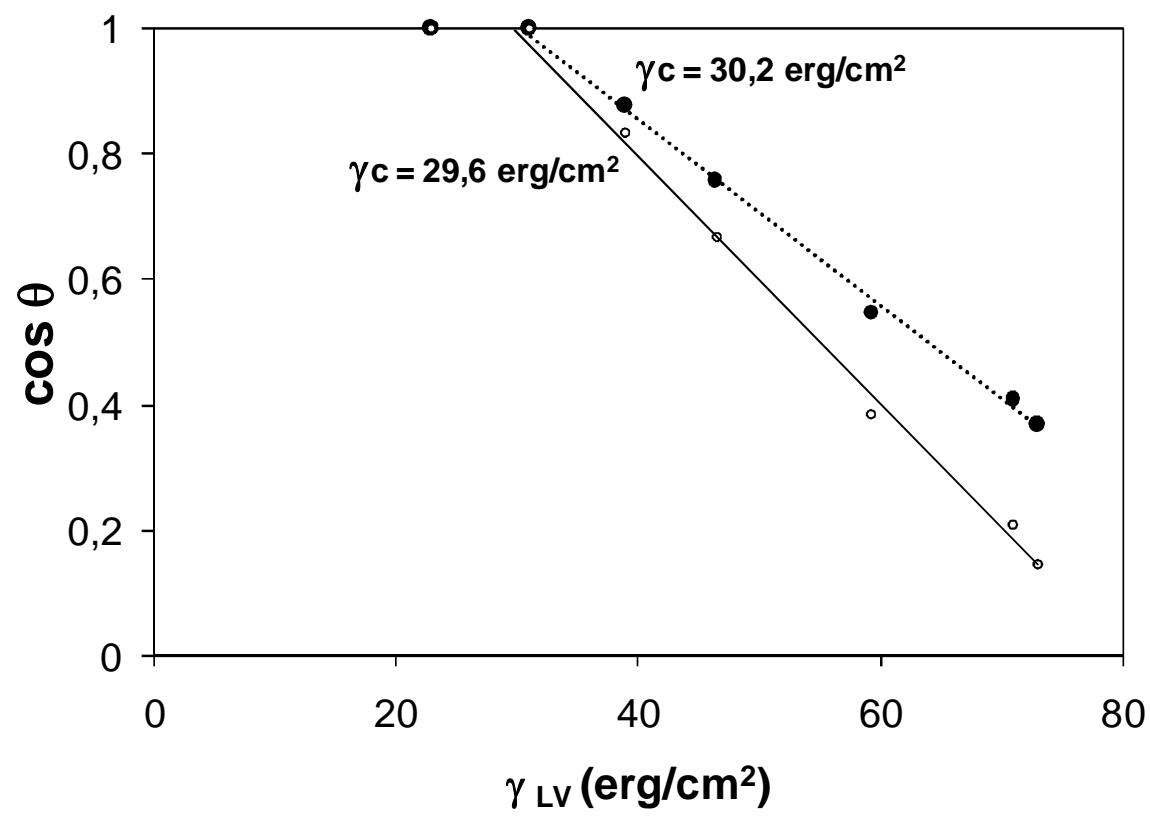

- Basal $\quad$ Frontal

Figura 29 - Determinação de $\gamma_{c}$ dos planos basal (001) e frontal (010) da apatita-Ipirá, tratada com oleato de sódio ( $75 \mathrm{mg} / \mathrm{L}$ ou $\left.2,7.10^{-4} \mathrm{~mol} / \mathrm{L}\right)$.

O valor de $\gamma_{c}$ para os planos basal e frontal apresentados pelo cristal de apatita-Ipirá (pré-tratado com oleato $=75 \mathrm{mg} / \mathrm{L}$ ou $2,7.10^{-4} \mathrm{~mol} / \mathrm{L}$ ) foi determinado graficamente através da Fig. 29, conforme metodologia proposta por Zisman (1964). Deste modo, chegou-se a valores de $\gamma_{c}=30,2 \mathrm{erg} / \mathrm{cm}^{2}$ para o plano basal e $\gamma_{c}=29,6$ $\mathrm{erg} / \mathrm{cm}^{2}$ para o plano frontal. Estes valores são muito semelhantes àqueles reportados por Ozcan (1992), $\gamma_{c}=30-31 \mathrm{erg} / \mathrm{cm}^{2}$, para apatita tratada com oleato de sódio $\left(1 \times 10^{-3} \mathrm{~mol} / \mathrm{L}\right)$.

Os resultados de $\gamma_{c}$ apresentados nesta seção $\left(\gamma_{c} \sim 30\right.$ dina $\left./ \mathrm{cm}^{2}\right)$ indicam que a flotação de apatita, na presença de oleato de sódio, não deverá ser conduzida em solução cujo $\gamma_{\text {LV }}$ seja inferior a $\sim 30$ dina $/ \mathrm{cm}^{2}$, visto que as partículas do mineral, mesmo que tenham sofrido prévia adsorção de oleato de sódio, apresentarão alta molhabilidade $\left(\theta_{\mathrm{a}}=0^{\circ}\right)$ pela fase líquida (solução). 


\subsection{Tensão Crítica de Molhabilidade da Apatita-Cajati Pré-tratada com Amido de Milho e Berol ${ }^{\circledR} 867$}

Partículas de apatita oriundas da mina de Cajati foram submetidas a prétratamento com amido de milho $(37,5 \mathrm{mg} / \mathrm{L})$ e Berol $^{\circledR} 867$ (25 mg/L) em pH=10,6 devido ao fato de serem estas as condições adotadas para concentração de apatita em escala de bancada com o minério desta jazida. Após pré-tratamento e secagem da amostra de apatita, determinou-se o ângulo de contato pelo método da ascensão capilar, utilizando soluções compostas por metanol e água em várias proporções. Deste modo, para cada solução particular de água+metanol tinha-se um valor característico para a energia livre superficial $\left(\gamma_{\mathrm{LV}}\right)$ e também o ângulo de contato obtido para aquele valor particular de $\gamma$ LV.

A constante c foi determinada através da percolação de hexano através do leito de partículas de apatita previamente tratadas com os reagentes de flotação. Por ser tratar de um líquido de baixa energia, verificou-se que o mesmo molhou perfeitamente o leito de partículas, satisfazendo a condição $\theta=0^{\circ}$. $O$ valor obtido para c foi de $(7,1103 \pm 0,0387) \cdot 10^{-6} \mathrm{~cm}^{5}$.

Os valores de ângulo de contato medidos em função de $\gamma_{L V}$ das soluções compostas de metanol e água são apresentados na Tab. 22 e graficamente ilustrados através da Fig. 30, onde se pode observar que:

i. A magnitude de $\theta$ decresce com a diminuição da energia livre superficial da fase líquida, conforme previsto por Zisman (1964);

ii. A partir de um determinado valor de $\gamma_{L V}-$ a denominada tensão crítica de molhabilidade $\left(\gamma_{c}\right)$ - a fase líquida passa a molhar completamente a superfície da apatita, ou seja, $\theta=0^{\circ}$;

iii. O valor de $\gamma_{c}=33,9 \mathrm{erg} / \mathrm{cm}^{2}$, foi obtido graficamente através da Fig.30, de acordo com a metodologia proposta por Zisman (1964). 
Tabela 22 - Ângulo de contato de avanço de solução água/metanol sobre partículas de apatita-Cajati, em função de $\gamma_{\mathrm{LV}}$ da fase líquida $\left(20,0 \pm 0,1^{\circ} \mathrm{C}\right)$.

\begin{tabular}{c|c|c}
\hline \hline \multicolumn{2}{c|}{ Solução água/metanol } & \multirow{2}{*}{$\theta_{\mathrm{a}}$ (graus) } \\
\hline \hline$\%$ metanol & $\gamma_{\mathrm{Lv}}\left(\mathbf{e r g} / \mathbf{c m}^{2}\right)$ & $64,2 \pm 1,1$ \\
\hline 0,0 & $72,90 \pm 0,02$ & $61,3 \pm 0,9$ \\
\hline 1,0 & $70,90 \pm 0,02$ & $53,3 \pm 0,3$ \\
\hline 9,8 & $59,17 \pm 0,03$ & $34,7 \pm 1,0$ \\
\hline 27,0 & $46,25 \pm 0,06$ & $20,3 \pm 0,3$ \\
\hline 78,0 & $38,81 \pm 0,05$ & $5,1 \pm 5,8$ \\
\hline 10,0 & $30,75 \pm 0,07$ & $0,0 \pm 0,0$ \\
\hline
\end{tabular}

Nota: Os desvios apresentados correspondem ao desvio padrão resultante de uma série de três medidas em cada condição experimental (APÊNDICES 1 e 3).

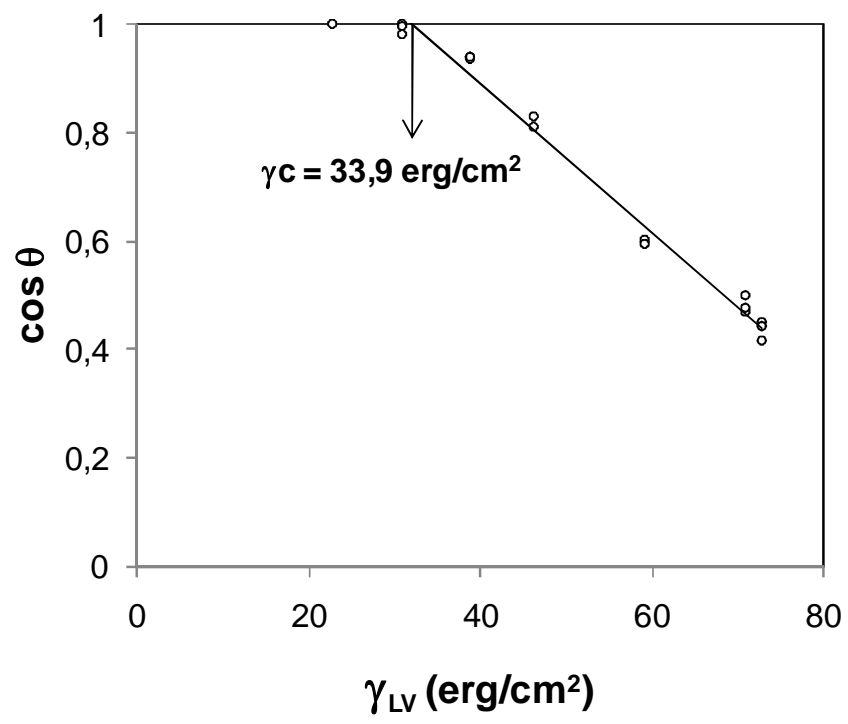

Figura 30 - Ângulo de contato de apatita previamente tratada com amido e Berol ${ }^{\circledR} 867$ versus energia livre superficial da solução água/metanol.

O valor de $\gamma_{c}=33,9 \mathrm{erg} / \mathrm{cm}^{2}$ para apatita de Cajati difere do valor de $\gamma_{c}$ obtido para os planos basal e frontal de um cristal de apatita de Ipirá: $\gamma_{c}=30,2 \mathrm{erg} / \mathrm{cm}^{2}$ (plano basal) e $\gamma_{c}=29,6 \mathrm{erg} / \mathrm{cm}^{2}$. Tal diferença pode ser devida aos seguintes motivos:

i. Os ângulos de contato para a apatita de Cajati foram determinados pelo método da ascensão capilar, enquanto que os da apatita de Ipirá foram medidos pelo método da bolha cativa; 
ii. O pré-tratamento dos dois tipos de apatita foram também diferentes: a apatita de Cajati utilizou amido (37,5 mg/L) e o coletor Berol®867 $(25 \mathrm{mg} / \mathrm{L})$; enquanto que a apatita de Ipirá foi pré-tratada com oleato de sódio $(75 \mathrm{mg} / \mathrm{L})$.

\subsection{Hidrodinâmica da Percolação da Fase Líquida Através do Leito de Partículas}

Enfocando as medidas de ângulo de contato executadas com apatita de Cajati através do método da ascensão capilar, foi possível calcular:

i. O raio médio $(r)$ dos capilares que caracterizam o leito de partículas de acordo com metodologia descrita na seção 2.7.3;

ii. Números hidrodinâmicos adimensionais que são relacionados ao fluxo ascendente do líquido (água, metanol ou misturas metanol/água) através do leito. Os resultados são apresentados na Tab. 23.

O leito de partículas que foi percolado pela fase líquida durante as medições do ângulo de contato pode ser caracterizado por um sistema de tubos capilares de raio médio de $1,41 \pm 0,03 \mu \mathrm{m}$, conforme informa a Tab. 23 . Uma vez que o erro relativo é da ordem de $2 \%$, pode-se assumir que a preparação do leito de partículas antes das medições (empacotamento do leito) apresentou razoável reprodutibilidade.

Como se verifica na Tab. 23, o fluxo ascendente dos líquidos através dos leitos de partículas de apatita ocorreu em regime laminar, que foi atestado pela magnitude do número de Reynolds $(R e)$ calculado para cada medição de ângulo de contato: $0,84 \times 10^{-3} \leq \operatorname{Re} \leq 1,95 \times 10^{-3}$. Apesar dos experimentos terem sido realizados com líquidos que exibiam viscosidade dinâmica $(\eta)$ que variou em ampla faixa $(0,585 \mathrm{mPas} \leq \eta \leq 1,799 \mathrm{mPas})$, as forças capilares foram da ordem de $100 \mathrm{mil}$ vezes $\left(10^{5}\right)$ superiores às forças viscosas, haja vista a magnitude do número de capilar (Cap): $0,93 \times 10^{-5} \leq$ Cap $\leq 2,54 \times 10^{-5}$. 
Tabela 23 - Valores dos parâmetros hidrodinâmicos dos sistemas experimentais na determinação de ângulo de contato pelo método da ascensão capilar.

\begin{tabular}{|c|c|c|c|c|c|}
\hline \multirow{2}{*}{$\begin{array}{c}\begin{array}{c}\text { Solução } \\
\text { água/metanol }\end{array} \\
\% \text { metanol }\end{array}$} & \multirow{2}{*}{$\mathbf{r}(\mu \mathrm{m})$} & \multicolumn{4}{|c|}{ Parâmetros Hidrodinâmicos } \\
\hline & & $\operatorname{Re}\left(10^{-3}\right)$ & We $\left(10^{-8}\right)$ & Bo $\left(10^{-6}\right)$ & Cap $\left(10^{-5}\right)$ \\
\hline 0,0 & 1,39 & 1,88 & 1,75 & 1,04 & 0,93 \\
\hline 0,0 & 1,40 & 1,95 & 1,87 & 1,05 & 0,96 \\
\hline 0,0 & 1,40 & 1,95 & 1,87 & 1,06 & 0,96 \\
\hline 1,0 & 1,41 & 1,88 & 1,99 & 1,09 & 1,06 \\
\hline 1,0 & 1,41 & 1,88 & 2,00 & 1,09 & 1,06 \\
\hline 1,0 & 1,40 & 1,89 & 2,04 & 1,07 & 1,08 \\
\hline 9,8 & 1,41 & 1,08 & 1,68 & 1,27 & 1,55 \\
\hline 9,8 & 1,40 & 1,07 & 1,64 & 1,27 & 1,53 \\
\hline 9,8 & 1,40 & 1,05 & 1,60 & 1,26 & 1,52 \\
\hline 27,0 & 1,41 & 0,84 & 1,88 & 1,58 & 2,23 \\
\hline 27,0 & 1,42 & 0,86 & 1,92 & 1,60 & 2,25 \\
\hline 27,0 & 1,41 & 0,89 & 2,11 & 1,57 & 2,37 \\
\hline 48,0 & 1,41 & 1,05 & 2,66 & 1,78 & 2,54 \\
\hline 48,0 & 1,41 & 1,02 & 2,52 & 1,78 & 2,47 \\
\hline 48,0 & 1,40 & 1,03 & 2,59 & 1,78 & 2,51 \\
\hline 75,0 & 1,41 & 1,78 & 4,26 & 2,12 & 2,39 \\
\hline 75,0 & 1,46 & 1,95 & 4,96 & 2,27 & 2,54 \\
\hline 75,0 & 1,40 & 1,78 & 4,32 & 2,08 & 2,42 \\
\hline 100,0 & 1,41 & 3,38 & 7,64 & 2,73 & 2,26 \\
\hline 100,0 & 1,44 & 3,49 & 8,01 & 2,84 & 2,29 \\
\hline 100,0 & 1,52 & 3,75 & 8,79 & 3,13 & 2,34 \\
\hline
\end{tabular}

Determinações de ângulo de contato pelo método de ascensão capilar utilizando-se a equação de Washburn são realizadas via medidas da velocidade de ascensão de líquidos através de leitos de partículas. No sistema experimental adotado na presente tese, tal velocidade foi indiretamente medida pelo ganho de massa do leito versus tempo, conforme ilustra a Fig. 21 (seção 2.7). Nesse sistema, para tempos de percolação muito próximos de zero, ocorre o domínio de forças inerciais (SZEKELY, NEUMANN, CHUANG, 1971), isto é, We $>1$. À medida que as forças inerciais são sobrepujadas pelas forças capilares $(\mathrm{We}<1)$, o fluxo entra no 
regime estacionário até que a influência da gravidade $($ Bo $>1)$ passe a dominar a hidrodinâmica do sistema, quando começa a diminuir a velocidade de percolação. Deste modo, para garantir a qualidade das medidas de ângulo de contato, optou-se por medir o ganho de massa dentro do intervalo de tempo $2 \mathrm{~s}<\mathrm{t}<15 \mathrm{~s}$. Para tal intervalo, os valores experimentais de We versus Bo ilustrados no diagrama de domínios das forças inerciais, capilares e gravitacionais (Fig. 31) mostram que, indubitavelmente, o sistema experimental estava sob o domínio das forças capilares.

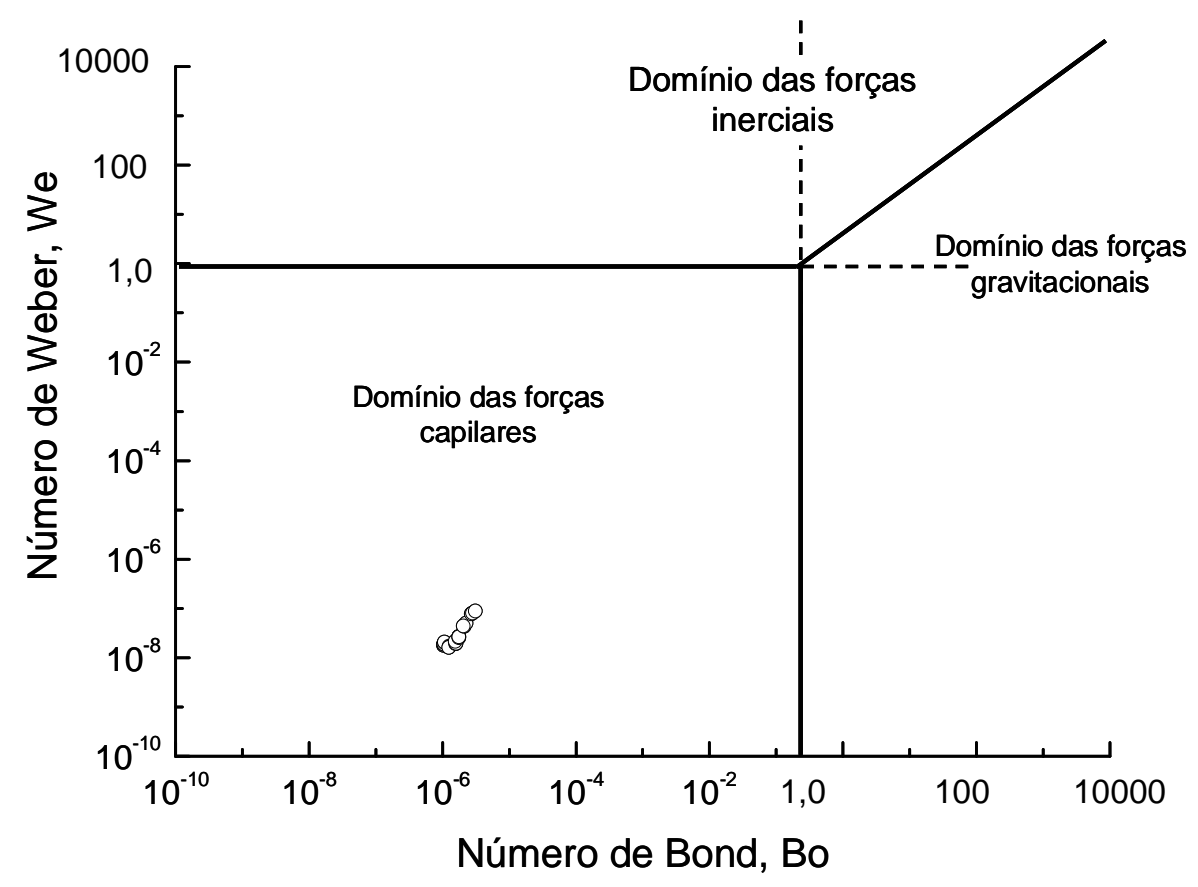

Figura 31 - Diagrama dos domínios hidrodinâmicos das forças inerciais, capilares e gravitacionais com os valores experimentais de Weber versus Bond.

\subsection{Flotação Gama}

Minério de fosfato de baixo teor $\left(5,75 \%\right.$ de $\left.\mathrm{P}_{2} \mathrm{O}_{5}\right)$ proveniente de Cajati foi submetido ao processo de flotação seguindo condições experimentais semelhantes àquelas do estágio rougher no circuito industrial. A solução de flotação, após a 
adsorção do coletor sobre os minerais, exibiu $\gamma_{L V}=35,1 \mathrm{erg} / \mathrm{cm}^{2}$ (Tab. 24), enquanto valores típicos de $\gamma_{L V}$ no circuito industrial encontram-se na faixa de $36-39 \mathrm{erg} / \mathrm{cm}^{2}$ (Tab. 5).

De acordo com a Tab. 12 da seção 2.1.4, o concentrado rougher apresentou teor de $20,1 \%$ de $\mathrm{P}_{2} \mathrm{O}_{5}$ ( $\approx 49 \%$ de apatita), $22,4 \%$ de $\mathrm{CaO}_{\text {CARB }}$ (dolomita + calcita), $3,77 \%$ de $\mathrm{MgO}$ (dolomita $+\mathrm{Mg}$-silicatos) e $1,06 \%$ de $\mathrm{SiO}_{2}$ (silicatos). Verifica-se na Tab. 24 que a recuperação de $\mathrm{P}_{2} \mathrm{O}_{5}$ (apatita), carbonatos e silicatos foi de $78,7 \%$, 13,4\% e 11,7\%, respectivamente. A eficiência de separação apatita/carbonatos é de $65 \%$, enquanto que a eficiência de separação apatita/silicatos é de $67 \%$. Estes resultados indicam a necessidade de se melhorar o processo.

Tabela 24 - Desempenho da separação de apatita versus minerais de ganga em ensaios de flotação rougher $\left(\gamma_{L V}=35.1 \mathrm{erg} / \mathrm{cm}^{2}\right.$ a $\left.20,0 \pm 0,1^{\circ} \mathrm{C}\right)$.

\begin{tabular}{c|c|c|c}
\hline \hline Minerais & Recuperação & Sistema Mineral & $\begin{array}{c}\text { Eficiência de } \\
\text { separação de Schulz }\end{array}$ \\
\hline \hline Apatita & $78,7 \%$ & \multirow{2}{*}{ Apatita/Carbonatos } & $65,3 \%$ \\
\hline Carbonatos & $13,4 \%$ & & $67,0 \%$ \\
\hline Silicatos & $11,7 \%$ & Apatita/Silicatos & 6 \\
\hline
\end{tabular}

O concentrado de apatita obtido através da flotação rougher com Berol@867 foi submetido a flotação gama, cuja recuperação de apatita é apresentada na Fig. 32, onde é possível observar que:

i. Um platô de máxima recuperação (95-98\%) é atingido em $52,7 \mathrm{erg} / \mathrm{cm}^{2}<$ $\gamma_{\mathrm{LV}}<72,9 \mathrm{erg} / \mathrm{cm}^{2}$;

ii. Quando $\gamma\left\llcorner\right.$ v diminui de $52,7 \mathrm{erg} / \mathrm{cm}^{2}$ a $22,8 \mathrm{erg} / \mathrm{cm}^{2}$, a recuperação de apatita decai abruptamente de $90 \%$ a $0 \%$;

iii. Usando a abordagem proposta por Yarar e Kaoma (1984), foi possível determinar o valor da tensão crítica de molhabilidade da apatita $\left(\gamma_{c}=34,7 \mathrm{erg} / \mathrm{cm}^{2}\right)$. Este valor é muito semelhante àquele encontrado usando a abordagem desenvolvida por Zisman (1964) $\left(33,9 \mathrm{erg} / \mathrm{cm}^{2}\right)$, porém ambos são maiores que o valores obtidos para apatita tratada com oleato de sódio $\left(\gamma_{c} \cong 30 \mathrm{erg} / \mathrm{cm}^{2}\right)$. 


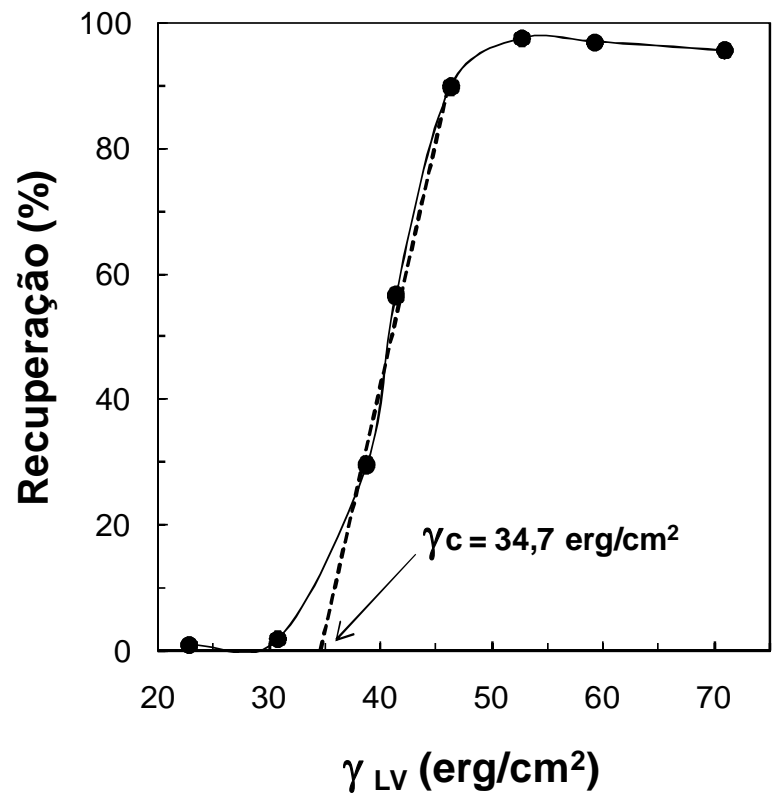

Figura 32 - Recuperação de apatita versus energia livre superficial da solução água/metanol.

As Figs. 33 e 34 mostram a recuperação dos minerais de ganga (carbonatos e silicatos) versus apatita nos experimentos de flotação gama. Ao contrário do comportamento da flotação de apatita, um platô de recuperação não foi observado para silicatos ou carbonatos. Em ambos os casos, quanto maior a magnitude de $\gamma_{\mathrm{LV}}$, maior foi a recuperação dos minerais de ganga. Uma vez que os termos "carbonatos" (dolomita e calcita) e "silicatos" (flogopita e piroxênios) foram adotados para se referir a um grupo de minerais de ganga, ao invés de uma única espécie mineral, não seria significativo determinar a tensão crítica de molhabilidade para este grupo de minerais. 


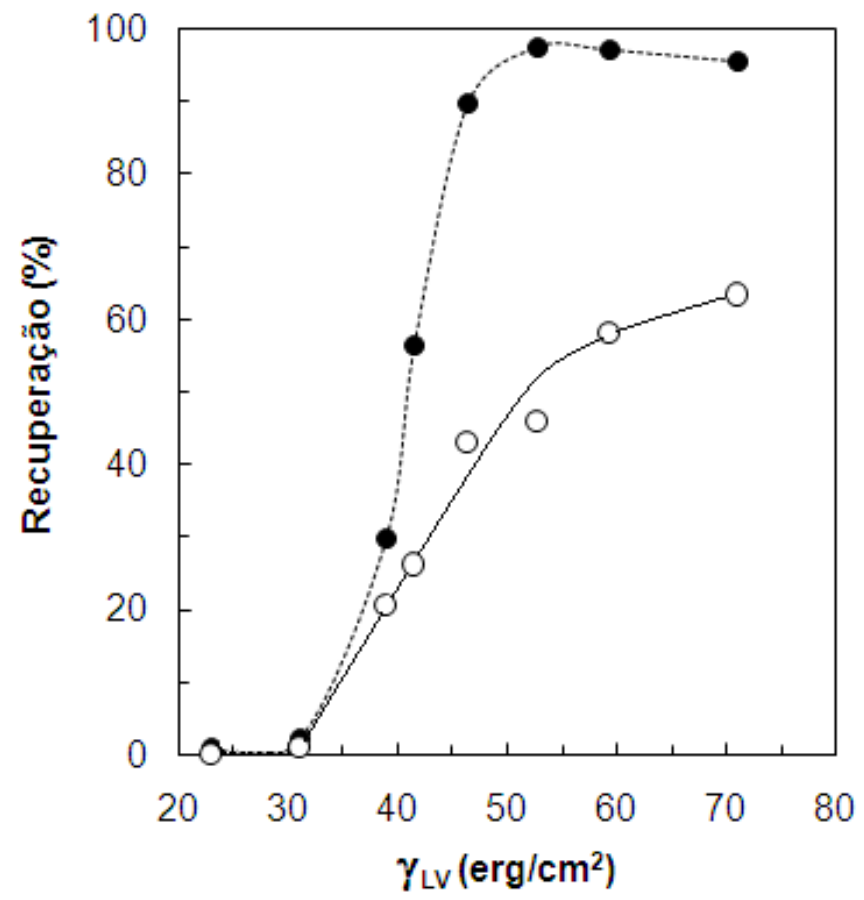

-.- Apatita $\quad$ Carbonatos

Figura 33 - Recuperação de apatita e carbonatos versus energia livre superficial da solução água/metanol.

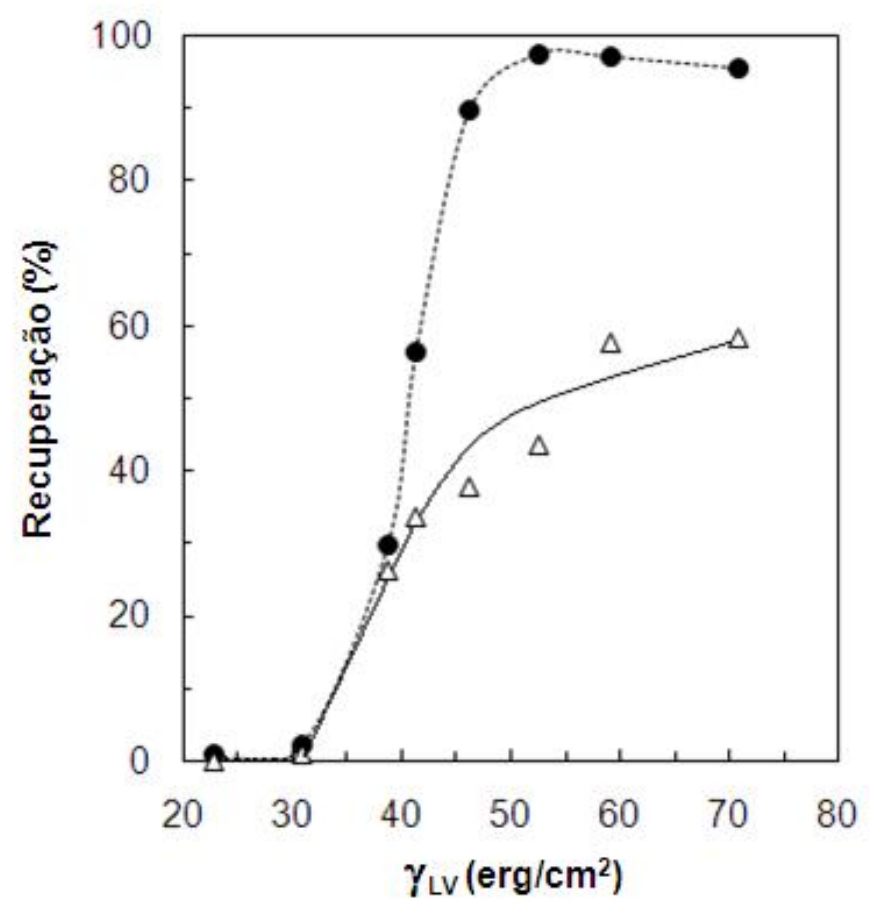

- Apatita $\Delta$ Silicatos

Figura 34 - Recuperação de apatita e silicatos versus energia livre superficial da solução água/metanol. 
As eficiências de separação de Schulz (E.S.) de apatita/silicatos (Fig. 35) e apatita/carbonatos (Fig. 36) podem ser representadas por curvas semelhantes. O valor máximo de E.S. para apatita/silicatos ocorreu em $\gamma_{L V}=50,5 \mathrm{erg} / \mathrm{cm}^{2}$, enquanto o valor máximo para apatita/carbonatos ocorreu em $\gamma_{\mathrm{LV}}=51,4 \mathrm{erg} / \mathrm{cm}^{2}$. Esses resultados indicam que o circuito industrial de flotação de Cajati deveria operar em $\gamma_{L V} \cong 51 \mathrm{erg} / \mathrm{cm}^{2}$ para atingir a mais eficiente separação entre apatita e minerais de ganga. Este valor é, entretanto, muito maior do que aqueles das etapas rougher $\left(36 \mathrm{erg} / \mathrm{cm}^{2}<\gamma_{\mathrm{LV}}<39 \mathrm{erg} / \mathrm{cm}^{2}\right)$ ou cleaner $\left(38 \mathrm{erg} / \mathrm{cm}^{2}<\gamma_{\mathrm{LV}}<40 \mathrm{erg} / \mathrm{cm}^{2}\right)$ no circuito industrial de Cajati. Contudo, é importante observar que os valores de $\gamma_{L V}$ medidos no circuito industrial foram obtidos manualmente, utilizando o método do anel de Du Noüy a $22-23^{\circ} \mathrm{C}$, enquanto os valores de $\gamma_{\mathrm{LV}}$ medidos em laboratório foram obtidos automaticamente com o auxílio de um tensiômetro, através do método da placa de Wilhelmy sob temperatura controlada de $(20,0 \pm 0,1)^{\circ} \mathrm{C}$.

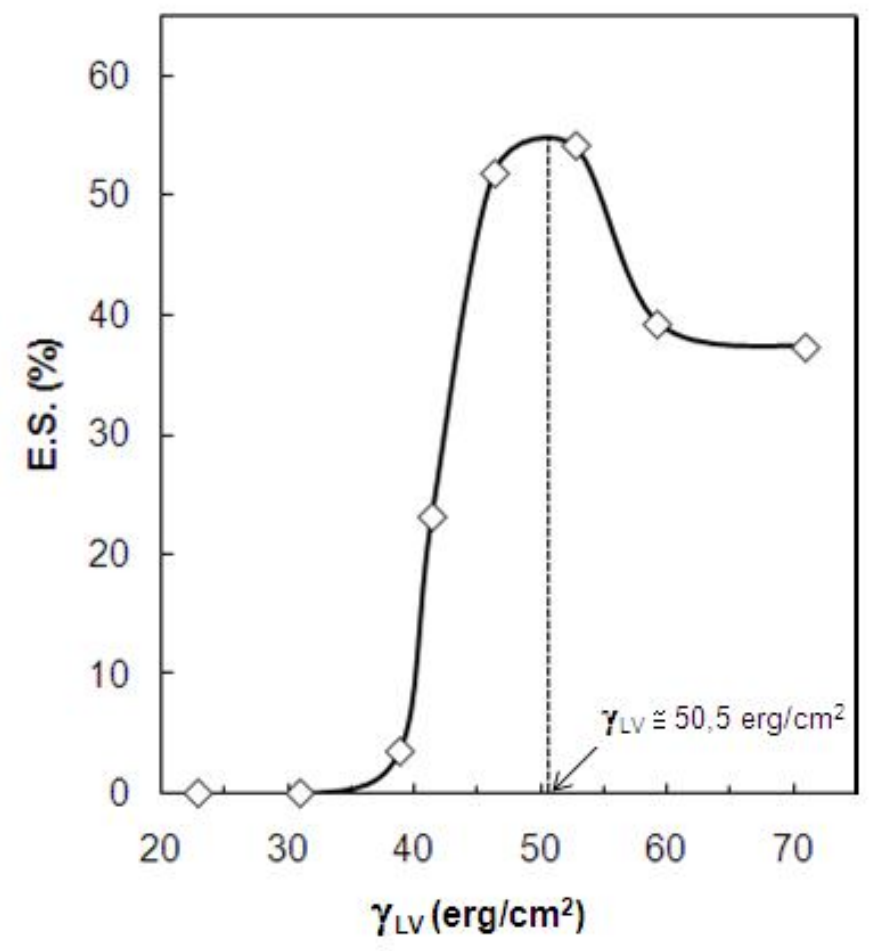

Figura 35 - Eficiência de separação de Schulz (E.S.) apatita/silicatos versus energia livre superficial da solução água/metanol. 


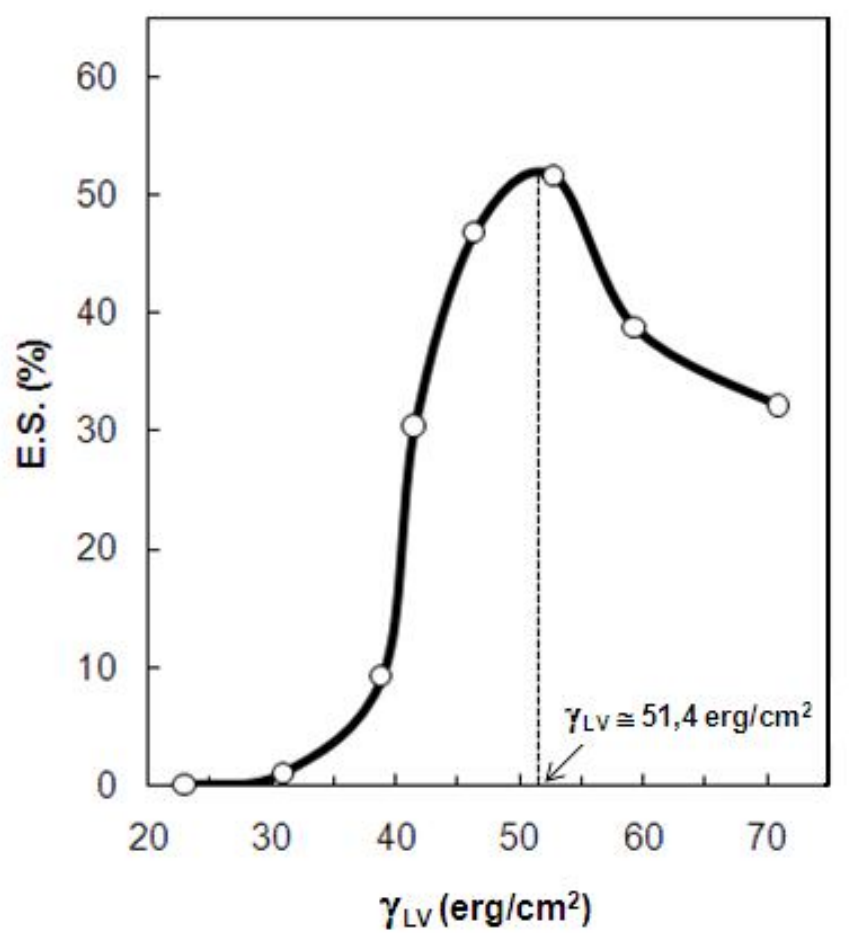

Figura 36 - Eficiência de separação de Schulz (E.S.) apatita/carbonatos versus energia livre superficial da solução água/metanol. 


\section{CONCLUSÕES}

Dentro do universo desta investigação, é possível concluir que:

1. Na determinação da constante $c$, necessária para a determinação de ângulo de contato pelo método da ascensão capilar, o hexano é indicado somente para sólidos que apresentam caráter hidrofóbico mais pronunciado (sólidos de baixa energia), como é o caso das partículas de apatita condicionadas com $25-75 \mathrm{mg} / \mathrm{L}$ de oleato de sódio. Para sólidos que exibem menor caráter hidrofóbico, como é o caso da apatita "in natura" (sem prévia adsorção com oleato de sódio), o uso da água para determinar a constante c é mais adequado;

2. A despeito do método da ascensão capilar (utilizando a equação de Washburn) envolver propriedades "bulk" dos líquidos (viscosidade e densidade), assim como propriedades dinâmicas (velocidade de percolação) e de superfície (tensão superficial), o sistema experimental é regido por forças de superfície (domínio da capilaridade). A validade do método adotado, portanto, é corroborada pela magnitude dos seguintes números hidrodinâmicos adimensionais: Reynolds $(0,84 \mathrm{x}$ $\left.10^{-3} \leq \operatorname{Re} \leq 1,95 \times 10^{-3}\right)$, Capilar $\left(0,93 \times 10^{-5} \leq \mathrm{Cap} \leq 2,54 \times 10^{-5}\right)$, Weber $(\mathrm{We}<1) \mathrm{e}$ Bond $(B 0<1)$. Para se trabalhar com confiança dentro desta faixa, foi necessário escolher o intervalo de tempo de percolação na faixa de $2 \mathrm{~s}<\mathrm{t}<15 \mathrm{~s}$.

3. Identificou-se uma relação de causa-efeito entre o aumento da concentração de oleato de sódio, utilizado no pré-tratamento da superfície da apatita, e diminuição da molhabilidade desse mineral, que foi evidenciada pelo aumento da magnitude do ângulo de contato de avanço $\left(\theta_{\mathrm{a}}\right)$; diminuição do trabalho de adesão $\left(\mathrm{W}_{\mathrm{a}}\right)$ da água à superfície do mineral e um menor coeficiente de espalhamento da água sobre o mineral.

4. O oleato de sódio adsorveu preferencialmente sobre o plano frontal (010) em detrimento do plano basal (001) apresentado pelo cristal de apatita-Ipirá, promovendo um caráter hidrofóbico mais pronunciado no plano (010), evidenciado pelos valores mais altos de $\theta_{\mathrm{a}}$ obtidos para este plano em comparação com o basal;

5. Identificou-se uma relação de causa-efeito entre altos ângulos de contato e alta flotabilidade da apatita-Ipirá; 
6. A tensão crítica de molhabilidade $\left(\gamma_{c}\right)$ dos planos basal e frontal do cristal de apatita-Ipirá pré-tratado com oleato $=75 \mathrm{mg} / \mathrm{L}$ ou $2,7 \times 10^{-4} \mathrm{~mol} / \mathrm{L}$, determinada através de diagramas $\cos \theta$ versus $\gamma_{L G}$ (metodologia proposta por Zisman), foi de $\gamma_{C}=$ $30,2 \mathrm{erg} / \mathrm{cm}^{2}$ para o plano basal e $\gamma_{c}=29,6 \mathrm{erg} / \mathrm{cm}^{2}$ para o plano frontal. Estes valores são muito semelhantes àqueles reportados por Ozcan (1992), $\gamma_{c}=30$ $31 \mathrm{erg} / \mathrm{cm}^{2}$, para apatita tratada com oleato de sódio $\left(1 \times 10^{-3} \mathrm{~mol} / \mathrm{L}\right)$.

7. Após ser condicionada com reagentes de flotação (amido $=37,5 \mathrm{mg} / \mathrm{L}$ e Berol $=$ $25 \mathrm{mg} / \mathrm{L})$ e flotada em estágio rougher, partículas de apatita-Cajati exibiram ângulo de contato de avanço de $64,2 \pm 1,1^{\circ}$. A tensão crítica de molhabilidade determinada por digrama de recuperação versus $\gamma_{L G}$ (metodologia proposta por Yarar), foi de $34,5 \mathrm{erg} / \mathrm{cm}^{2}$; enquanto que a determinada através de diagrama $\cos \theta$ versus $\gamma_{\mathrm{LG}}$, conforme metodologia proposta por Zisman, foi de $33,9 \mathrm{erg} / \mathrm{cm}^{2}$.

8. Um platô de máxima recuperação (95-98\%) foi obtido para a apatita em $52,7 \mathrm{erg} / \mathrm{cm}^{2}<\gamma_{L V}<72,9 \mathrm{erg} / \mathrm{cm}^{2}$ nos experimentos de flotação gama realizados com o minério de fosfato proveniente de Cajati-SP. Ao contrário da apatita, os minerais de ganga não exibiram um platô de máxima recuperação: quanto maior a energia livre superficial da solução de flotação, maior foi a recuperação dos silicatos e carbonatos. A máxima eficiência de separação apatita/ganga foi obtida em $\gamma_{L V}=50,5 \mathrm{erg} / \mathrm{cm}^{2}$ para silicatos e em $\gamma_{\mathrm{LV}}=51,4 \mathrm{erg} / \mathrm{cm}^{2}$ para carbonatos;

9. Os resultados obtidos nos experimentos de flotação gama indicam que, no circuito industrial de Cajati-SP, a magnitude de $\gamma_{\mathrm{LV}}$ pode ser modulada pela dosagem de coletor, podendo guiar engenheiros na tomada de decisões a respeito da dosagem de coletor que promove a maior seletividade de separação apatita/ganga. Entretanto, a falta dos instrumentos apropriados para realizar medidas on-line confiáveis de $\gamma_{L V}$ em circuitos industriais tem impedido a execução destas medidas. Deste modo, decisões a respeito da dosagem do coletor continuam a ser baseadas em uma abordagem empírica (teor de $\mathrm{P}_{2} \mathrm{O}_{5}$ no concentrado) ao invés de científica (através do conhecimento da magnitude de $\gamma\llcorner\mathrm{LV}$ ). 


\section{REFERÊNCIAS}

BUTTNER, B. Selektive flotation des carbonatitischen phosphaterzes von jacupiranga und untersuchungen zur adsorption der spezifischen reagenzien auf apatit und calcite. 1987. 118 p. Tese (Doutorado) - University of Clausthal, Clausthal, 1987.

DE BRUYN, P.L.; AGAR, G.E. Surface chemistry of flotation. In: FUERSTENAU, D.W. (Ed.) Froth Flotation: $50^{\text {th }}$ anniversary volume. New York: American Institute of Mining, Metallurgical and Petroleum Engineers, 1962. Cap. 5, p. 91-138.

DRZYMALA,J. Hydrophobicity and collectorless flotation of inorganic materials. Advances in Colloid and Interface Science, Amsterdam, v.50, p.143-185, 1994.

FINCH, J.A.; DOBBY, G.S. Column flotation. Oxford: Pergamon Press, 1990. Cap. 3, p. 37-58.

FINKELSTEIN, N.P. Review of interactions in flotation of sparingly soluble calcium minerals with anionic collectors. Transactions of the Institution of Mining and Metallurgy. Section C, London, v. 98, p.157-78, 1989.

FORÇAS intermoleculares. Florianópolis: UFSC, [200?]. Disponível em: http://www.qmc.ufsc.br/qmcweb/artigos/forcas intermoleculares.html. Acesso em: abr. 2009.

FOWKES, F.M. Additivity of intermolecular interactions in surfaces I: determination of the contribution to surface and interfacial tensions of dispersion forces in various liquids. Journal of Physical Chemistry, Ithaca, v.67, p.2538-2541, 1963.

FOWKES, F.M. Attractive forces at interfaces. Industrial and Engineering Chemistry, Easton, v.56, n.12, p.40-52, 1964.

FOWKES, F.M. Determination of interfacial tensions, contact angles, and dispersion forces in surfaces by assuming additivity of intermolecular interactions in surfaces. Journal of Physical Chemistry, Ithaca, v.66, p.382, 1962.

FOX, H.W.; HARE, E.F.; ZISMAN, W.A. Wetting properties of organic liquids on high energy surfaces. Journal of Physical Chemistry, Ithaca, v.59, p.1097-1106, 1955. 
FOX, H.W.; ZISMAN, W.A. The spreading of liquids on low energy surfaces I: polytetrafluoroethylene. Journal of Colloid Science, New York, v.5, p.514-531, 1950.

FUERSTENAU, D.W.; CHANDER, S. Thermodynamics of flotation. In: SOMASUNDARAN, P. (Ed.) Advances in mineral processing.Littleton:SME, 1986. Cap.7, p.121-136.

FUERSTENAU, D.W.; URBINA, R.H. Flotation Fundamentals. In: SOMASSUNDARAM, P.; MOUDGIL, B.M. (Ed.) Reagents in mineral technology. New York: Marcel Dekker, 1987. v. 27, cap. 1. p 1 - 38.

GIRIFALCO, L.A.; GOOD, R.J. A theory for the estimation of surface and interfacial energies I: derivation and application to interfacial tension. Journal of Physical Chemistry, Ithaca, v.61, p.904-909, 1957.

GONZÁLEZ, B. et al. Density, dynamic viscosity, and derived properties of binary mixtures of methanol or ethanol with water, ethyl acetate, and methyl acetate at $\mathrm{T}=(293.15,298.15$, and 303.15$) \mathrm{K}$. The Journal of Chemical Thermodynamics, New York, v.39, p.1578-1588, 2007.

GOOD, R.J. Contact angle, wetting, and adhesion: a critical review. In: MITTAL, K.L. (Ed.) Contact angle, wettability and adhesion. Utrecht: VSP, 1993. p. 3 - 36.

GOOD, R.J.; GIRIFALCO, L.A.; KRAUS, G. A theory for estimation of interfacial energies II: application to interfacial thermodynamics of Teflon and graphite. Journal of Physical Chemistry, Ithaca, v.62, p.1418-1421, 1958.

HANNA, H.S.; SOMASSUNDARAN, P. Flotation of salt-type minerals. In: FUERSTENAU, M.C. (Ed.) Flotation: A. M. Gaudin memorial volume. New York: American Institute of Mining, Metallurgical and Petroleum Engineers, 1976. v. 1, cap. 8, p. 197-272.

JAŃCZUK, B. et al. Components of the surface free energy of low rank coals in the presence of n-alkanes. Powder Technology, Lausanne, v.86, p.229-238, 1996.

KANAZAWA, T. Inorganic phosphate materials. Amsterdam: Elsevier, 1989.

KATCHMAN, B.J. Phosphates in life process. In: VAN WAZER, J.R. (Ed.) Phosphorus and this compounds. New York: Interscience, 1961. p.1281-1343. 
KISSA, E. Wettability. In: Dispersions: characterization, testing, and measurement. New York: Marcel Dekker, 1999. v.84, cap.5, p.137-172.

KRÜSS GmbH. Processor tensiometer K12: user's manual. Hamburg, 1994. 84 p.

LASKOWSKI, J. The relationship between floatability and hydrophobicity. In: SOMASUNDARAN, P. (Ed.) Advances in mineral processing. Littleton:SME, 1986. Cap.11, p.189-208.

LEAL FILHO, L.S. Aspectos relevantes na separação apatita/minerais de ganga via processo Serrana. 1991. 265 p. Tese (Doutorado) - Escola Politécnica, Universidade de São Paulo, São Paulo, 1991.

LEAL FILHO, L.S. A seletividade na separação apatita/silicatos por flotação: subsídios para a solução de problemas tipicamente brasileiros. 1999.160 p. Tese (Livre-Docência) - Escola Politécnica, Universidade de São Paulo, São Paulo, 1999.

LEAL FILHO, L. S. et al. Activation and depression of silicates during anionic flotation of igneous apatite. In: ZHANG, P. et al. (Eds). Beneficiation of phosphates: technology and sustainability. Littleton: SME, 2006. Cap. 3, p.25-36.

LEAL FILHO, L.S. et al. Molecular modeling of reagents for flotation processes. Minerals Engineering, Oxford, v.13, n.14-15, p.1495-1503, 2000.

LEAL FILHO, L. S. et al. The role of hydrodynamics in coarse apatite flotation. In: ZHANG, P. et al. (Eds). Beneficiation of phosphates: fundamentals and technology. Littleton: SME, 2002. Cap. 6, p.55-65.

LEAL FILHO, L.S.; RODRIGUES, W.J.; RALSTON, J. Importance of hydrodynamics in coarse particle flotation. In: STRATEGIC CONFERENCE AND WORKSHOP ON FLOTATION AND FLOCULATION: FROM FUNDAMENTALS TO APPLICATIONS, 2002, Hawaii. Flotation and flocculation. Medindie: Snap Printing, 2002. p. 203212.

LEJA, J. Surface chemistry of froth flotation. New York: Plenum Press, 1982.

LU, Y.; DRELICH, J.; MILLER, J.D. Oleate adsorption at an apatite surface studied by ex-situ FTIR internal reflection spectroscopy. Journal of Colloid and Interface Science, New York, v.202, p.462-476, 1998. 
MARTINS, M. Aspectos estereoquímicos da interação entre apatita e moléculas de amido e sua influência na flotação. 2004. 93p. Dissertação (Mestrado) - Escola Politécnica, Universidade de São Paulo, São Paulo, 2004.

MILLER, J.D. The flotation chemistry of nonsulfide minerals. In: STRATEGIC CONFERENCE AND WORKSHOP ON FLOTATION AND FLOCULATION: FROM FUNDAMENTALS TO APPLICATIONS, 2002, Hawaii. Flotation and flocculation: proceedings; ed. by RALSTON, J.; MILLER, J.; RUBIO, J. Medindie: Snap Printing, 2002. p. 249-256.

MOY, E.; LI, D. Solid/fluid interfacial tensions from contact angles: corroboration by independent approaches. Advances in Colloid and Interface Science, Amsterdam, v.39, p.257-297, 1992.

NEUMANN, A.W.; GOOD, R.J. Techniques of measuring contact angles. In: GOOD, R.J and STROMBERG, R.R. (Eds) Surface and colloid science. Plenum Press, New York, p. 31-91, 1979.

OWENS, D.K.; WENTD, R.C. Estimation of the surface free energy of polymers. Journal of Applied Polymer Science, New York, v.13, p.1741-1747, 1969.

OZCAN, O. Classification of minerals according to their critical surface tension of wetting values. International Journal of Mineral Processing, Amsterdam, n.34, p. 191-204, 1992.

PADDAY, J.F. Spreading, wetting, and contact angles. In: MITTAL, K.L. (Ed.) Contact angle, wettability and adhesion. Utrecht: VSP, 1993. p. 97 - 108.

PAREKH, B.K.; APLAN, F.F. The critical surface tension of wetting of minerals coated with collectors. In: INTERNATIONAL MINERAL PROCESSING CONGRESS, 15. 1985, Cannes, France. Flotation. [Cannes]:BRGM, 1985. v.2, p. 3-15.

PINTO, C.A.F.; ARAUJO, A.C. Estudos fundamentais de flotação de apatita com coletores alternativos. In: ENCONTRO NACIONAL DE TRATAMENTO DE MINÉRIOS E HIDROMETALURGIA, 14. 1990, Salvador. Anais. São Paulo: ABM, 1990. p.435-450.

RABOCKAI, T. Físico-química de superfícies. Washington:OEA, 1979. 128 p. (Série de Química) 
RAICHUR, A.M.; WANG, X.H.; PAREKH, B.K. Estimation of surface free energy of pyrites by contact angle measurements. Minerals Engineering, Oxford, v.14, n.1, p.65-75, 2001.

RAKOVAN, J. Growth and surface properties of apatite. In: KOHN, M.J.; RAKOVAN, J.; HUGHES, J.M. (Eds) Phosphates: geochemical, geobiological, and materials importance. Washington: Mineralogical Society of America, 2002. Cap.3, p.51-86. (Reviews in Mineralogy and Geochemistry, v.48).

RALSTON, J.; DUKHIN, S.S.; MISHCHUK, N.A. Wetting film stability and flotation kinetics. Advances in Colloid and Interface Science, Amsterdam, v.95, p.145-236, 2002.

ROSEN, J.M. Surfactants and interfacial phenomena. New York: John Wiley \& Sons, 1989. Cap. 6, p. 240-275.

RULLISON, C. Wettability studies for porous solids including powders and fibrous materials. Charlotte: Krüss, [1996?]. Technical Note \#302. Disponível em: http//surfchem.co.kr/newapplications/pdf/7.pdf. Acesso:12 abr.2007.

SCHRÖDER, H. Untersuchungen zur adsorption von ampholyttensiden und deren mischungen mit einem nichtionogenen, polar-unpolaren tensid auf apatit und scheelit. 1986. 89 p. Tese (Doutorado) - University of Clausthal, Clausthal, 1986.

SCHULZ, N. F. Separation efficiency. Transactions of the American Institute of Mining, Metallurgical and Petroleum Engineers, New York, v.247, p. 81-87, 1970.

SHAW, D.J. Introdução à química dos colóides e de superfícies. São Paulo: Edgard Blücher, 1975. 185 p.

SIEBOLD, A. et al. Effect of dynamic contact angle on capillary rise phenomena. Colloids and Surfaces. A: Physicochemical and Engineering Aspects. Amsterdam, v. 161 , p. $81-87,2000$.

SLANSKY, M. Mineralogy of sedimentary phosphates. In: Geology of sedimentary phosphates. Anchor Brendon: North Oxford Academic, 1980. Cap.2, p.19-33. 
SOMORJAI, G.A. Principles of surface chemistry. New Jersey: Prentice-Hall, 1972. Cap. 2, p. 52-81.

STROH, G.; STAHL, W. Basicals of surfactant aided dewatering in mineral processing. In: INTERNATIONAL MINERAL PROCESSING CONGRESS, 17., 1991, Dresden. Preprints. Freiberg: Poligraphischer Bereich, 1991. v.3, p. 287-300.

SUN, Z.X.; FORSLING, W. Mineral surface complexation in flotation. In: NATO ADVANCED STUDY INSTITUTE ON INNOVATIONS IN FLOTATION TECHNOLOGY, 1991, Kallithea. Innovations in flotation technology; ed. by P. Mavros and K. A. Matis. Dordrecht: Kluwer Academic Publishers, 1992. p. 263-281. (NATO ASI Series E: Applied Science, 208).

SZEKELY, J.; NEUMANN, A.W.; CHUANG, Y.K. The rate of capillary penetration and the applicability of the washburn equation. Journal of Colloid and Interface Science, New York, v.35, n.2, p. 273-278, 1971.

TAMAI, Y.; MAKUUCHI, K.; SUZUKI, M. Experimental analysis of interfacial forces at the plane surface of solids. Journal of Physical Chemistry, Ithaca, v.71, n.13, p.4176-4179, 1967.

TRAHAR, W.J. A rational interpretation of the role of particle size in flotation. International Journal of Mineral Processing, Amsterdam, v.8, p.289-327, 1981.

TSENG, W. et al. Directional/acidic dissolution kinetics of $(\mathrm{OH}, \mathrm{F}, \mathrm{Cl})$-bearing apatite. Journal of Biomedical Materials Research. Part A, Hoboken, v.76, p.753-764, 2006.

VAN OSS, C.J.; CHAUDHURY, M.K.; GOOD, R.J. Monopolar surfaces. Advances in Colloid and Interface Science, Amsterdam, v.28, p.35-64, 1987.

VAN OSS, C.J.; CHAUDHURY, M.K.; GOOD, R.J. Estimation of the polar parameters of the surface tension of liquids by contact angle measurements on gels. Journal of Colloid and Interface Science, New York, v.128, n.2, p.313-319, 1989.

WASHBURN, E.W. The dynamics of capillary flow. Physical Review, Lancaster, v.17, n.3, p. 273-283, 1921. 
WIEGEL, R.L. Phosphate rock beneficiation practice in Florida. In: ZHANG, P. et al. (Eds). Beneficiation of phosphates: advances in research and practice, Littleton: SME, 1999. Cap. 23, p.271-275.

WU, S. Surface and interfacial tensions of polymer melts II: Poly(methyl methacrylate), Poly(n-butyl methacrylate), and Polystyrene. Journal of Physical Chemistry, Ithaca, v.74, n.3, p.632-638, 1970.

YARAR, B. Gamma flotation: a new approach to flotation using liquid-vapor surface tension control. In: CASTRO, S.H.; ALVAREZ, J. (Eds). Froth flotation. Amsterdam: Elsevier, 1988. p. 41-64.

YARAR, B.; KAOMA, J. Estimation of the critical surface tension of wetting of hydrophobic solids by flotation. Colloids and Surfaces, Amsterdam, v.11, p. 429436, 1984.

ZISMAN, W.A. Relation of the equilibrium contact angle to liquid and solid constitution. Advances in Chemistry Series, Washington, v.43, p.1-51, 1964. 


\section{APÊNDICE 1 - RESULTADOS DE ENERGIA LIVRE SUPERFICIAL}

\section{A1.1 Determinação de $\gamma_{\mathrm{LV}}$ da água e do hexano}

Os valores de $\gamma_{\mathrm{LV}}$ obtidos para água deionizada e hexano utilizados nas determinações da constante $c$ e de ângulo de contato pelo método da ascensão capilar com as amostras de apatita-Ipirá são apresentados na Fig. A1.1 e Tab. A1.1.

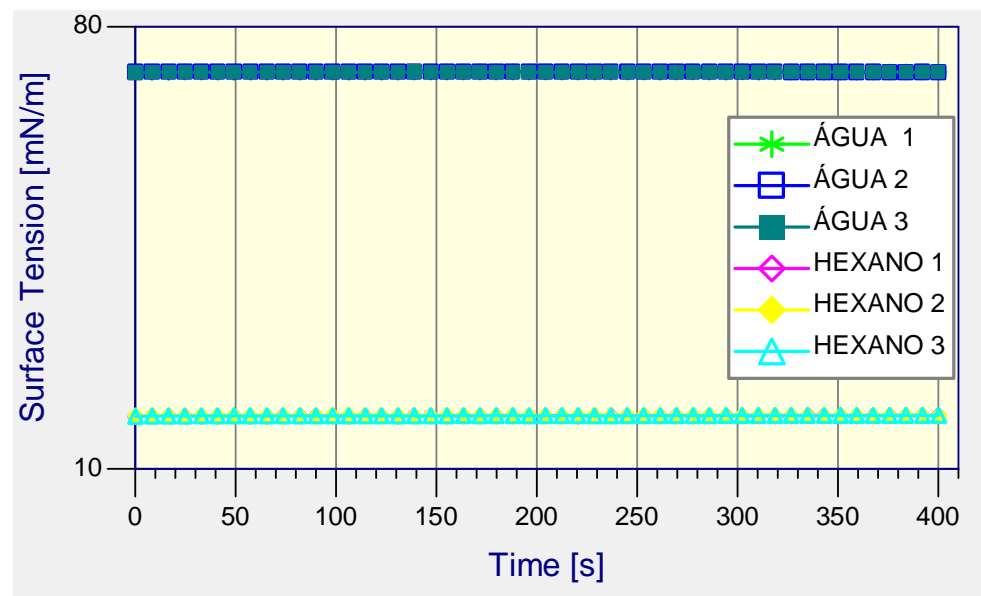

Figura A1.1 - Energia livre superficial versus tempo para água deionizada e hexano (utilizados em experimentos com apatita-Ipirá).

Tabela A1.1 - Energia livre superficial da água deionizada e hexano (utilizados em experimentos com apatita-Ipirá) $\left(20,0 \pm 0,1^{\circ} \mathrm{C}\right)$.

\begin{tabular}{|c|c|}
\hline AMOSTRA & ENERGIA LIVRE SUPERFICIAL $\left(\mathbf{e r g} / \mathbf{c m}^{\mathbf{2}}\right)$ \\
\hline ÁGUA 1 & $72,82 \pm 0,02$ \\
\hline ÁGUA 2 & $72,80 \pm 0,02$ \\
\hline ÁGUA 3 & $72,81 \pm 0,01$ \\
\hline Média e desvio & $\mathbf{7 2 , 8 1 \pm 0 , 0 1}$ \\
\hline HEXANO 1 & $18,40 \pm 0,01$ \\
\hline HEXANO 2 & $18,41 \pm 0,01$ \\
\hline HEXANO 3 & $18,44 \pm 0,01$ \\
\hline Média e desvio & $\mathbf{1 8 , 4 2} \pm \mathbf{0 , 0 2}$ \\
\hline
\end{tabular}

Os valores de $\gamma_{\mathrm{LV}}$ obtidos para água deionizada e hexano utilizados nas determinações da constante $\mathrm{c}$ de ângulo de contato pelo método da ascensão capilar com as amostras de apatita-Cajati são apresentados na Fig. A1.2 e Tab. A1.2. 


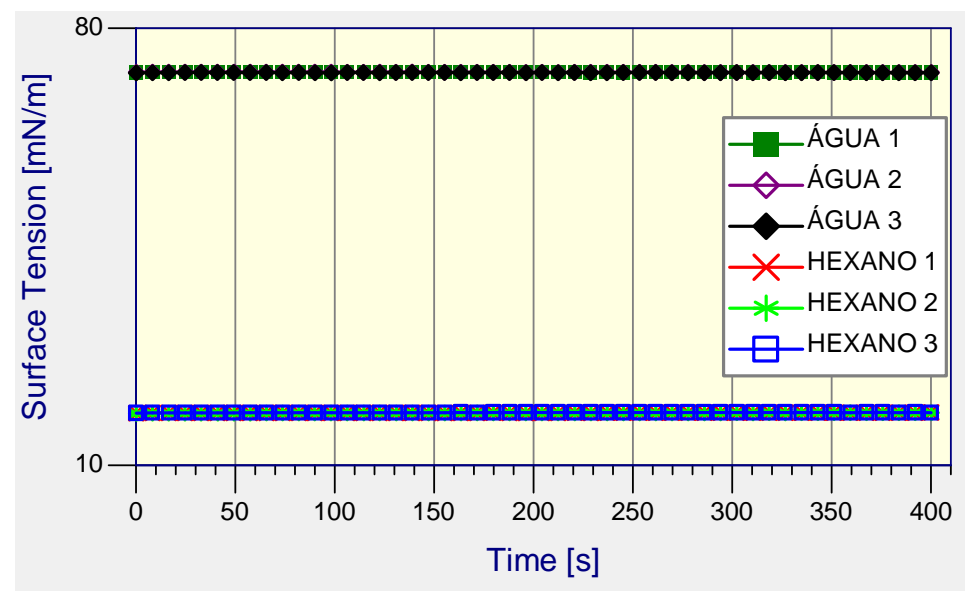

Figura A1.2 - Energia livre superficial versus tempo para água deionizada e hexano (utilizados em experimentos com apatita-Cajati).

Tabela A1.2 - Energia livre superficial da água deionizada e hexano (utilizados em experimentos com apatita-Cajati) $\left(20,0 \pm 0,1^{\circ} \mathrm{C}\right)$.

\begin{tabular}{|c|c|}
\hline AMOSTRA & ENERGIA LIVRE SUPERFICIAL $\left(\mathrm{erg} / \mathrm{cm}^{2}\right)$ \\
\hline ÁGUA 1 & $72,92 \pm 0,02$ \\
\hline ÁGUA 2 & $72,91 \pm 0,01$ \\
\hline ÁGUA 3 & $72,87 \pm 0,01$ \\
\hline Média e desvio & $72,90 \pm 0,02$ \\
\hline HEXANO 1 & $18,42 \pm 0,01$ \\
\hline HEXANO 2 & $18,41 \pm 0,01$ \\
\hline HEXANO 3 & $18,44 \pm 0,02$ \\
\hline Média e desvio & $18,42 \pm 0,02$ \\
\hline
\end{tabular}

Os valores de $\gamma_{\mathrm{LV}}$ obtidos para água MILIQ utilizada nas medidas de ângulo de contato pelo método da bolha cativa com cristal de apatita-Ipirá são apresentados na Fig. A1.3 e Tab. A1.3.

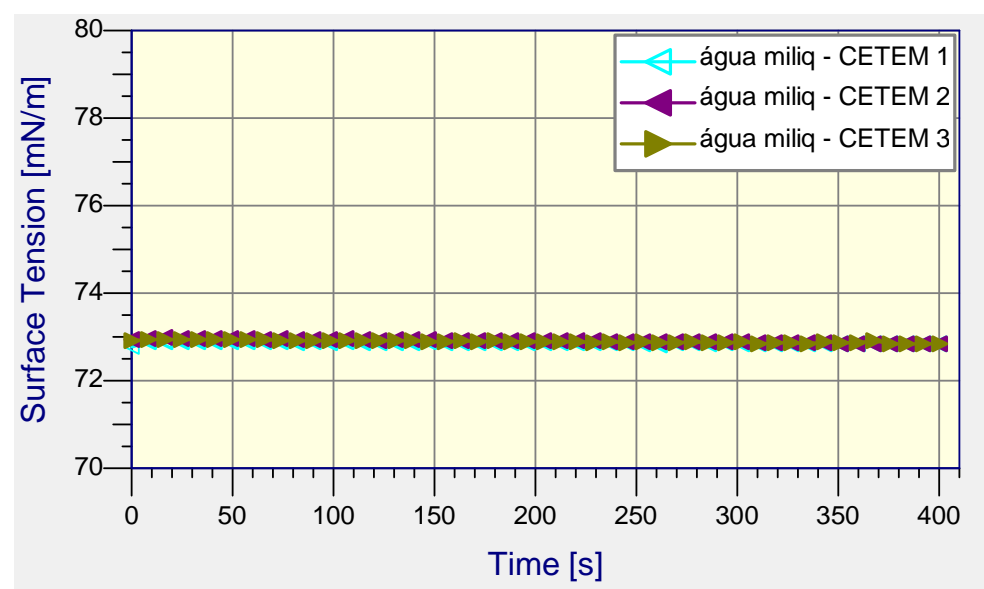

Figura A1.3 - Energia livre superficial versus tempo para água MILIQ (utilizada em experimentos com apatita-Ipirá). 
Tabela A1.3 - Energia livre superficial da água MILIQ (utilizada em experimentos com apatita-Ipirá) $\left(19,9 \pm 0,1^{\circ} \mathrm{C}\right)$.

\begin{tabular}{|c|c|}
\hline AMOSTRA & ENERGIA LIVRE SUPERFICIAL $\left(\mathbf{e r g} / \mathbf{c m}^{\mathbf{2}}\right)$ \\
\hline ÁGUA 1 & $72,84 \pm 0,01$ \\
\hline ÁGUA 2 & $72,86 \pm 0,02$ \\
\hline ÁGUA 3 & $72,86 \pm 0,02$ \\
\hline Média e desvio & $\mathbf{7 2 , 8 6} \pm \mathbf{0 , 0 2}$ \\
\hline
\end{tabular}

\section{A1.2 Determinação de $\gamma$ Lv da solução de flotação rougher}

Os valores de $\gamma_{\text {LV }}$ obtidos para a solução de flotação rougher são apresentados na Fig. A1.4 e Tab. A1.4.

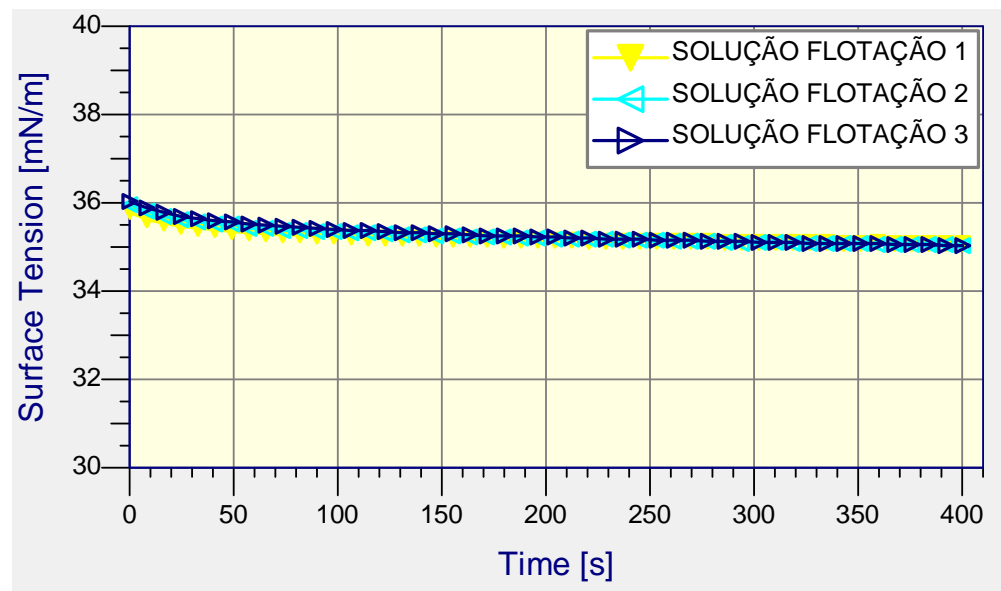

Figura A1.4 - Energia livre superficial versus tempo para solução de flotação rougher.

Tabela A1.4 - Energia livre superficial da solução de flotação rougher $\left(20,0 \pm 0,1^{\circ} \mathrm{C}\right)$.

\begin{tabular}{|c|c|}
\hline AMOSTRA & ENERGIA LIVRE SUPERFICIAL $\left(\mathbf{e r g} / \mathbf{~ c m}^{\mathbf{2}}\right)$ \\
\hline ÁGUA 1 & $35,09 \pm 0,01$ \\
\hline ÁGUA 2 & $35,07 \pm 0,02$ \\
\hline ÁGUA 3 & $35,08 \pm 0,03$ \\
\hline Média e desvio & $\mathbf{3 5 , 0 8} \pm \mathbf{0 , 0 2}$ \\
\hline
\end{tabular}

\section{A1.3 Determinação de $\gamma$ Lv das soluções água/metanol}

Os valores de $\gamma_{\mathrm{LV}}$ obtidos para as soluções água/metanol utilizadas nas medidas de ângulo de contato com cristal de apatita-Ipirá e partículas de apatitaCajati são apresentados na Fig. A1.5 e Tab. A1.5. 


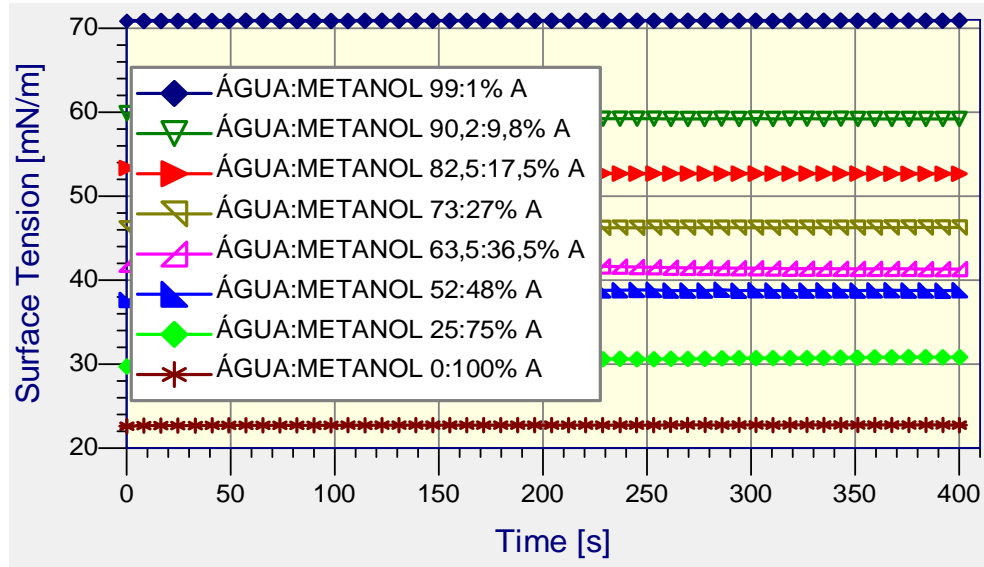

Figura A1.5 - Energia livre superficial versus tempo para as soluções água/metanol.

Tabela A1.5 - Energia livre superficial das soluções água/metanol $\left(20,0 \pm 0,1^{\circ} \mathrm{C}\right)$.

\begin{tabular}{|c|c|}
\hline AMOSTRA & ENERGIA LIVRE SUPERFICIAL $\left(\mathrm{erg} / \mathrm{cm}^{2}\right)$ \\
\hline ÁGUA:METANOL 99:1\% A & $70,90 \pm 0,01$ \\
\hline ÁGUA:METANOL 99:1\% B & $70,88 \pm 0,01$ \\
\hline ÁGUA:METANOL 99:1\% C & $70,93 \pm 0,01$ \\
\hline Média e desvio & $70,90 \pm 0,02$ \\
\hline ÁGUA:METANOL 90,2:9,8\%A & $59,22 \pm 0,02$ \\
\hline ÁGUA:METANOL 90,2:9,8\% B & $59,14 \pm 0,02$ \\
\hline ÁGUA:M ETANOL $90,2: 9,8 \% \mathrm{C}$ & $59,16 \pm 0,00$ \\
\hline Média e desvio & $59,17 \pm 0,03$ \\
\hline ÁGUA:METANOL 82,5:17,5\% A & $52,68 \pm 0,01$ \\
\hline ÁGUA:M ETANOL 82,5:17,5\% B & $52,74 \pm 0,00$ \\
\hline ÁGUA:M ETANOL 82,5:17,5\% C & $52,70 \pm 0,01$ \\
\hline Média e desvio & $52,71 \pm 0,03$ \\
\hline ÁGUA:METANOL 73:27\% A & $46,26 \pm 0,01$ \\
\hline ÁGUA:METANOL 73:27\% B & $46,17 \pm 0,01$ \\
\hline ÁGUA:METANOL 73:27\% C & $46,32 \pm 0,01$ \\
\hline Média e desvio & $46,25 \pm 0,06$ \\
\hline ÁGUA:METANOL 63,5:36,5\% A & $41,37 \pm 0,04$ \\
\hline ÁGUA:M ETANOL 63,5:36,5\% B & $41,36 \pm 0,06$ \\
\hline ÁGUA:M ETANOL 63,5:36,5\% C & $41,54 \pm 0,09$ \\
\hline Média e desvio & $41,42 \pm 0,11$ \\
\hline ÁGUA:M ETANOL 52:48\% A & $38,78 \pm 0,03$ \\
\hline ÁGUA:METANOL 52:48\% B & $38,79 \pm 0,02$ \\
\hline ÁGUA:M ETANOL 52:48\% C & $38,84 \pm 0,06$ \\
\hline Média e desvio & $38,81 \pm 0,05$ \\
\hline ÁGUA:M ETANOL 25:75\% A & $30,76 \pm 0,05$ \\
\hline ÁGUA:METANOL 25:75\% B & $30,79 \pm 0,04$ \\
\hline ÁGUA:METANOL 25:75\% C & $30,68 \pm 0,07$ \\
\hline Média e desvio & $30,75 \pm 0,07$ \\
\hline ÁGUA:M ETANOL 0:100\% A & $22,76 \pm 0,01$ \\
\hline ÁGUA:M ETANOL 0:100\% B & $22,86 \pm 0,00$ \\
\hline ÁGUA:M ETANOL 0:100\% C & $22,84 \pm 0,02$ \\
\hline Média e desvio & $22,82 \pm 0,05$ \\
\hline
\end{tabular}




\section{APÊNDICE 2 - RESULTADOS DE CONSTANTE C}

\section{A2.1 Determinação da constante c com água e com hexano}

Os valores da constante $c$, determinados com água $\left(c_{a}\right)$ e hexano $\left(c_{h}\right)$ para as amostras de apatita-Ipirá "in natura" e apatita-Cajati pré-tratada com amido e Berol ${ }^{\circledR} 867$, foram obtidos a partir de curvas $\mathrm{m}^{2} \times \mathrm{t}$ (Fig. A2.1) e são apresentados na Tab. A2.1.

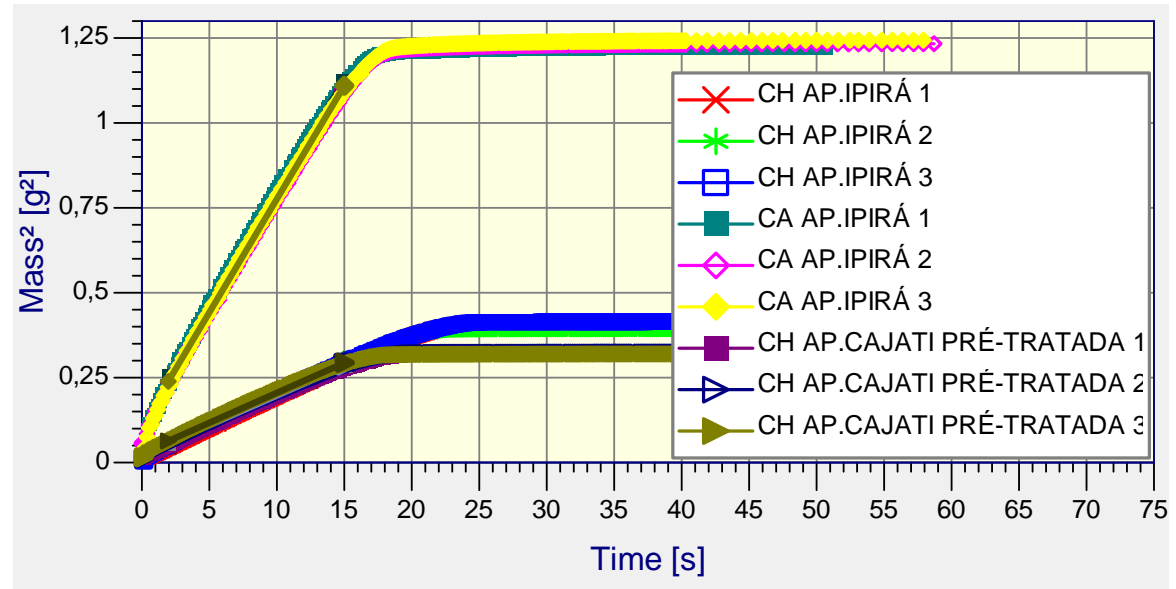

Figura A2.1 - Curvas de $\mathrm{m}^{2}$ versus t para a determinação da constante c.

Tabela A2.1 - Valores da constante c determinados com hexano $\left(c_{h}\right)$ e água $\left(c_{a}\right)$ para partículas de apatita-Ipirá "in natura" e de apatita-Cajati pré-tratadas com amido e Berol ${ }^{\circledR} 867$ $\left(20,0 \pm 0,2^{\circ} \mathrm{C}\right)$.

\begin{tabular}{|c|c|}
\hline MEDIDA & CONSTANTE $C\left(x 10^{-6}\right), \mathrm{cm}^{5}$ \\
\hline AAP3CHCOKL 1 & 7,4964 \\
\hline AAP3CHCOKL 2 & 7,4006 \\
\hline AAP3CHCOKL 3 & 7,4243 \\
\hline Média e desvio & $7,4404 \pm 0,0499$ \\
\hline AAP3CACOKL 1 & 9,2923 \\
\hline AAP3CACOKL 2 & 9,1443 \\
\hline AAP3CACOKL 3 & 9,2228 \\
\hline Média e desvio & $9,2198 \pm 0,0741$ \\
\hline ACT3CHCOKL 1 & 7,0986 \\
\hline ACT3CHCOKL 2 & 7,0788 \\
\hline ACT3CHCOKL 3 & 7,1535 \\
\hline Média e desvio & $7,1103 \pm 0,0387$ \\
\hline
\end{tabular}




\section{APÊNDICE 3 - RESULTADOS DE ANGULO DE CONTATO}

\section{A3.1 Determinação do ângulo de contato de avanço ( $\left.\theta_{\mathrm{a}}\right)$ pelo método da ascensão capilar}

Os valores de $\theta_{\mathrm{a}}$ entre água deionizada e partículas de apatita-Ipirá prétratadas com oleato de sódio foram obtidos através das curvas $m^{2} \times t$ (Fig. A3.1), utilizando-se as constantes $\mathrm{c}_{\mathrm{a}}$ e $\mathrm{c}_{\mathrm{h}}$, e são apresentados na Tab. A3.1.

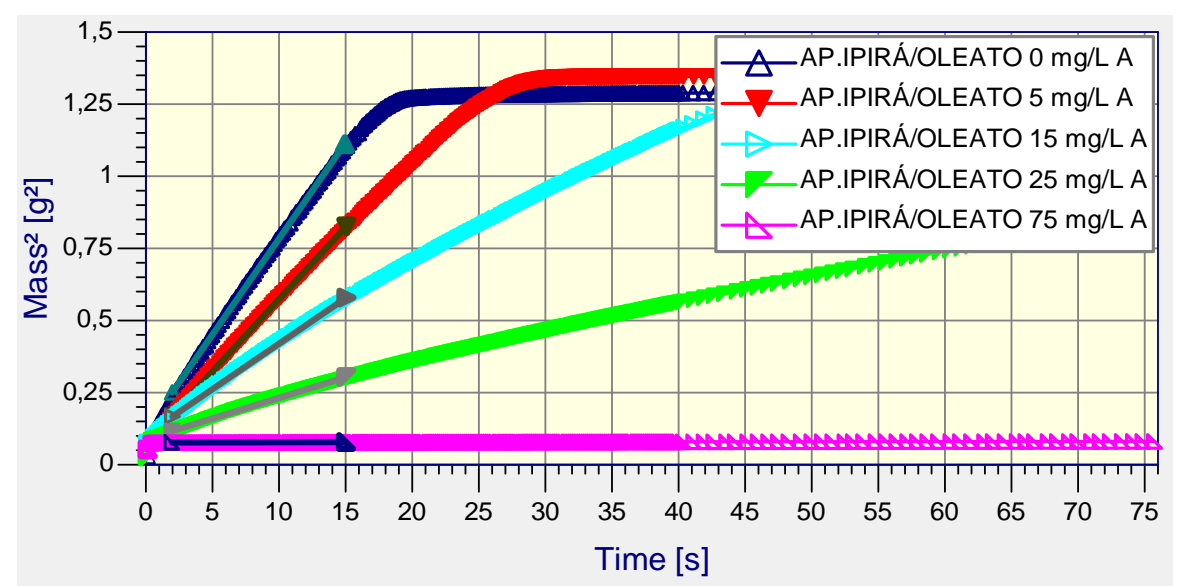

Figura A3.1 - Curvas de $\mathrm{m}^{2}$ versus t para a determinação de ângulo de contato de avanço.

Tabela A3.1 - Ângulo de contato de avanço de água sobre apatita-Ipirá em função da concentração de oleato de sódio e da constante c $\left(20,0 \pm 0,0^{\circ} \mathrm{C}\right)$.

\begin{tabular}{|c|c|c|}
\hline Medida & $\theta_{a}$ (graus) $\left(c_{h}=7,4404.10^{-6} \mathrm{~cm}^{5}\right)$ & $\theta_{a}$ (graus) $\left(c_{a}=9,2198.10^{-6} \mathrm{~cm}^{5}\right)$ \\
\hline OLEATO 0 mg/L A & $\mathrm{n} / \mathrm{a}$ & 5,07 \\
\hline OLEATO $0 \mathrm{mg} / \mathrm{L} \mathrm{B}$ & $\mathrm{n} / \mathrm{a}$ & 6,54 \\
\hline OLEATO 0 mg/L C & $\mathrm{n} / \mathrm{a}$ & 6,63 \\
\hline Média e desvio & $\mathrm{n} / \mathrm{a}$ & $6,08 \pm 0,88$ \\
\hline OLEATO 5 mg/L A & 21,68 & 41,42 \\
\hline OLEATO 5 mg/L B & 22,87 & 41,97 \\
\hline OLEATO $5 \mathrm{mg} / \mathrm{LC}$ & 17,32 & 39,61 \\
\hline Média e desvio & $20,62 \pm 2,92$ & $41,00 \pm 1,23$ \\
\hline OLEATO $15 \mathrm{mg} / \mathrm{L} \mathrm{A}$ & 54,07 & 61,74 \\
\hline OLEATO $15 \mathrm{mg} / \mathrm{L} \mathrm{B}$ & 55,81 & 63,04 \\
\hline OLEATO $15 \mathrm{mg} / \mathrm{LC}$ & 55,28 & 62,64 \\
\hline Média e desvio & $55,05 \pm 0,89$ & $62,47 \pm 0,67$ \\
\hline OLEATO $25 \mathrm{mg} / \mathrm{L} \mathrm{A}$ & 74,60 & 77,63 \\
\hline OLEATO 25 mg/L B & 73,42 & 76,69 \\
\hline OLEATO $25 \mathrm{mg} / \mathrm{L} \mathrm{C}$ & 73,57 & 76,80 \\
\hline Média e desvio & $73,86 \pm 0,64$ & $77,04 \pm 0,51$ \\
\hline OLEATO $75 \mathrm{mg} / \mathrm{L} \mathrm{A}$ & 89,90 & 89,92 \\
\hline OLEATO 75 mg/L B & 89,91 & 89,93 \\
\hline OLEATO $75 \mathrm{mg} / \mathrm{L} \mathrm{C}$ & 89,91 & 89,93 \\
\hline Média e desvio & $89,91 \pm 0,01$ & $89,93 \pm 0,01$ \\
\hline
\end{tabular}


Os valores de $\theta_{\mathrm{a}}$ entre soluções água/metanol e partículas de apatita-Cajati pré-tratadas com amido e Berol ${ }^{\circledR} 867$ foram obtidos através das curvas $\mathrm{m}^{2} \times \mathrm{t}$ (Fig. A3.2), utilizando-se a constante $c_{h}$, e são apresentados na Tab. A3.2.

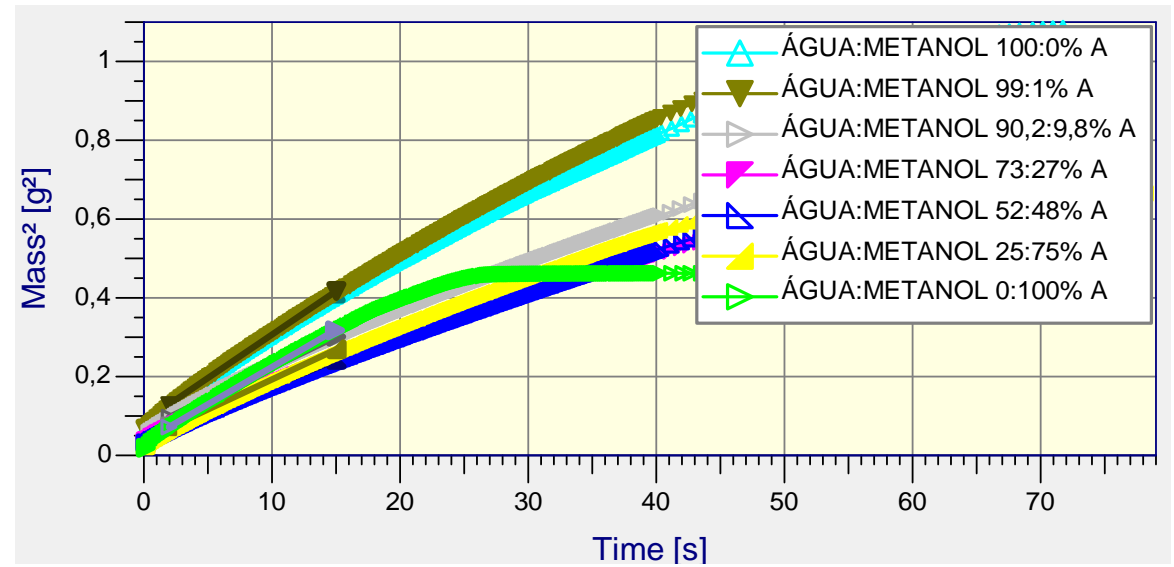

Figura A3.2 - Curvas de $\mathrm{m}^{2}$ versus t para a determinação de ângulo de contato de avanço.

Tabela A3.2 - Ângulo de contato de avanço de água/metanol sobre apatita-Cajati em função da energia livre superficial da fase líquida percolante $\left(20,0 \pm 0,1^{\circ} \mathrm{C}\right)$.

\begin{tabular}{|c|c|}
\hline Medida & $\theta_{\mathrm{a}}$ (graus) $\left(c_{\mathrm{h}}=7,1103 \cdot 10^{-6} \mathrm{~cm}^{5}\right)$ \\
\hline ÁGUA:METANOL 100:0\% A & 65,5 \\
\hline ÁGUA:METANOL 100:0\% B & 63,3 \\
\hline ÁGUA:METANOL 100:0\% C & 63,9 \\
\hline Média e desvio & $64,2 \pm 1,1$ \\
\hline ÁGUA:METANOL 99:1\%A & 62,0 \\
\hline ÁGUA:M ETANOL 99:1\%B & 61,6 \\
\hline ÁGUA:METANOL 99:1\%C & 60,2 \\
\hline Média e desvio & $61,3 \pm 0,9$ \\
\hline ÁGUA:METANOL 90,2:9,8\%A & 53,2 \\
\hline ÁGUA:METANOL 90,2:9,8\% B & 53,0 \\
\hline ÁGUA:METANOL $90,2: 9,8 \%$ C & 53,6 \\
\hline Média e desvio & $53,3 \pm 0,3$ \\
\hline ÁGUA:METANOL 73:27\% A & 35,9 \\
\hline ÁGUA:METANOL $73: 27 \% \mathrm{~B}$ & 34,1 \\
\hline ÁGUA:METANOL 73:27\% C & 34,2 \\
\hline Média e desvio & $34,7 \pm 1,0$ \\
\hline ÁGUA:METANOL 52:48\% A & 20,0 \\
\hline ÁGUA:METANOL 52:48\% B & 20,5 \\
\hline ÁGUA:METANOL $52: 48 \%$ C & 20,3 \\
\hline Média e desvio & $20,3 \pm 0,3$ \\
\hline ÁGUA:METANOL 25:75\% A & 11,4 \\
\hline ÁGUA:METANOL 25:75\% B & 0,0 \\
\hline ÁGUA:METANOL 25:75\% C & 3,8 \\
\hline Média e desvio & $5,1 \pm 5,8$ \\
\hline ÁGUA:METANOL 0:100\% A & 0,0 \\
\hline ÁGUA:METANOL 0:100\% B & 0,0 \\
\hline ÁGUA:METANOL 0:100\% C & 0,0 \\
\hline Média e desvio & $0,0 \pm 0,0$ \\
\hline
\end{tabular}




\section{A3.2 Determinação do ângulo de contato de avanço $\left(\theta_{a}\right)$ pelo método da bolha cativa}

Os valores de $\theta_{\mathrm{a}}$ entre água deionizada e cristal de apatita-Ipirá pré-tratado com soluções de oleato de sódio são apresentados na Tab. A3.3.

Tabela A3.3 - Ângulo de contato de avanço de água sobre os planos basal e frontal do cristal de apatita-Ipirá em função da concentração de oleato de sódio $\left(20^{\circ} \mathrm{C}\right)$.

\begin{tabular}{|c|c|c|}
\hline \multirow{2}{*}{$\begin{array}{c}\text { Concentração de } \\
\text { oleato (mg/ L) }\end{array}$} & \multicolumn{2}{|c|}{ Ângulo de contato de avanço (graus) } \\
\hline & Plano basal (001) & Plano frontal (010) \\
\hline 0 & 0,0 & 0,0 \\
\hline 0 & 0,0 & 0,0 \\
\hline 0 & 0,0 & 0,0 \\
\hline 0 & 0,0 & 0,0 \\
\hline 0 & 0,0 & 0,0 \\
\hline 0 & 0,0 & 0,0 \\
\hline Média e desvio & $0,0 \pm 0,0$ & $0,0 \pm 0,0$ \\
\hline 5 & 25,0 & 50,8 \\
\hline 5 & 23,7 & 47,4 \\
\hline 5 & 21,6 & 50,2 \\
\hline 5 & 25,1 & 48,2 \\
\hline 5 & 23,9 & 50,2 \\
\hline 5 & 23,7 & 48,5 \\
\hline Média e desvio & $23,8 \pm 1,3$ & $49,2 \pm 1,4$ \\
\hline 15 & 34,0 & 63,2 \\
\hline 15 & 33,1 & 63,5 \\
\hline 15 & 34,4 & 62,9 \\
\hline 15 & 32,9 & 63,5 \\
\hline 15 & 33,4 & 63,2 \\
\hline 15 & 33,6 & 63,3 \\
\hline Média e desvio & $33,6 \pm 0,6$ & $63,3 \pm 0,2$ \\
\hline 25 & 60,5 & 69,8 \\
\hline 25 & 61,0 & 69,7 \\
\hline 25 & 60,4 & 69,4 \\
\hline 25 & 60,8 & 69,3 \\
\hline 25 & 60,2 & 69,9 \\
\hline 25 & 60,9 & 69,7 \\
\hline Média e desvio & $60,6 \pm 0,3$ & $69,6 \pm 0,2$ \\
\hline 75 & 68,9 & 81,6 \\
\hline 75 & 68,2 & 82,0 \\
\hline 75 & 68,6 & 82,2 \\
\hline 75 & 68,2 & 81,3 \\
\hline 75 & 68,6 & 81,6 \\
\hline 75 & 68,7 & 81,3 \\
\hline Média e desvio & $68,5 \pm 0,3$ & $81,7 \pm 0,4$ \\
\hline
\end{tabular}

Os valores de $\theta_{a}$ entre soluções água/metanol e cristal de apatita-Ipirá prétratado com oleato de sódio (75 mg/L) são apresentados na Tab. A3.4. 
Tabela A3.4 - Ângulo de contato de avanço de água/metanol sobre os planos basal e frontal do cristal de apatita-Ipirá em função da concentração de oleato de sódio $\left(20^{\circ} \mathrm{C}\right)$.

\begin{tabular}{|c|c|c|}
\hline \multirow{2}{*}{$\begin{array}{c}\text { Solução água metanol } \\
\text { (\% metanol) }\end{array}$} & \multicolumn{2}{|c|}{ Ângulo de contato de avanço (graus) } \\
\hline & Plano basal (001) & Plano frontal (010) \\
\hline 0,0 & 68,9 & 81,6 \\
\hline 0,0 & 68,2 & 82,0 \\
\hline 0,0 & 68,6 & 82,2 \\
\hline 0,0 & 68,2 & 81,3 \\
\hline 0,0 & 68,6 & 81,6 \\
\hline 0,0 & 68,7 & 81,3 \\
\hline Média e desvio & $68,5 \pm 0,3$ & $81,7 \pm 0,4$ \\
\hline 1,0 & 65,7 & 78,1 \\
\hline 1,0 & 65,9 & 78,2 \\
\hline 1,0 & 66,1 & 77,9 \\
\hline 1,0 & 65,9 & 77,9 \\
\hline 1,0 & 66,0 & 78,0 \\
\hline 1,0 & 65,8 & 77,8 \\
\hline Média e desvio & $65,9 \pm 0,1$ & $78,0 \pm 0,1$ \\
\hline 9,8 & 57,1 & 67,4 \\
\hline 9,8 & 56,7 & 67,6 \\
\hline 9,8 & 57,0 & 67,4 \\
\hline 9,8 & 57,0 & 67,4 \\
\hline 9,8 & 56,7 & 67,6 \\
\hline 9,8 & 57,1 & 67,4 \\
\hline Média e desvio & $56,9 \pm 0,2$ & $67,5 \pm 0,1$ \\
\hline 27,0 & 40,6 & 48,2 \\
\hline 27,0 & 40,5 & 48,1 \\
\hline 27,0 & 40,5 & 48 \\
\hline 27,0 & 40,4 & 48,1 \\
\hline 27,0 & 40,3 & 48,4 \\
\hline 27,0 & 40,4 & 48 \\
\hline Média e desvio & $40,5 \pm 0,1$ & $48,1 \pm 0,2$ \\
\hline 48,0 & 28,6 & 33,8 \\
\hline 48,0 & 28,2 & 33,4 \\
\hline 48,0 & 28,4 & 33,6 \\
\hline 48,0 & 28,4 & 33,3 \\
\hline 48,0 & 28,5 & 33,5 \\
\hline 48,0 & 28,5 & 33,6 \\
\hline Média e desvio & $28,4 \pm 0,1$ & $33,5 \pm 0,2$ \\
\hline 75,0 & 0,0 & 0,0 \\
\hline 75,0 & 0,0 & 0,0 \\
\hline 75,0 & 0,0 & 0,0 \\
\hline 75,0 & 0,0 & 0,0 \\
\hline 75,0 & 0,0 & 0,0 \\
\hline 75,0 & 0,0 & 0,0 \\
\hline Média e desvio & $0,0 \pm 0,0$ & $0,0 \pm 0,0$ \\
\hline 100,0 & 0,0 & 0,0 \\
\hline 100,0 & 0,0 & 0,0 \\
\hline 100,0 & 0,0 & 0,0 \\
\hline 100,0 & 0,0 & 0,0 \\
\hline 100,0 & 0,0 & 0,0 \\
\hline 100,0 & 0,0 & 0,0 \\
\hline Média e desvio & $0,0 \pm 0,0$ & $0,0 \pm 0,0$ \\
\hline
\end{tabular}

